\title{
Reduced Forms of Rational Expectations Models
}

\author{
Laurence BROZE, Christian GOURIEROUX \\ and Ariane SZAFARZ
}

We are grateful to J. Ablett for help in translation and to Th. Malle for typing this book. Our work received support from CEPREMAP, the Commissariat général du Plan and from CEME and DULBEA (University of Brussels). 


\section{CONTENTS}

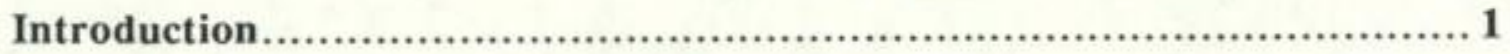

Chapter 1 : Expectation Schemes......................................... 7

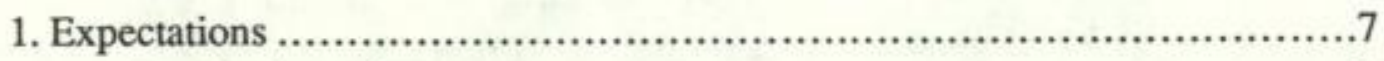

1.a. Basic notions ...................................................

1.b. Successive predictions ...........................................8

2. Adaptive scheme ....................................................... 9

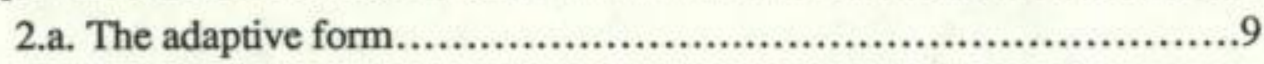

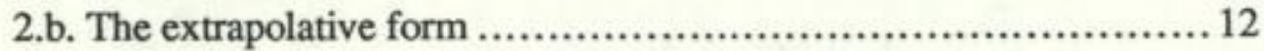

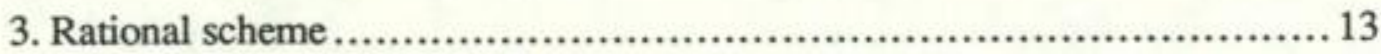

3.a. Optimal predictions ........................................... 13

3.b. Some properties of optimal predictions ......................... 13

3.c. Prediction errors and updating........................................ 17

References.................................................................22

Chapter 2 : A Model with Current Expectations...................................25

1. An equilibrium model in an uncertain environment .........................25

1.a. A Walrasian equilibrium model.........................................25

1.b. Extension of the model...........................................26

1.c. The linear case.......................................................29

2. Dynamic properties of the current expectation model.........................31

2.a. The rational expectations model ................................ 31

2.b. Comparison of the constrained and unconstrained reduced

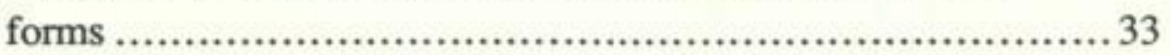

2.c. Comparison of various expectation schemes ...................... 34

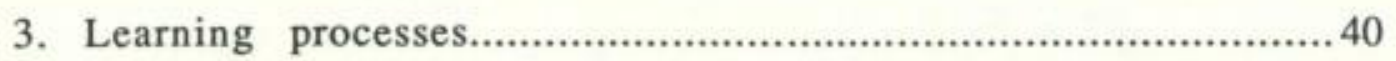

References................................................................. 43 
1. Examples................................................................. 45

1.a. Hyperinflation models........................................... 45

1.b. The Taylor model .................................................. 46

1.c. Some remarks on the price equation ............................... 48

1.d. The evolution of an asset price ..................................... 51

2. A description of the solution methods .................................... 51

2.a. The 'forward' - 'backward' approach ...........................52

2.b. Linear solutions ................................................. 56

2.c. The general solution ............................................. 62

3. Properties of the solution set.........................................................6 66

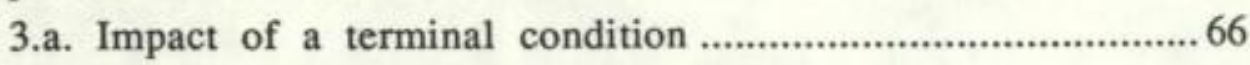

3.b. Impact of an initial condition ...................................66

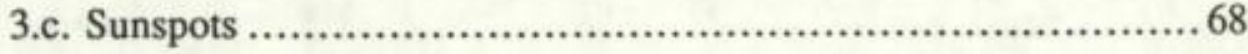

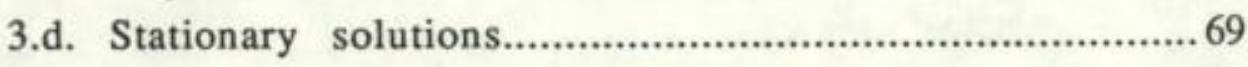

3.e. Variability of the linear stationary solutions.............................70

4. Learning processes.......................................................... 73

References................................................................... 77

Chapter 4: Dynamic Complications .......................................81

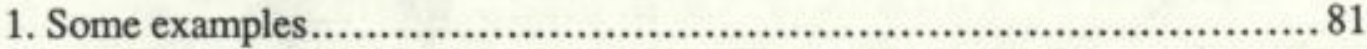

1.a. A model with various expectations of the current

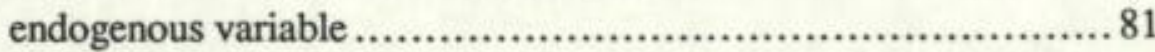

1.b. A model with a two-periods-ahead future expectation.................. 83

1.c. A model with one current expectation and one future expectation ......................................................... 84

1.d. Some remarks ................................................... 86

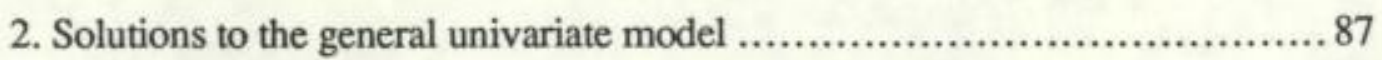

2.a. The model........................................................ 87

2.b. Expression of the expectations in terms of realizations.................87 87

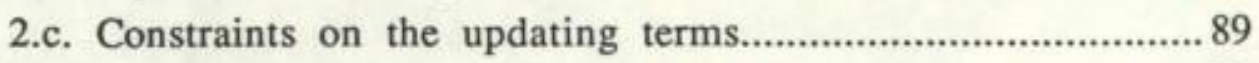

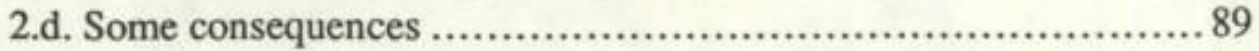

2.e. Some applications ............................................. 91

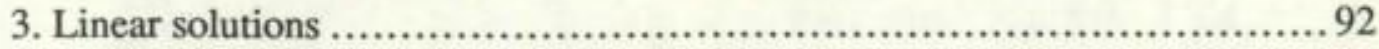

3.a. The general form of the linear solutions......................... 92 
3.b. (Asymptotic) stationarity of the linear solutions........................ 93

3.c. An example .............................................. 94

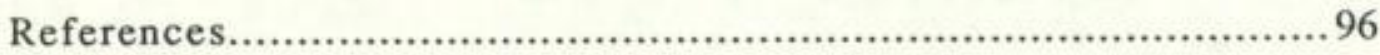

Chapter 5 : Multivariate Models .............................................97

1. Dynamic macroeconometric models .................................... 97

2. A simple case ..........................................................100

2.a. The case without recursivities ..................................101

2.b. The special case of a nilpotent structural matrix.....................101

2.c. The general case ...............................................101

3. The general model................................................................104

3.a. Canonical forms................................................104

3.b. Reduction of the canonical form ...................................108

3.c. Reduction of the general model.........................................110

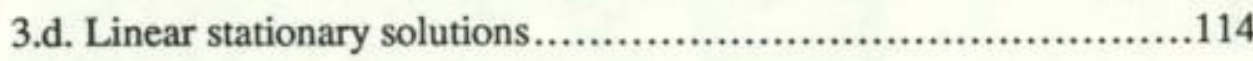

4. Rational expectations and non-stationary models .........................115

4.a. Decomposition of an ARIMA series and cointegration ..............116

4.b. Application to rational expectations models.............................120

References.............................................................................

Chapter 6 : A Mean-Variance Model..............................................129

1. The model ................................................................... 129

1.a. Demand function of the speculators.....................................130

1.b. Excess supply function of storable good...............................131

1.c. Equilibrium condition...............................................132

2. Evolution of the equilibrium price..................................................132

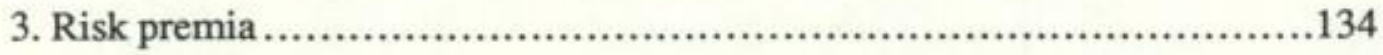

3.a. Asymptotic behavior of the solutions .............................134

3.b. Comparative statics .............................................137

References................................................................ 


\section{INTRODUCTION}

The taking into account of expectations remains an important subject in macroeconomic model building. This book presents the most recent results concerning the formulation of models including rational expectations. In clarifying the technical aspects of these results, we hope to allow the reader - who is not necessarily familiar with the econometric literature treating models with rational expectations - to measure the impact of the rationality hypothesis formulated by Muth in 1961 and its repercussions, especially in terms of macroeconomic models.

Macroeconomic model building is habitually based on two major simplifications. On the one hand, macroeconomic models are constructed with reference to behavioral models under the hypothesis of existence of representative agents. No direct reference is made to individual behavior or to the heterogeneity of this behavior. Consequently a problem of aggregation arises, i.e. a problem concerning the microeconomic foundations of the model's equations. On the other hand, the models are established using long term relations, these being essentially static equations.

These two major simplifications have been the object of an abundant literature, the broad outlines of which we will now mention. Regarding the problem of aggregation of individual behavior, it appears that models which are linear in their variables are relatively more robust than nonlinear models. We can thus accord a preference to this type of specification, quite apart from the fact that linear models afford simplicity. Consequently, in this book we will concentrate essentially on the study of linear models.

With regard to dynamics, this is introduced naturally at the macro level in the description of various phenomena. We can classify these phenomena into three categories, each of which merits a specific treatment. For example, one can distinguish :

a) dynamic processes of accumulation, of the 'tendency' type, which aim to describe aspects of growth.

b) dynamic adjustment processes, which explain how long term equilibria are attained.

c) dynamic processes of anticipation, which take into account the effects of previsions formed by agents. 
The introduction of dynamic components in macro models can be achieved in a variety of ways. One often proceeds by including some 'dynamic' elements in a static model. Carried out in two stages, this procedure involves firstly establishing a static model expressing the long term relationships considered, then adding some lagged variables. This procedure incorporates some dynamic effects in the model without really distinguishing the three categories mentioned above. Often characterized as 'ad hockery', it is associated methodologically with models including error correction.

An alternative method, 'general to specific', is based on a statistical analysis of the joint evolution of the various time series associated with the variables of the model. Subsequently, one isolates, making reference to this study, certain structural relationships. Although it represents a quite different approach, this type of procedure is compatible with the first procedure mentioned above. Moreover, it would be desirable to combine both approaches.

In this book we will be specifically interested in one of the causes of dynamics, namely the presence of expectations. On the other hand, we will not consider in detail the other two causes cited. We will suppose, when we study the various models, that these two effects are summarized either by lagged variables or by a particular dynamic property of the exogenous variables.

Expectations of economic variables are mostly non-observable, at least at the macro level. Even when one has data available (notably from opinion surveys) on the previsions made by various categories of economic agents, these observations are essentially disaggregated. Three approaches can then be envisaged. The first involves aggregating the observations, making use of weighted means calculated using the method usually unemployed for the purposes of short term prevision. The second possibility involves a search for a summary measure of individual expectations which is based on a direct aggregation of microeconomic models. However this approach is often very complicated and can only be easily developed under restrictive hypotheses.

Finally, the most commonly utilized approach involves forgetting completely individual observations and writing a subsidiary model or expectation scheme describing the formation of aggregated expectations. In fact the necessity of such schemes exceeds even the problem of non-observability of expectations. The presence of expectations can have an indirect effect (this effect forms the basis of Lucas'critique (1976)). Hence, even in the ideal case where one has available observations of previsions which are usable at the macro level, the mode of formation can remain important for the calculation of multipliers or economic policy simulations. 
Expectation schemes can be divided into two broad categories :

a) Exogenous schemes that fix the method of calculating previsions independently of the structure of the model. In this category, one finds in particular the adaptive scheme. The facility offered by this type of approach lies in the replacement of expectations by 'proxies' established outside of the model.

b) Endogenous schemes for which there is simultaneous determination of the expectations and the other endogenous variables of the model. Notably, this category includes rational expectations, but it is much broader. The simultaneous nature of these schemes evidently renders the model more complex. However, it permits the formulation of a response to the critique of Lucas concerning the taking into account of structural modifications.

The rational expectations hypothesis as formulated by Muth (1961) is stated as follows: 'The rational expectations are the same as the predictions of the relevant economic theory'. Rational previsions are obtained by utilizing available information and a knowledge of the model. The expectations therefore depend on the structural parameters, and this has repercussions on the multipliers of the model.

The dynamic properties of the models are crucially linked to the scheme retained for the previsions. Thus the choice of an endogenous scheme can lead to a reduced form quite different from that deduced from an exogenous scheme, owing to the indirect effects. From this point of view, the originality of the rational expectations hypothesis vis-à-vis the adaptive expectations hypothesis lies essentially in rendering the previsions endogenous.

\section{Plan of the book}

This book includes six chapters. The first chapter reviews briefly certain generalities concerning expectation schemes. It introduces the formal definitions of adaptive and rational schemes. The latter is defined as an optimal method of calculating the prevision based on the information available. We then examine the principal properties of these two schemes. In particular, those characteristics of rational expectations which permit the formulation of direct tests are illustrated with the aid of a concrete example. 
Economic models with rational expectations can be divided into two broad classes according to whether or not they include expectations of future endogenous variables. In fact, for univariate models, the presence of multiple solutions concern exclusively models with expectations of future variables. In order to introduce the problems of reduction gradually, we commence by presenting, in chapter 2 , a model including expectations of current variables only. This model is an extension of a Walrasian equilibrium model. In studying this model, we compare different expectation schemes and point out the specific indirect effect due to the endogenous nature of the rational scheme. Finally we present a learning process. It will become apparent that, in certain cases, the rationality hypothesis can be represented as the limit of a suboptimal mechanism for revising previsions.

Chapter 3 considers a model, probably the most well known model of rational expectations, which includes expectations of future variables. In its synthetic form, this model corresponds to the hyperinflation model of Cagan, to the Taylor model, and to the model of price determination of an asset traded on the stock exchange. This model admits an infinity of solutions, as evidenced by the presence of an arbitrary term in its reduced form. We consider successively various aspects of this phenomenon, which is specific to models with rational expectations. Essentially, we show how and why one may be led to give preference to some of these solutions.

At the end of chapters 2 and 3 , one could be tempted to believe that all the problems of reduction associated with the presence of rational expectations have been covered. In chapter 4 we show that this is far from being the case. In fact, a certain number of dynamic complications (notably expectations associated with different horizons) can seriously complicate the reduction technique to such a degree that most of the methods previously developed become unusable. Without devoting too much attention to the general results, we illustrate various possibilities of models presenting much 'complications'.

Chapter 5 is devoted to the reduction of multivariate models with rational expectations. These models require a specific treatment as soon as the constraints imposed on the structural parameters introduce singular matrices. After having indicated the general solution and stationary solutions of these models, we give particular attention to the nonstationary trajectories. The methodology of the literature on cointegration permits one to show, in particular, that the effects of expectational errors are only short term.

In the formulation of the linear models, we have adopted a simplification whereby the entire conditional distribution of the future variables is summarized by its first moment, i.e. the conditional expectation. In certain situations, notably in the context of 
micro models where risk has to be taken into account, it is indispensable to retain more than one moment of the conditional distribution. Chapter 6 illustrates this type of approach by envisaging a mean-variance model with rational expectations. Nonlinearity evidently leads to new reduction problems. In particular, one observes that the phenomenon of multiplicity can affect the growth paths of the solutions. It follows that, contrary to what is obtained with linear models, the effect of expectational errors on the tendency can be significiant. 


\section{References}

LUCAS, R.E. (1976) : 'Econometric policy evaluation : a critique', in The Phillips Curve and Labor Markets, Karl Brunner (ed.), supplement to the Journal of Monetary Economics, 1, 19-46.

MUTH, J.F. (1961) : 'Rational expectations and the theory of price movements', Econometrica, 29, 315-335. 


\section{CHAPTER 1}

\section{EXPECTATION SCHEMES}

\section{Expectations}

\section{1.a. Basic notions}

The values taken by a variable of interest, denoted y, may be unknown. This occurs for instance when information is needed on future values of some economic characteristics or on variables that influence the behavior of agents. In such circumstances, one may look for proxies $\tilde{y}$ of $y$. These proxies are henceforth called predictions or expectations.

Expectations are generally determined by using the available information about some other variables summarized by the notation $\mathrm{x}$. The prediction of $\mathrm{y}$ is then written as :

$$
\tilde{y}=f(x),
$$

where $\mathrm{f}$ denotes the computational mechanism that describes the transition from the observable variables $\mathrm{x}$ to the expectation $\tilde{\mathrm{y}}$ of $\mathrm{y}$.

Thus, for a given information set $\mathrm{I}=\{\mathrm{x}\}$, the ways to derive expectations are as numerous as the possible choices of the mapping $\mathrm{f}$. This mapping is often called the expectation scheme. In this presentation, we always consider the case where the approximated variable $\mathrm{y}$ and the variables $\mathrm{x}$ used to form the expectation are random variables. On the other hand, the computational mechanism $f$ is assumed to be deterministic. Consequently, the expectation $\tilde{y}$ is stochastic since it is a deterministic mapping of random variables.

The expectation problem consists in the search for a well adapted prediction of $y$. It may be seen as the problem of choosing a stochastic proxy $\tilde{y}$ for the stochastic variable y. Generally, the proxy leads to some error, which is called the prediction error. The error is also stochastic : it is given by : e = y - $\tilde{y}$. A possible measure of the prediction error is provided by the mean square error defined by :

$$
\text { (1.1) } \mathrm{E} \mathrm{e}^{2}=\mathrm{E}(\mathrm{y}-\tilde{\mathrm{y}})^{2} \text {, }
$$


where $\mathrm{E}$ denotes the expectation operator.

\section{1.b. Successive predictions}

We now consider predictions formed in successive time periods. For this purpose, it is necessary to introduce sequences of random variables that are indexed by time, called (time) processes. We will use the notation $\mathrm{y}=\left(\mathrm{y}_{\mathrm{t}}, \mathrm{t} \in \mathbf{Z}\right)$ for the variables to be predicted and $\mathrm{x}=\left(\mathrm{x}_{\mathrm{t}}, \mathrm{t} \in \mathbf{Z}\right)$ for those used to compute expectations.

Also, a sequence of information sets $I=\left(I_{t}, t \in Z\right)$ is required. The set denoted $I_{t}$ represents the information available at time t. It is often formed from the observable variables by taking their past and current values :

$$
I_{t}=\left\{x_{t}, x_{t-1}, x_{t-2}, \ldots\right\}=\left\{x_{t-j}, j \geq 0\right\}
$$

It follows that the available information grows with time (nothing is forgotten). At time $t+1$, the information set is obtained from the preceding one by adding the new observation $\mathrm{x}_{\mathrm{t}+1}$ :

$$
I_{t+1}=I_{t} \cup\left\{x_{t+1}\right\}
$$

In such a dynamic context, various prediction problems may be treated. Let us first consider a given date $\mathrm{t}$ and the information set $\mathrm{I}_{\mathrm{t}}$ available at that time. It may be used to forecast various values of the process of interest $y$. These values may be written as $y_{t+h}$, $\mathrm{h} \in \mathbf{Z}$, where $\mathrm{h}$ denotes the duration between time $\mathrm{t}$ (at which the prediction is formed) and time $\mathrm{t}+\mathrm{h}$ (at which $\mathrm{y}_{\mathrm{t}+\mathrm{h}}$ is realized). We call $\mathrm{h}$ the expectation horizon. Finally, the prediction of $\mathrm{y}_{\mathrm{t}+\mathrm{h}}$ formed at time $\mathrm{t}$ is represented by one of the following expressions :

$$
t \tilde{y}_{t+h}=f_{t, h}\left(x_{t}, x_{t-1}, \ldots\right)=f_{t, h}\left(I_{t}\right) \text {. }
$$

One thus obtains a twice indexed sequence of expectations. For a fixed value of $t$, variations of $h$ result in a sequence of expectations of $y_{t+h}$ made at the same date $t$. In turn, for a fixed value of $\mathrm{t}+\mathrm{h}=\mathrm{T}$, variations of $\mathrm{t}$ produce a sequence of successive expectations of the same variable $\mathrm{y}_{\mathrm{T}}=\mathrm{y}_{\mathrm{t}+\mathrm{h}}$ formed at various dates.

It is then possible to analyze the evolution of the expectations with respect to the increasing information sequence I. In particular, it is interesting to study the impact of an increase in the information occurring between two successive periods. This is given by : 


$$
t \tilde{y}_{T}-t-1 \tilde{y}_{T}=f_{t, T-t}\left(I_{t}\right)-f_{t-1, T-t+1}\left(I_{t-1}\right) .
$$

This difference is the updating of the expectation process.

In practice, we usually fix a maximal horizon $\mathrm{H}$ and in such a case, the various predictions may be summarized by the following table, which is given for $\mathrm{H}=3$.

\begin{tabular}{|c|c|c|c|c|c|c|c|}
\hline \multirow{2}{*}{$\begin{array}{l}\text { date } \\
\text { of the } \\
\text { prediction }\end{array}$} & \multicolumn{7}{|c|}{ variable to be predicted } \\
\hline & $\mathrm{y}_{\mathrm{T}}$ & $\mathrm{y}_{\mathrm{T}+1}$ & $\mathrm{y}_{\mathrm{T}+2}$ & $\mathrm{y}_{\mathrm{T}+3}$ & $\mathrm{y}_{\mathrm{T}+4}$ & $\mathrm{y}_{\mathrm{T}+5}$ & $\mathrm{y}_{\mathrm{T}+6}$ \\
\hline $\mathrm{T}$ & $y_{T}$ & $\mathrm{~T} \tilde{y}_{\mathrm{T}+1}$ & $\mathrm{~T} \tilde{\mathrm{y}}_{\mathrm{T}+2}$ & $\mathrm{~T} \tilde{\mathbf{y}}_{\mathrm{T}+3}$ & & & \\
\hline $\mathrm{T}+1$ & $\mathrm{y}_{\mathrm{T}}$ & $\mathrm{y}_{\mathrm{T}+1}$ & $\mathrm{~T}+1 \tilde{\mathrm{y}}_{\mathrm{T}+2}$ & $\mathrm{~T}+1 \tilde{\mathrm{y}}_{\mathrm{T}+3}$ & $\mathrm{~T}+1 \tilde{\mathrm{y}}_{\mathrm{T}+4}$ & & \\
\hline $\mathrm{T}+2$ & $\mathrm{y}_{\mathrm{T}}$ & $\mathrm{y}_{\mathrm{T}+1}$ & $\mathrm{y}_{\mathrm{T}+2}$ & $\mathrm{~T}+2 \tilde{y}_{\mathrm{T}+3}$ & $\mathrm{~T}+2 \tilde{\mathrm{y}}_{\mathrm{T}+4}$ & $\mathrm{~T}+2 \tilde{\mathbf{y}}_{\mathrm{T}+5}$ & \\
\hline$\cdots$ & $\cdots$ & $\cdots$ & $\cdots$ & $\cdots$ & $\cdots$ & $\cdots$ & $\cdots$ \\
\hline
\end{tabular}

Table 1

In this table, the sequence of expectations made at the same date is described by a given row and the updating of expectations is obtained with reference to a column.

\section{Adaptive scheme}

\section{2.a. The adaptive form}

The adaptive expectation scheme is one of the most frequent schemes used in macroeconometrics. It is due to Fisher (1930) [See also Arrow (1959), Nerlove (1958), Friedman (1957) for some 'historical' applications of this scheme]. The basic idea is to define the expectation scheme using a simple updating formula. In this section, we only consider one-period-ahead predictions.

The expectation of $y_{t+1}$ made at time $t$ is taken as a convex combination of the last expectation, i.e. of $y_{t}$ made at time $t-1$, and the last available observation on the $y$ process, $y_{t}$. Thus, one obtains the following expression : 
(1.2) ${ }_{\mathrm{t}} \tilde{\mathrm{y}}_{\mathrm{t}+1}=\lambda_{\mathrm{t}-1} \tilde{\mathrm{y}}_{\mathrm{t}}+(1-\lambda) \mathrm{y}_{\mathrm{t}}$,

where the smoothing coefficient $\lambda$ takes a value between 0 and 1 .

Implicitly, the information used is assumed to be fully summarized by the values of $t_{t-1} \tilde{y}_{t}$ and $y_{t}$. Subsequently, it will become apparent that this information set might also be viewed as composed of $y_{t}, y_{t-1}, y_{t-2} \ldots$

Furthermore the computational mechanism that leads from ${ }_{t-1} \tilde{y}_{t}$ and $y_{t}$ to $\tilde{y}_{t+1}$ involves a linear mapping with time-invariant coefficients $\lambda$ and $1-\lambda$. It follows that the same formula is used at any time. In addition, linearity implies that adaptive expectations do not depend on the units used in the specification of the variable of interest $y$.

Equation (1.2) may be interpreted directly as an updating formula. Indeed, it is equivalent to :

$$
\text { (1.3) } t_{\mathrm{y}} \tilde{\mathrm{t}}_{\mathrm{1}}-\mathrm{t}-1 \tilde{\mathrm{y}}_{\mathrm{t}}=(1-\lambda)\left(\mathrm{y}_{\mathrm{t}}-\mathrm{t}-1 \tilde{\mathrm{y}}_{\mathrm{t}}\right) \text {. }
$$

The updating value depends linearly on the last observed prediction error. Since the smoothing coefficient $\lambda$ is smaller than 1 , a positive (negative) prediction error leads to an increase (a decrease) in the next expectation. Moreover, since $\lambda$ is positive, the modification made to the last prediction is always smaller than the last error. Therefore, the error correction procedure appears to be generally partial.

On the other hand, the prediction mechanism obviously depends on the value chosen for the smoothing coefficient. A smaller value for $\lambda$ gives a larger weight to the current observation. In the limiting case where the smoothing coefficient vanishes, the expectation coincides with the current observation and the expectation scheme is equivalent to the naive one :

$$
\tilde{y}_{t+1}=y_{t} \text {. }
$$

Finally, one can easily determine the evolutions of $y$ so that adaptive expectations correspond to perfect foresight (i.e. no prediction error). By imposing :

$$
\tilde{\mathrm{y}}_{\mathrm{t}+1}=\mathrm{y}_{\mathrm{t}+1}, \quad \forall \mathrm{t},
$$

one obtains from (1.3) the following recursive formula : 


$$
y_{t+1}-y_{t}=(1-\lambda)\left(y_{t}-y_{t}\right)=0
$$

Thus, adaptive expectations are perfect when $\mathrm{y}$ is a constant process.

In all other cases, prediction errors occur. For instance, let us consider a process y exhibiting exponential growth :

$$
y_{t}=A \rho^{t} \text {, }
$$

where $\mathrm{A}$ and $\rho$ are positive coefficients (they could be either deterministic or stochastic), with $\rho>1$. The adaptive expectations are solutions of the following linear recursive equation :

$$
{ }_{t} \tilde{y}_{t+1}=\lambda_{t-1} \tilde{y}_{t}+(1-\lambda) A \rho^{t}
$$

The solutions may be written as :

$$
\tilde{y}_{t+1}=\frac{(1-\lambda) A \rho^{t+1}}{\rho-\lambda}+C \lambda^{t+1}
$$

where $\mathrm{C}$ is a real number.

If $\lambda$ is strictly smaller than 1 , then one has approximately for large values of $\mathrm{t}$ :

$$
\tilde{y}_{t+1} \# \frac{1-\lambda}{\rho-\lambda} A \rho^{t+1}
$$

The prediction error becomes :

$$
y_{t+1}-\tilde{y}_{t+1} \# \frac{1-\lambda}{\rho-\lambda} A \rho^{t+1}-A \rho^{t+1}=\frac{1-\rho}{\rho-\lambda} A \rho^{t+1} \text {. }
$$

The prediction error is always negative. This example illustrates the partial correction mechanism of the adaptive scheme. Indeed, the expectation scheme is not flexible enough to capture the evolution of the variable. The absolute error becomes more and more important while the relative error remains constant (see Figure 1). 


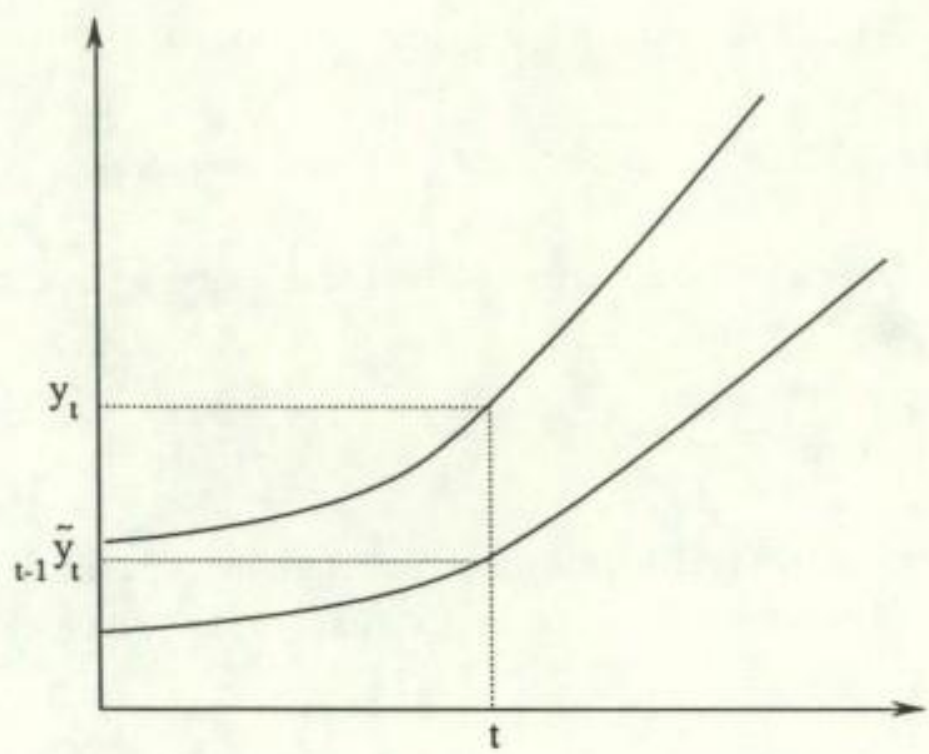

Figure 1

\section{2.b. The extrapolative form}

The updating formula that has been introduced does not define unambigously the expectations. It has to be completed by an initial condition, i.e. by a given value of the expectation at an initial date.

In practice, the initial period is often taken as $t_{0}=-\infty$ and the initial condition is stated as :

$\lim _{t \rightarrow \infty} \lambda-t \quad \tilde{y}_{t}=0$.

Under this constraint, successive substitutions yield :

$$
\begin{aligned}
{ }_{\mathrm{t}} \tilde{y}_{\mathrm{t}+1}= & \lambda_{\mathrm{t}-1} \tilde{y}_{\mathrm{t}}+(1-\lambda) \mathrm{y}_{\mathrm{t}} \\
= & \lambda^{2}{ }_{\mathrm{t}-2} \tilde{y}_{\mathrm{t}-1}+\lambda(1-\lambda) \mathrm{y}_{\mathrm{t}-1}+(1-\lambda) \mathrm{y}_{\mathrm{t}} \\
= & \lambda^{j}{ }_{t-j} \tilde{y}_{t-j-1}+\sum_{\mathrm{k}=0}^{j-1}(1-\lambda) \lambda^{\mathrm{k}} \mathrm{y}_{\mathrm{t}-\mathrm{k}} \\
& \vdots \\
= & \sum_{\mathrm{k}=0}^{\infty}(1-\lambda) \lambda^{\mathrm{k}} \mathrm{y}_{\mathrm{t}-\mathrm{k}} .
\end{aligned}
$$


A solution can only exist if the infinite sum, having $\lambda^{\mathrm{k}} \mathrm{y}_{\mathrm{t}-\mathrm{k}}$ as its general term, converges. It is then given by :

$$
\text { (1.4) } \quad \tilde{y}_{t+1}=(1-\lambda) y_{t}+(1-\lambda) \lambda y_{t-1}+\ldots+(1-\lambda) \lambda k^{k} y_{t-k}+\ldots
$$

Consequently, the prediction of $\mathrm{y}_{\mathrm{t}+1}$ is seen to be based on the information represented by the current and past values of the process of interest. The weights affected to each component decrease exponentially. Further past values have less importance in the computation of the expectation. The special form of the weighting coefficients shows why this expectation scheme is also called exponential smoothing.

\section{Rational scheme}

\section{3.a. Optimal predictions}

Various criteria may be used in order to select an expectation scheme. Such criteria are, for instance, tractability, faithful reflections of the cycles existing in the evolution of $\mathrm{y}$, or overall precision of the approximation procedure.

Since this precision is measured by the mean square error $E(y-\tilde{y})^{2}$, it seems quite natural to minimize this value. The minimization problem is then specified with respect to a given information set. Its formulation involves the choice of an expectation scheme among the set of mappings $\mathrm{f}$ describing the computational mechanisms (see section 1.a). The following property gives the solution to the minimization problem.

Property (1.5) : Let $\mathrm{y}$ be the variable to be predicted and $\mathrm{I}=\{\mathrm{x}\}$ the information set. There exists a mapping $f$ such that $E[y-f(x)]^{2}$ reaches its minimal value. This mapping is the expectation of $y$ conditional on $\mathrm{x}$.

The conditional expectation is denoted $\mathrm{E}[\mathrm{y} \mid \mathrm{x}]$ or $\mathrm{E}[\mathrm{y} \mid \mathrm{I}]$. It is the mean of the conditional distribution of $\mathrm{y}$ given $\mathrm{x}$. We will use the following terms interchangeably : conditional expectation (of $\mathrm{y}$ given $\mathrm{x}$ ), optimal prediction (of $\mathrm{y}$ based on $\mathrm{x}$ ), rational expectation (of $\mathrm{y}$ based on $\mathrm{x}$ ).

\section{3.b. Some properties of optimal predictions}

The optimal prediction $\mathrm{E}[\mathrm{y} \mid \mathrm{x}]$ may be seen as the orthogonal projection of $\mathrm{y}$ on the set of all mappings of $x$ which are square-integrable, with the inner-product 
$\langle\mathrm{x}, \mathrm{y}\rangle=\mathrm{E}(\mathrm{xy})$. This interpretation implies some important properties of the rational expectation scheme.

Property (1.6) : The prediction error is orthogonal to the prediction :

$$
E\{(y-E[y \mid I]) E[y \mid I]\}=0 \text {. }
$$

Property (1.6) is a direct consequence of the optimality of the rational scheme. If it were not satisfied, i.e. if the prediction error was correlated with the information set, it could be possible to take into account this correlation and improve expectations.

If joint observations of realizations $\mathrm{y}_{\mathrm{t}}$ and expectations ${ }_{\mathrm{t}-1} \tilde{\mathrm{y}}_{\mathrm{t}}$ are available, then one can compute the empirical counterpart $\frac{1}{\mathrm{~T}} \sum_{\mathrm{t}=1}^{\mathrm{T}}\left(\mathrm{y}_{\mathrm{t}-\mathrm{t}-1} \tilde{\mathrm{y}}_{\mathrm{t}}\right)_{\mathrm{t}-1} \tilde{\mathrm{y}}_{\mathrm{t}}$ and examine whether it is close to zero. If it is not, then the hypothesis of rational expectations should be rejected. Such series of expectations and realizations may be obtained by a sample survey. In many European countries, economic agents (firms, households, financial institutions,...) are questioned at regular intervals on their expectations about the evolution of various economic variables. These data are collected in order to analyse the economic cycle. However, they may also be used to study the expectational behavior of economic agents. Table 2 gives the households' expectations and the realizations of the retail price index in France. These data are collected three times a year and regularly published in «Tendances de la Conjoncture» (INSEE).

\begin{tabular}{|l|rrr|rrr|rrr|}
\hline Year & \multicolumn{3}{|c|}{1980} & \multicolumn{3}{|c|}{1981} & \multicolumn{3}{c|}{1982} \\
\hline True value & 59,5 & 59,5 & 55,5 & 57,0 & 51,5 & 58,5 & 47,0 & 42,0 & $-3,0$ \\
\hline Expectation & $-10,0$ & 4,5 & $-1,5$ & $-4,0$ & $-11,5$ & $-19,5$ & $-25,5$ & $-13,5$ & 15,0 \\
\hline Year & & 1983 & & & 1984 & & 1985 & \\
\hline True value & 1,5 & 25,0 & 20,5 & 20,0 & 20,0 & 21,0 & 12,0 & 2,0 & $-22,0$ \\
\hline Expectation & $-18,0$ & $-9,0$ & $-18,0$ & $-15,5$ & $-14,0$ & $-14,5$ & $-22,0$ & $-23,5$ & $-32,5$ \\
\hline Year & & 1986 & & & 1987 & & & 1988 & \\
\hline True value & $-39,5$ & $-48,0$ & $-45,0$ & $-42,0$ & $-38,5$ & $-44,0$ & $-51,5$ & & \\
\hline Expectation & $-35,5$ & $-7,5$ & $-26,0$ & $-16,5$ & $-30,0$ & $-32,0$ & $-39,0$ & & \\
\hline
\end{tabular}

Table 2 
Figure 2 shows that the values predicted by the agents are generally lower than the true levels of the variable. However, this picture exhibits no clear evidence concerning the rationality of the expectation scheme. To test the rational expectation hypothesis, it is preferable to consider the joint observations of realizations and prediction errors. Figure 3 gives the series of products $\left(y_{t}-t-1 \tilde{y}_{t}\right)_{t-1} \tilde{y}_{t}$. Under the rational expectation hypothesis, this series should vary around zero. Clearly, this condition is not satisfied and rationality should probably be rejected for these particular variables.

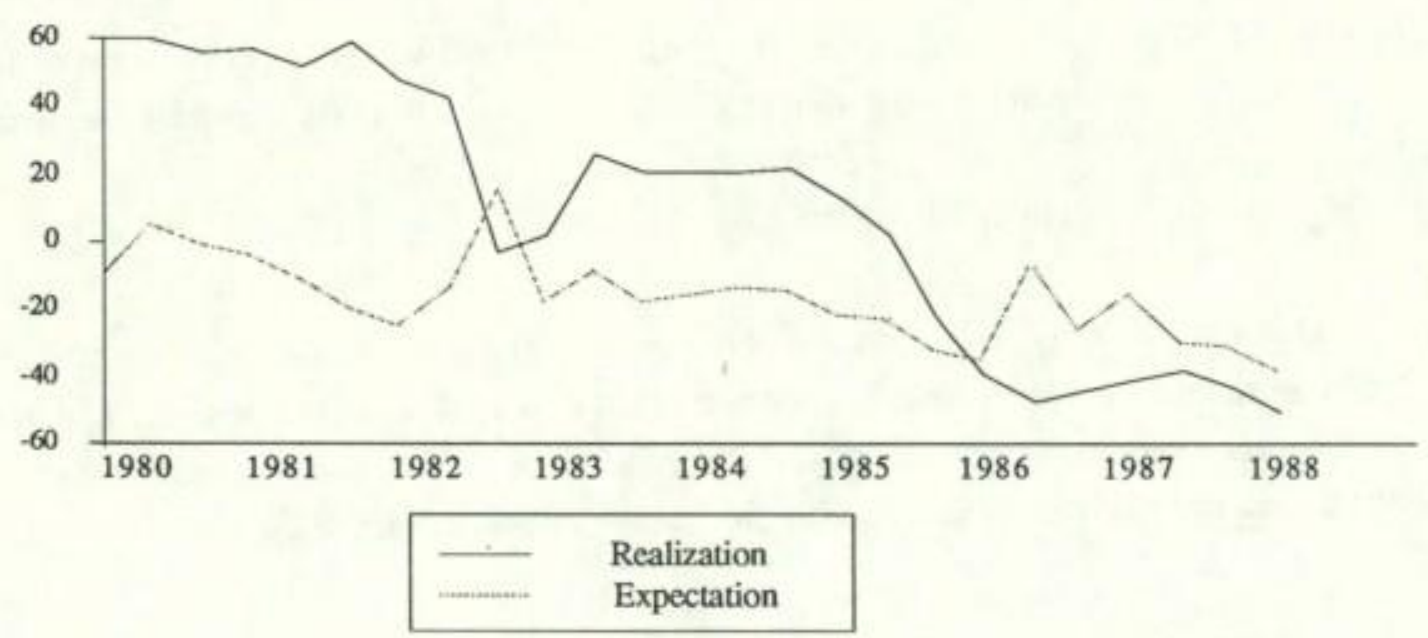

Figure 2

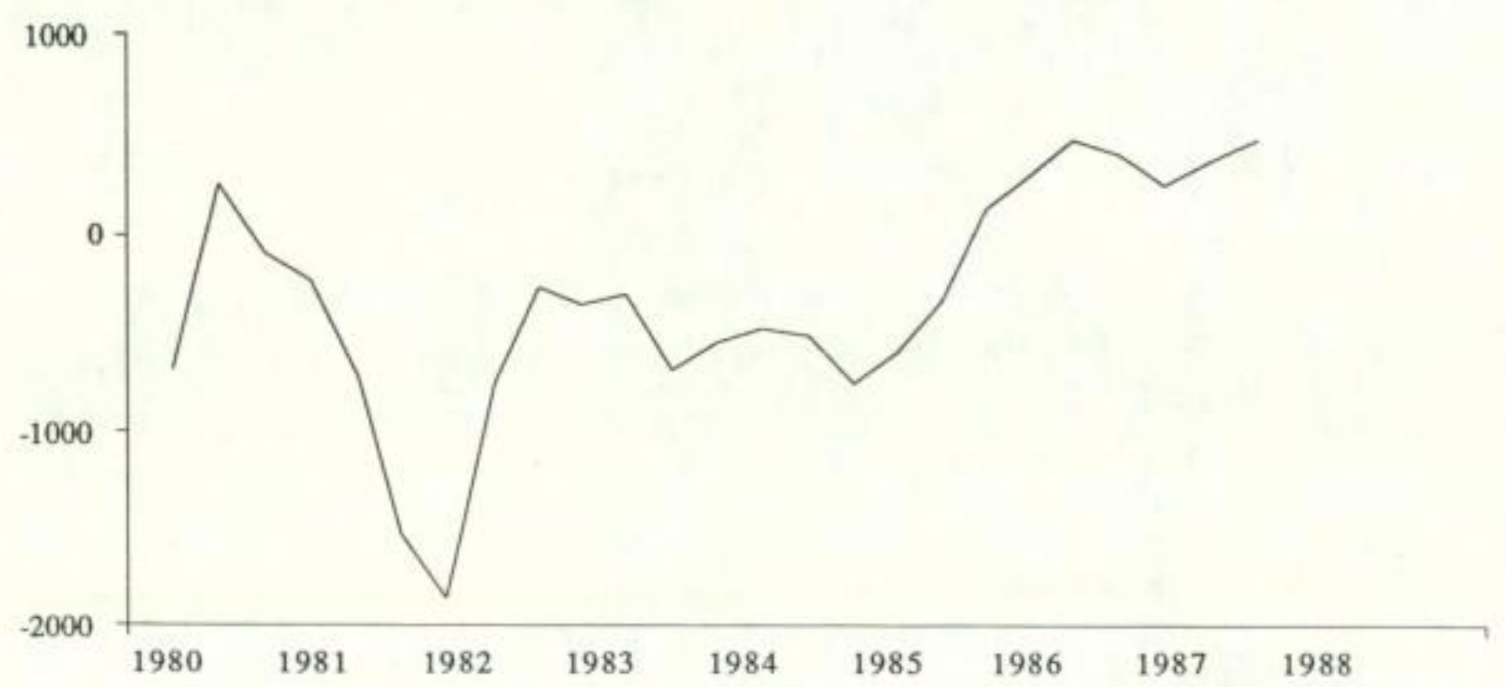

Figure 3 
Property (1.7) : $\quad$ The prediction error is uncorrelated with any variable included in the information set :

$$
\mathrm{E}\left\{(\mathrm{y}-\mathrm{E}[\mathrm{y} \mid \mathrm{I}]) \mathrm{x}_{\mathrm{k}}\right\}=0, \forall \mathrm{x}_{\mathrm{k}} \in \mathrm{I} \text {. }
$$

If joint observations of realizations $\mathrm{y}_{\mathrm{t}}$, expectations $\mathrm{t}_{\mathrm{t}-\mathrm{y}} \tilde{\mathrm{y}}_{\mathrm{t}}$ and another variable $\mathrm{x}_{\mathrm{kt}}$ are available, then one can compute the empirical counterpart $\frac{1}{\mathrm{~T}} \sum_{\mathrm{t}=1}^{\mathrm{T}}\left(\mathrm{y}_{\mathrm{t}}-\mathrm{t}-1 \tilde{\mathrm{y}}_{\mathrm{t}}\right) \mathrm{x}_{\mathrm{kt}}$. If it is not close to zero, then one can assume that the variable $x_{k}$ does not belong to the information set.

Property (1.8) : The variance of the variable y (total variance) is the sum of the variance of the prediction (explained variance) and the mean square error (residual variance) :

$V y=V E[y \mid I]+E[y-E[y \mid I]]^{2}$.

This variance analysis equation is the basis of the expectation quality measures. Indeed the mean square error that has been used till now to discuss the prediction quality is an absolute measure. In other words, it is not invariant with respect to unit changes in the variables. Invariance is obtained with the relative measure defined by :

$$
\frac{E[y-E[y \mid I]]^{2}}{V y}
$$

As a consequence of the variance analysis equation, this measure takes values between 0 and 1. Furthermore, it is equal to 0 when expectations are perfect, i.e. $\mathrm{y}=\mathrm{E}[\mathrm{y} \mid \mathrm{I}]$, and to 1 when the information set is the smallest one. In the latter case the rational expectation is given by the mean of the variable : $\mathrm{E}[\mathrm{y} \mid \mathrm{I}]=\mathrm{Ey}$.

\section{Property (1.9) or Law of iterated predictions}

Let $\mathrm{I}$ and $\mathrm{J}$ be two information sets such that $\mathrm{J}$ is included in $\mathrm{I}$.

The prediction of $\mathrm{y}$ based on $\mathrm{J}$ is equal to the prediction of $\mathrm{E}[\mathrm{y} \mid \mathrm{I}]$ based on $\mathrm{J}$ :

$E[E[y \mid I] \mid J]=E[y \mid J]$.

A consequence of property (1.7) or (1.9) is of great importance. Taking as a special case for $\mathrm{J}$ the smallest information set yields $\mathrm{E}[\mathrm{y} \mid \mathrm{J}]=\mathrm{Ey}$. It follows that rational expectations are unbiased: 
(1.10) $E[E[y \mid I]]=E y$.

The rational scheme does not allow for systematically positive or negative prediction errors. The property of unbiasedness may also be used for empirically testing rationality. From observations on realizations and expectations, it is possible to compute the empirical counterpart $\frac{1}{\mathrm{~T}} \sum_{\mathrm{t}=1}^{\mathrm{T}}\left(\mathrm{y}_{\mathrm{t}}-\mathrm{t}-1 \tilde{\mathrm{y}}_{\mathrm{t}}\right)$. If this quantity is not close to zero, one would reject the hypothesis of rational expectations. Let consider again the example of the French households' forecasts of the retail price. Figure 4 gives the prediction errors associated with these forecasts. Clearly, they don't fluctuate around zero and the rational expectation hypothesis should be reject.

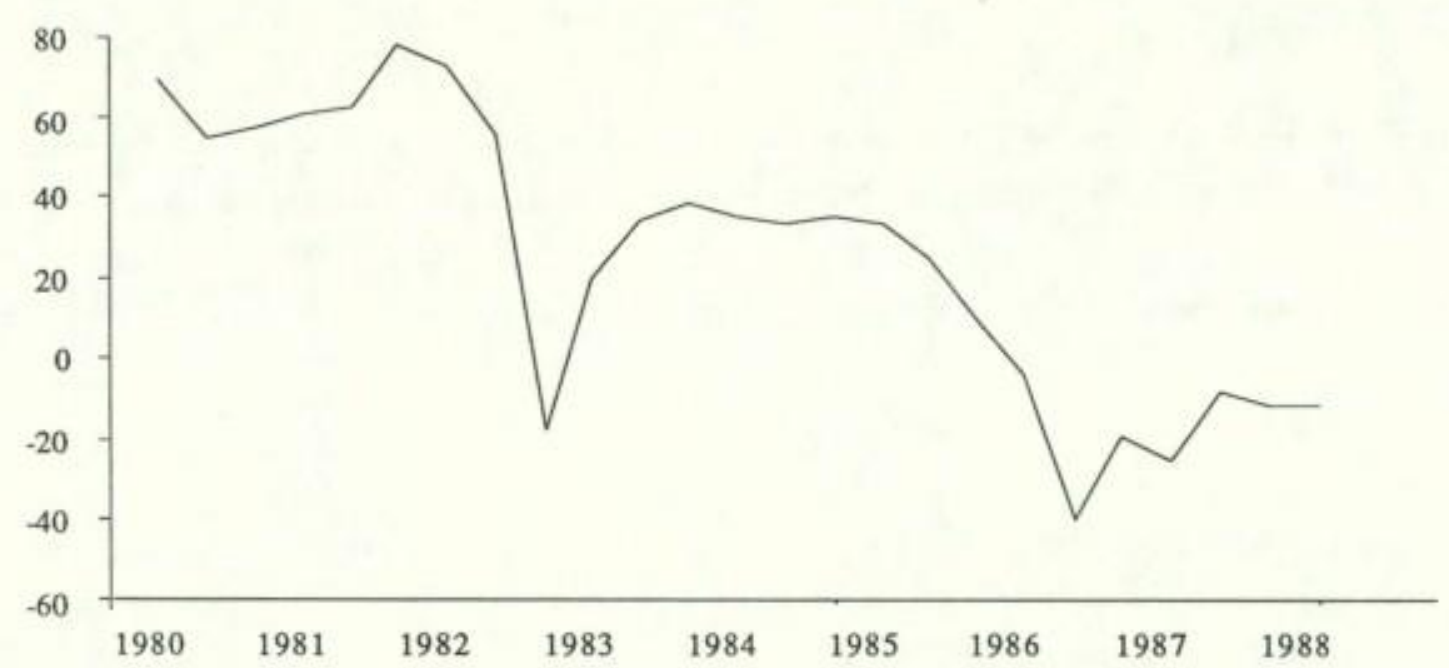

Figure 4

Property (1.11) : The prediction error diminishes when the information set becomes larger :

$\mathrm{I} \supset \mathrm{J} \Rightarrow \mathrm{E}[\mathrm{y}-\mathrm{E}[\mathrm{y} \mid \mathrm{I}]]^{2} \leq \mathrm{E}[\mathrm{y}-\mathrm{E}[\mathrm{y} \mid \mathrm{J}]]^{2}$.

The mean square prediction error is then linked to the quantity of available information.

\section{3.c. Prediction errors and updating}

We now consider a dynamic framework where $y=\left(y_{t}, t \in Z\right)$ is the process of interest and $\mathrm{I}=\left(\mathrm{I}_{\mathrm{t}}, \mathrm{t} \in \mathrm{Z}\right)$ is the increasing sequence of information sets. At time $t, \mathrm{I}_{\mathrm{t}}$ is 
given by $I_{t}=\left\{x_{t}, x_{t-1}, \ldots\right\}$. The preceding properties enable us to show some characteristics of the prediction errors and the updating. The notions of martingales and martingale differences will be needed, therefore we recall their definitions.

Definition (1.12) : Let $\mathrm{I}=(\mathrm{I} t, \mathrm{t} \in \mathrm{Z})$ be an increasing sequence of information sets.

a) A process $M=\left(M_{t}, t \in Z\right)$ is a martingale if and only if

$$
\mathrm{E}\left[\mathrm{M}_{\mathrm{t}+1} \mid \mathrm{I}_{\mathrm{t}}\right]=\mathrm{M}_{\mathrm{t}}, \quad \forall \mathrm{t} \in \mathrm{Z} \text {. }
$$

b) A process $\Delta=(\Delta t, t \in Z)$ is a martingale difference if and only if

$$
\mathrm{E}\left[\Delta_{\mathrm{t}} \mid \mathrm{I}_{\mathrm{t}}\right]=\Delta_{\mathrm{t}}, \forall \mathrm{t} \in \mathrm{Z},
$$

and

$$
\mathrm{E}\left[\Delta_{\mathrm{t}+1} \mid \mathrm{I}_{\mathrm{t}}\right]=0, \forall \mathrm{t} \in \mathrm{Z} \text {. }
$$

A martingale is a stochastic process for which the rational and naive expectations coïncide whilst a martingale difference is such that each component is uncorrelated with the past.

Let us now consider prediction errors relative to horizon $\mathrm{h}$ :

$$
\text { (1.13) } \mathrm{v}_{\mathrm{t}, \mathrm{h}}=\mathrm{y}_{\mathrm{t}+\mathrm{h}}-E\left[\mathrm{y}_{\mathrm{t}+\mathrm{h}} \mid \mathrm{I}_{\mathrm{t}}\right] \text {, }
$$

and the successive updating terms :

$$
\text { (1.14) } \varepsilon_{\mathrm{t}}^{\mathrm{h}}=\mathrm{E}\left[\mathrm{y}_{\mathrm{t}+\mathrm{h}} \mid \mathrm{I}_{\mathrm{t}}\right]-\mathrm{E}\left[\mathrm{y}_{\mathrm{t}+\mathrm{h}} \mid \mathrm{I}_{\mathrm{t}-1}\right] \text {. }
$$

Following the law of iterated predictions on $y$, the updating term $\varepsilon_{t}^{h}$ may also be written as :

$$
\varepsilon_{t}^{h}=E\left[y_{t+h} \mid I_{t}\right]-E\left[E\left[y_{t+h} \mid I_{t}\right] \mid I_{t-1}\right]
$$

This may be interpreted as the one-period-ahead prediction error on the prediction of $y_{t+h}$ made at time t. It follows from property (1.7) that the error $\varepsilon_{t}^{h}$ is uncorrelated with all elements of the information set $I_{t-1}: E\left[\varepsilon_{t}^{h} \mid I_{t-1}\right]=0$. 
Property (1.15) : The sequence of updating terms (with horizon h), i.e. $\left(\varepsilon_{\mathrm{t}}^{\mathrm{h}}, \mathrm{t} \in \mathrm{Z}\right)$, is a martingale difference for any fixed value of $h$.

On the other hand, the prediction errors are not martingale differences as soon as the horizon is larger than or equal to 2 . They can however be expressed easily by means of such processes. Indeed, any prediction error may be written in terms of successive updating terms :

$$
\begin{aligned}
& v_{t, h}=y_{t+h}-E\left[y_{t+h} \mid I_{t}\right] \\
&=y_{t+h}-E\left[y_{t+h} \mid I_{t+h-1}\right] \\
&+E\left[y_{t+h} \mid I_{t+h-1}\right]-E\left[y_{t+h} \mid I_{t+h-2}\right] \\
& \vdots \\
&+E\left[y_{t+h} \mid I_{t+1}\right]-E\left[y_{t+h} \mid I_{t}\right], \\
& \text { (1.16) } v_{t, h}=\sum_{i=0}^{h-i} \varepsilon_{t+h-i}^{i} .
\end{aligned}
$$

Other interesting results concern the evolution of the expectations of a given variable $\mathrm{y}_{\mathrm{T}}$. These expectations are given by :

$$
\mathrm{t} \tilde{y}_{T}=E\left[y_{T} \mid I_{t}\right], t \in Z \text {. }
$$

As time goes on, these predictions are modified. The updating term from one period to another is :

$$
\varepsilon_{t}^{T-t}=E\left[y_{T} \mid I_{t}\right]-E\left[y_{T} \mid I_{t-1}\right], t \in Z .
$$

It has already been noted that updating terms are uncorrelated with the past. In summary, we get the following result.

$$
\begin{aligned}
& \text { Property (1.17): a) The updating sequence }\left(\varepsilon_{t}^{\mathrm{T}-\mathrm{t}}, \mathrm{t} \in \mathrm{Z}\right) \text { is a martingale difference. } \\
& \text { b) The rational expectations sequence }\left(\tilde{\mathrm{y}}_{\mathrm{T}}=\mathrm{E}\left[\mathrm{y}_{\mathrm{T}} \mid \mathrm{I}\right], \mathrm{t} \in \mathrm{Z}\right) \text { is } \\
& \text { a martingale. }
\end{aligned}
$$


An illustration of the second part of property (1.17) is provided by the sequence of forward prices on an efficient market. Indeed, if we let $\mathrm{T}$ denote the term of the contract, the forward price at time $\mathrm{t}<\mathrm{T}$ is given by $\mathrm{E}\left[\mathrm{p}_{\mathrm{T}} \mid \mathrm{I}_{\mathrm{t}}\right]$. It is the rational expectation of $\mathrm{p}_{\mathrm{T}}$ formed using the available information $\mathrm{I}_{\mathbf{t}}$. It follows from property (1.17.b) that the forward prices sequence is a martingale (Samuelson (1965)).

Finally, it is possible to study the successive prediction errors. The prediction error, $\mathrm{v}_{\mathrm{T}-\mathrm{t}, \mathrm{t}}=\mathrm{y}_{\mathrm{T}}-\mathrm{E}\left[\mathrm{y}_{\mathrm{T}} \mid \mathrm{I}_{\mathrm{t}}\right]$, is such that :

$$
\begin{aligned}
v_{T-t+1, t-1} & =y_{t}-E\left[y_{T} \mid I_{t-1}\right] \\
& =y_{T}-E\left[y_{T} \mid I_{t}\right]+E\left[y_{T} \mid I_{t}\right]-E\left[y_{T} \mid I_{t-1}\right] \\
& =v_{T-t, t}+\varepsilon_{t}^{T-t} .
\end{aligned}
$$

It follows that the sequence $\left(v_{T-t, t}, t \in Z\right)$ is a martingale. This allows for a comparison between successive prediction errors.

Property (1.18) : The mean square prediction error diminishes as $t$ increases: $\mathrm{E}\left(\mathrm{y}_{T}-\mathrm{E}\left[\mathrm{y}_{T} \mid \mathrm{It}\right]\right)^{2}$ is a decreasing function of index $\mathrm{t}$.

In practice, it is often assumed that the information set $\mathrm{I}_{\mathrm{t}}$ includes the past and current values of the process $\mathrm{y}$. In this case, for $\mathrm{t}$ larger than $\mathrm{T}, \mathrm{y}_{\mathrm{T}}$ belongs to the set $\mathrm{It}$. It

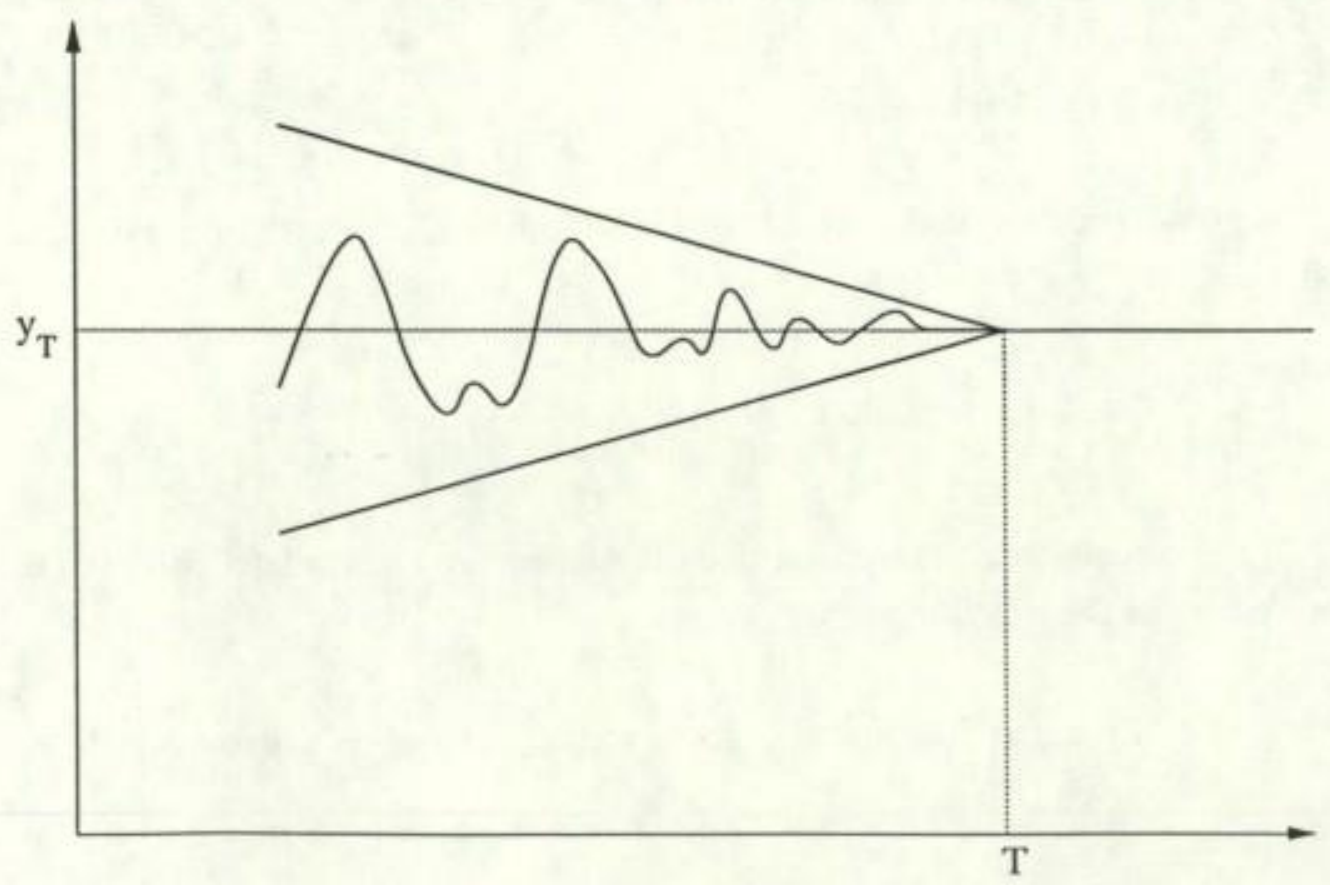

Figure 5 
follows that $y_{T}$ is known perfectly at time $t: E\left[y_{T} \mid I_{t}\right]=y_{T}, t \geq T$. The sequence of successive predictions of $\mathrm{y}_{\mathrm{T}}$ together with the corresponding prediction intervals are illustrated in Figure 5. For instance, if $\mathbf{y}$ denotes the sequence of forward prices, Figure 5 shows that predictions become better as time draws nearer to the term. 


\section{References}

ARROW, K.J. (1959) : 'Towards a theory of price adjustment', in Abramowitz, M. et al. (Eds), The Allocation of Economic Ressources, Stanford University Press, 49-51.

ARROW, K.J. AND NERLOVE, M. (1958) : 'A note on expectations and stability', Econometrica, 26, 297-305.

BROWN, B. AND S. MATTAL (1981): 'What do economists know ? : An empirical study of experts'expectations', Econometrica, 49, 491-504.

CARLSON, J. (1975) : 'Are price expectations normally distributed ?', Journal of the American Statistical Association, 70, 749-754.

DOOB, J. (1953) : Stochastic Processes, Wiley.

FISHER, I. (1930): The Theory of Interest as Determined by Impatience to Spend Income and the Opportunity to Invest it, New-York, MacMillan.

FRIEDMAN, B. (1980) : 'Survey evidence and the rationality of interest rate expectations', Journal of Monetary Economics, 6, 453-465.

FRIEDMAN, M. (1957) : A Theory of Consumption Function, NBER, New-York.

GOURIÉROUX, C. AND J. PRADEL (1985) : 'Direct test of the rational expectation hypothesis (with special attention to qualitative variables', European Economic Review, 30, 265-284.

HOUTHEKKER, H. (1961): 'Systematic and random elements in short term price movements', American Economic Review, 51, 164-172.

INSEE, Tendances de la conjoncture, $\mathrm{n}^{\circ} 4$ March 1982, $\mathrm{n}^{\circ} 12$ March 1984, $\mathrm{n}^{\circ} 20$ March 1986, n²8 March 1988.

KENDALL, M. (1964) : 'The analysis of economic time series, Part I : Prices', in Cootner, P. (Ed), The random Character of Stock Market Prices, MIT Press, 85-99.

LOVELL, M. (1986) : 'Test of the rational expectation hypothesis', American Economic Review, 76, 110-124.

MullineauX, D. (1978) : 'On testing for rationality : Another look at the Livingstone price expectations data', Journal of Political Economy, 86, 329-336.

NERLOVE, M. (1958) : 'Adaptive expectations and Cobweb phenomena', Quarterly Journal of Economics, 73, 227-240.

PESANDO, J. (1975) : ‘A note on the rationality of the Livingstone price expectations', Journal of Political economy, 83, 849-858. 
SAMUELSON, P. (1965) : 'Proof that properly anticipated prices fluctuate randomly', Industrial Management Review, 6, 41-49.

TURNOWSKI, S. AND M. WACHTER (1972) : 'A test of the expectation hypothesis using directly observed wage and price expectations', Review of Economics and Statistics, 54, 47-54. 


\section{CHAPTER 2}

\section{A MODEL WITH CURRENT EXPECTATIONS}

\section{An equilibrium model in an uncertain environment}

The model described in this section is concerned with price determination in a context where producers have to make decisions without knowing for sure the values of some variables influencing their economic environment. As a consequence, the equilibrium condition will include expectations of these variables. In order to emphasize the particularities of the model and discuss the underlying assumptions, we will briefly recall the classical Walrasian equilibrium model. As will be shown, this model corresponds to the perfect foresight case : it is based on the hypothesis of complete knowledge of the future.

\section{1.a. A Walrasian equilibrium model}

We consider the determination of the price in a market where two kinds of agents are involved : demanders and suppliers. Since we will mainly discuss the expectational behavior of the suppliers, a very simple formulation of the total demand function is retained.

Let $\mathrm{p}_{\mathrm{t}}, \mathrm{q}_{\mathrm{t}}$ and $\mathrm{z}_{\mathrm{l}}$ denote respectively the price of the good at time $\mathrm{t}$, the quantity demanded at time $t$ and the vector of exogenous variables that influence the demand at time $t$. The inverse demand relation is given by :

$$
\text { (2.1) } \mathrm{p}_{\mathrm{t}}=\mathrm{D}\left(\mathrm{q}_{\mathrm{t}}, \mathrm{z}_{1 \mathrm{t}}\right) \text {, }
$$

where D (.,.) is a mapping that decreases with respect to its first argument (for a fixed value of the second argument).

Let us now consider the supply side of the model. All firms are assumed identical. Formally this yields a single firm problem. Let $\mathrm{z}_{2 \mathrm{t}}$ be the exogenous variables that influence the current production function. It follows that, for any quantity $\mathrm{q}$, the cost function at time $\mathrm{t}$ is $\mathrm{C}\left(\mathrm{q}, \mathrm{z}_{2 \mathrm{t}}\right)$. 
The firm's maximization problem is written as :

$\operatorname{Max} \mathrm{p}_{\mathrm{t}} \mathrm{q}_{\mathrm{t}}-\mathrm{C}\left(\mathrm{q}_{\mathrm{t}}, \mathrm{z}_{2 \mathrm{t}}\right)$.

$\mathrm{qt}_{\mathrm{t}}$

Assuming a convex cost function, the solution to the maximization problem is deduced from the first order condition :

$$
p_{t}=\frac{\partial C}{\partial q}\left(q_{t}, z_{2 t}\right)
$$

Equation (2.2) shows that price and marginal cost are equal at the optimum. It can be rewritten with the use of the inverse marginal cost, denoted $\mathrm{H}\left(., \mathrm{z}_{2 \mathrm{~V}}\right)$, as :

$$
\text { (2.3) } \mathrm{q}_{\mathrm{t}}=\mathrm{H}\left(\mathrm{p}_{\mathrm{t}}, \mathrm{z}_{2 \mathrm{t}}\right) \text {. }
$$

Finally, the equilibrium price $\mathrm{p}_{\mathrm{t}}^{\mathrm{e}}$ is obtained by equating the supply and demand quantities. It is thus the solution of the following equation :

(2.4) $\mathrm{p}_{\mathrm{t}}^{\mathrm{e}}=\mathrm{D}\left[\mathrm{H}\left(\mathrm{p}_{\mathrm{t}}^{\mathrm{e}}, \mathrm{z}_{2 \mathrm{t}}\right), \mathrm{z}_{1 \mathrm{t}}\right]$.

This price depends on the current period through the exogenous variables $\mathrm{z}_{1 \mathrm{t}}$ and $\mathrm{z}_{2 \mathrm{t}}$. In other words, dynamics is present in eq. (2.4) but it is only caused by exogenous terms. No intrinsic endogenous dynamics appears.

\section{1.b. Extension of the model}

Let us now modify the preceding model and assume that the suppliers only know partially the price level $\mathrm{p}_{\mathrm{t}}$ and the exogenous terms $\mathrm{z}_{1 \mathrm{t}}$ and $\mathrm{z}_{2 \mathrm{t}}$ at the time they make their decisions. There is thus a lag between the decision period and the realization of the variables.

Since profit is unknown, the suppliers are supposed to maximize their expected profit. Implicitly they are considered to be risk-neutral. More precisely, all variables appearing in the model are taken to be stochastic. The information available to the agents at time $t$ is denoted $\mathrm{I}_{\mathrm{t}-1}$, hence the optimal prediction is given by $\mathrm{E}\left[. \mathrm{I}_{\mathrm{t}-1}\right]$. The new maximization problem based on optimal predictions is : 
(2.5) Max E $\left[p_{t} q_{t}-C\left(q_{t}, z_{2 t}\right) \mid I_{t-1}\right]$,

$\mathrm{q}_{\mathrm{t}}$

where the optimization is carried out with reference to all quantities $\mathrm{q}_{\mathrm{t}}$ that are expressed as functions of the available information $\mathrm{I}_{\mathrm{t}-1}$.

In this framework, the entrepreneur is rational in the sense that he/she knows the transition mechanism that leads from the information $\mathrm{I}_{\mathrm{t}-1}$ to the forthcoming values $\mathrm{p}_{\mathrm{t}}$ and $z_{2 t}$. This transition is summarized by the conditional distribution of $\mathrm{p}_{t}$ and $\mathrm{z}_{2 \mathrm{t}}$ based on $I_{t-1}$. Let $d \pi\left[p_{t}, z_{2 t} \mid I_{t-1}\right]$ denote this distribution. The expected profit may be written as :

$$
\begin{aligned}
\mathrm{E}\left[\mathrm{p}_{\mathrm{t}} \mathrm{q}_{\mathrm{t}}-\mathrm{C}\left(\mathrm{q}_{\mathrm{t}}, \mathrm{z}_{2 t}\right) \mid \mathrm{I}_{\mathrm{t}-1}\right] & =\int\left(\mathrm{p}_{\mathrm{t}} \mathrm{q}_{\mathrm{t}}-\mathrm{C}\left(\mathrm{q}_{\mathrm{t}}, \mathrm{z}_{2 t} \mathrm{t}\right) \mathrm{d} \pi\left[\mathrm{p}_{\mathrm{t}}, \mathrm{z}_{2 \mathrm{t}} \mid \mathrm{I}_{\mathrm{t}-1}\right]\right. \\
& =\left\{\int \mathrm{p}_{\mathrm{t}} \mathrm{d} \pi\left[\mathrm{p}_{\mathrm{t}}, \mathrm{z}_{2 \mathrm{t}} \mid \mathrm{I}_{\mathrm{t}-1}\right]\right) \mathrm{q}_{\mathrm{t}}-\int \mathrm{C}\left(\mathrm{q}_{\mathrm{t}}, \mathrm{z}_{2 \mathrm{t}}\right) \mathrm{d} \pi\left[\mathrm{p}_{\mathrm{t}}, \mathrm{z}_{2 \mathrm{t}} \mid \mathrm{I}_{\mathrm{t}-1}\right] \\
& =\mathrm{E}\left[\mathrm{p}_{\mathrm{t}} \mid \mathrm{I}_{\mathrm{t}-1}\right] \mathrm{q}_{\mathrm{t}}-\mathrm{E}\left[\mathrm{C}\left(\mathrm{q}_{\mathrm{t}}, \mathrm{z}_{2 \mathrm{t}}\right) \mid \mathrm{I}_{\mathrm{t}-1}\right] .
\end{aligned}
$$

In these derivations it has been supposed that $\mathrm{q}_{t}$ only depends on $\mathrm{I}_{\mathrm{t}-1}$. This is a consequence of the maximization formulation which requires $\mathrm{q}_{\mathrm{t}}$ to be fixed at the time when only $\mathrm{I}_{\mathrm{t}-1}$ is available.

The expected profit thus depends on both the expected price and expected costs. Note that the expectation of the cost function, i.e. :

$$
C^{a}\left(q, I_{t-1}\right)=E\left[C\left(q, z_{2 t}\right) \mid I_{t-1}\right] \text {, }
$$

is, like the cost function itself, convex with respect to its first argument. Indeed :

$$
\begin{aligned}
\mathrm{C}^{\mathrm{a}}\left(\lambda_{1} \mathrm{q}_{1}+\left(1-\lambda_{1}\right) \mathrm{q}_{2}, \mathrm{I}_{\mathrm{t}-1}\right) & =\mathrm{E}\left[\mathrm{C}\left(\lambda_{1} \mathrm{q}_{1}+\left(1-\lambda_{1}\right) \mathrm{q}_{2}, \mathrm{z}_{2 \mathrm{t}}\right) \mid \mathrm{I}_{\mathrm{t}-1}\right] \\
& \leq \mathrm{E}\left[\lambda_{1} \mathrm{C}\left(\mathrm{q}_{1}, \mathrm{z}_{2 \mathrm{t}}\right)+\left(1-\lambda_{1}\right) \mathrm{C}\left(\mathrm{q}_{2}, \mathrm{z}_{2} \mathrm{t}\right) \mid \mathrm{I}_{\mathrm{t}-1}\right] \\
& =\lambda_{1} \mathrm{C}^{\mathrm{a}}\left(\mathrm{q}_{1}, \mathrm{I}_{\mathrm{t}-1}\right)+\left(1-\lambda_{1}\right) \mathrm{C}^{\mathrm{a}}\left(\mathrm{q}_{2}, \mathrm{I}_{\mathrm{t}-1}\right),
\end{aligned}
$$

for $0 \leq \lambda_{1} \leq 1$.

The first order condition giving the quantity supplied is :

$$
E\left[p_{t} \mid I_{t-1}\right]=\frac{\partial C^{a}}{\partial q}\left(q_{t}, I_{t-1}\right)
$$


We retain the preceding formulation of the demanders' behavior and denote by $\mathrm{H}^{\mathrm{a}}\left(., \mathrm{I}_{\mathrm{t}-1}\right)$ the inverse of the expected marginal cost. It follows that the new equilibrium condition is :

$$
\text { (2.6) } \mathrm{p}_{\mathrm{t}}=\mathrm{D}\left[\mathrm{H}^{\mathrm{a}}\left(\mathrm{E}\left[\mathrm{p}_{\mathrm{t}} \mid \mathrm{I}_{\mathrm{t}-1}\right], \mathrm{I}_{\mathrm{t}-1}\right), \mathrm{z}_{1} \mathrm{t}\right. \text {. }
$$

Equation (2.6) expresses the price in terms of price expectation, variables influencing the demand, and expectations of the exogenous influences on the supply (through the intermediary of the expected cost function). However, at this stage, the price remains implicitly given because it appears in both sides of (2.6). Nevertheless it can be made explicit in the following way :

a) Consider the expected inverse demand :

$D^{a}\left(q, I_{t-1}\right)=\int D\left(q, z_{1 t}\right) d \pi\left[z_{1 t} \mid I_{t-1}\right]$

A condition normally imposed on inverse demand function is that it must be decreasing with respect to quantity. This condition should also be satisfied by the expectation $\mathrm{D}^{\mathrm{a}}$.

b) On taking the optimal prediction of both sides of eq (2.6) with respect to the information set $\mathrm{I}_{\mathrm{t}-1}$, one obtains :

$$
E\left[p_{t} \mid I_{t-1}\right]=D^{a}\left[H^{a}\left(E\left[p_{t} \mid I_{t-1}\right], I_{t-1}\right), I_{t-1}\right] .
$$

The mapping $\mathrm{D}^{\mathrm{a}}\left[\mathrm{H}^{\mathrm{a}}\left(., \mathrm{I}_{\mathrm{t}-1}\right), \mathrm{I}_{\mathrm{t}-1}\right]$ is decreasing. Equation (2.7) generally admits a unique solution, i.e. it defines a unique path for the expectation process $E\left[p_{t} \mid I_{t-1}\right]$. Let $\mathrm{g}^{\mathrm{a}}\left(\mathrm{I}_{\mathrm{t}-1}\right)$ denote this solution.

c) The equilibrium price in an uncertain environment is then obtained by replacing the expectation in eq (2.6) by its expression :

$$
\mathrm{p}_{\mathrm{t}}=\mathrm{D}\left[\mathrm{H}^{\mathrm{a}}\left(\mathrm{g}^{\mathrm{a}}\left(\mathrm{I}_{\mathrm{t}-1}\right), \mathrm{I}_{\mathrm{t}-1}\right), \mathrm{z}_{1 \mathrm{t}}\right]
$$

The current price depends on current values of the exogenous variables that influence the demand. It also depends on the expected values of all exogenous variables through $\mathrm{H}^{\mathrm{a}}$ and $\mathrm{g}^{\mathrm{a}}$. 


\section{1.c. The linear case}

The model presented in the preceding section is often considered in the particular case of a linear demand function and a quadratic cost function. Under these restrictions, one has :

$$
\begin{cases}D\left(q, z_{1}\right)=\alpha\left(z_{1}\right) q+\beta\left(z_{1}\right), & \alpha\left(z_{1}\right)<0, \\ C\left(q, z_{2}\right)=\frac{1}{2} \gamma\left(z_{2}\right) q^{2}+\delta\left(z_{2}\right) q+\varepsilon\left(z_{2}\right), & \gamma\left(z_{2}\right)>0 .\end{cases}
$$

It follows that the expectations are :

$$
\left\{\begin{array}{l}
\frac{\partial C^{a}}{\partial q}\left(q, I_{t-1}\right)=E\left[\gamma\left(z_{2 t}\right) \mid I_{t-1}\right] q+E\left[\delta\left(z_{2 t}\right) \mid I_{t-1}\right] \\
H^{a}\left(p, I_{t-1}\right)=\frac{1}{E\left[\gamma\left(z_{2 t}\right) \mid I_{t-1}\right]} p-\frac{E\left[\delta\left(z_{2 t}\right) \mid I_{t-1}\right]}{E\left[\gamma\left(z_{2 t}\right) \mid I_{t-1}\right]}, \\
D^{a}\left(q, I_{t-1}\right)=E\left[\alpha\left(z_{1 t}\right) \mid I_{t-1}\right] q+E\left[\beta\left(z_{1 t}\right) \mid I_{t-1}\right] .
\end{array}\right.
$$

Note that these mappings are different from one period to another because they depend on the information set used to make predictions.

The equilibrium condition given by equation (2.6) describes the evolution of prices with respect to the diverse expectations entering the model. In the linear case, it is written as :

$$
\text { (2.9) } \mathrm{p}_{\mathrm{t}}=\frac{\alpha\left(\mathrm{z}_{1 \mathrm{t}}\right)}{\mathrm{E}\left[\gamma\left(\mathrm{z}_{2 \mathrm{t}}\right) \mid \mathrm{I}_{\mathrm{t}-1}\right]} \mathrm{E}\left[\mathrm{p}_{\mathrm{t}} \mid \mathrm{I}_{\mathrm{t}-1}\right]-\alpha\left(\mathrm{z}_{1 \mathrm{t}}\right) \frac{\mathrm{E}\left[\delta\left(\mathrm{z}_{2 \mathrm{t}}\right) \mid \mathrm{I}_{\mathrm{t}-1}\right]}{\mathrm{E}\left[\gamma\left(\mathrm{z}_{2 \mathrm{t}}\right) \mid \mathrm{I}_{\mathrm{t}-1}\right]}+\beta\left(\mathrm{z}_{1 \mathrm{t}}\right) \text {. }
$$

Taking the expectation of both sides yields :

$$
\begin{aligned}
E\left[p_{t} \mid I_{t-1}\right] & =\left(1-\frac{E\left[\alpha\left(z_{1 t}\right) \mid I_{t-1}\right]}{E\left[\gamma\left(z_{2 t}\right) \mid I_{t-1}\right]}\right)^{-1} \\
& \left(-E\left[\alpha\left(z_{1 t}\right) \mid I_{t-1}\right] \frac{E\left[\delta\left(z_{2 t}\right) \mid I_{t-1}\right]}{E\left[\gamma\left(z_{2 t}\right) \mid I_{t-1}\right]}+E\left[\beta\left(z_{1 t}\right) \mid I_{t-1}\right]\right) \\
& =g^{a}\left(I_{t-1}\right) .
\end{aligned}
$$


Subtituting for $\mathrm{E}\left[\mathrm{p}_{\mathrm{t}} \mid \mathrm{I}_{\mathrm{t}-1}\right]$ in equation (2.9) leads to an expression of the price in terms of the exogenous variables and their expectations :

$$
\begin{aligned}
p_{t}= & \frac{\alpha\left(z_{1 t}\right)}{E\left[\gamma\left(z_{2 t}\right) \mid I_{t-1}\right]}\left(1-\frac{E\left[\alpha\left(z_{1 t}\right) \mid I_{t-1}\right]}{E\left[\gamma\left(z_{2 t}\right) \mid I_{t-1}\right]}\right)^{-1} \\
& \left(-E\left[\alpha\left(z_{1 t}\right) \mid I_{t-1}\right] \frac{E\left[\delta\left(z_{2 t}\right) \mid I_{t-1}\right]}{E\left[\gamma\left(z_{2 t}\right) \mid I_{t-1}\right]}+E\left[\beta\left(z_{1 t}\right) \mid I_{t-1}\right]\right) \\
& -\alpha\left(z_{1 t}\right) \frac{E\left[\delta\left(z_{2 t}\right) \mid I_{t-1}\right]}{E\left[\gamma\left(z_{2 t}\right) \mid I_{t-1}\right]}+\beta\left(z_{1 t}\right) .
\end{aligned}
$$

In order to further simplify this expression, one may impose linearity with respect to the exogenous variables on the equation giving the price. For this purpose, one has to assume :

$$
\begin{aligned}
& D\left(q, z_{1}\right)=\alpha q+z_{1} \beta \\
& \frac{\partial C}{\partial q}\left(q, z_{2}\right)=\gamma q+\delta .
\end{aligned}
$$

Equation (2.9) then has the form of a linear model. The explanatory variables are the expectations of the price and the exogenous variables entering the demand side :

$$
\text { (2.11) } \mathrm{p}_{\mathrm{t}}=\frac{\alpha}{\gamma} \mathrm{E}\left[\mathrm{p}_{\mathrm{t}} \mid \mathrm{I}_{\mathrm{t}-1}\right]-\frac{\delta \alpha}{\gamma}+\mathrm{z}_{1 \mathrm{t}} \beta \text {. }
$$

A model of this very simplified type was used by Muth (1961) in his seminal paper on rational expectations. Clearly this model is based on some very restrictive assumptions : risk neutrality of the suppliers, agents' knowledge of the transition from the information $\mathrm{I}_{\mathrm{t}-1}$ to the current price $\mathrm{p}_{\mathrm{t}}$, time-invariance of the supply function, linearity of the demand and supply functions, and constant marginal propensity to demand with respect to price. All of these assumptions might of course be questioned. However the next section will deal exclusively with simple models like (2.11). The aim is to emphasize their dynamic properties and to discuss the robustness of the dynamics with respect to the chosen expectation scheme. 


\section{Dynamic properties of the current expectation model}

\section{2.a. The rational expectations model}

Before removing the expectation, the reduced form of the model is the following :

$$
\text { (2.12) } \mathrm{y}_{\mathrm{t}}=\mathrm{a} E\left[\mathrm{y}_{\mathrm{t}} \mid \mathrm{I}_{\mathrm{t}-1}\right]+\mathrm{x}_{\mathrm{t}} \mathrm{b} \text {, }
$$

where $y$ and $x$ denote respectively the endogenous variable (i.e. the price in the preceding model) and the exogenous variables (including the constant term). Coefficients a and $b$ are the reduced form parameters. They generally depend (in a non-linear way) on the structural parameters. As seen before, the last equation yields :

$$
\text { (2.13) } E\left[y_{t} \mid I_{t-1}\right]=E\left[x_{t} \mid I_{t-1}\right] \frac{b}{1-a} \text {. }
$$

It follows that :

$$
\text { (2.14) } y_{t}=E\left[x_{t} \mid I_{t-1}\right] \frac{a b}{1-a}+x_{t} b \text {. }
$$

Equation (2.14) shows that the dynamics of the endogenous process relies crucially on the evolution of exogenous processes and, more specifically, on the way current exogenous variables depend on the past information. It is thus necessary to complete the model by specifying :

a) the available information set $\mathrm{I}_{\mathrm{t}-1}$;

b) the evolution of the exogenous processes (or only of their expectations).

To each specification corresponds a generally distinct dynamics of the endogenous process.

\section{The perfect foresight case}

Firstly, assume that the available information set $\mathrm{I}_{\mathrm{t}-1}$ includes the current values of the exogenous variables $x_{t}$. Whatever the evolution of the exogenous process, expectations are made without error: $\mathrm{E}\left[\mathrm{x}_{\mathrm{t}} \mid \mathrm{I}_{\mathrm{t}-1}\right]=\mathrm{x}_{\mathrm{t}}$. The relation giving the current value of the endogenous variable, i.e. equation (2.14), becomes :

$$
y_{t}=x_{t} \frac{a b}{1-a}+x_{t} b=x_{t} \frac{b}{1-a} .
$$


It corresponds to the perfect foresight model

$$
y_{t}=a y_{t}+x_{t} b
$$

As one could expect, the perfect foresight hypothesis appears as a special case of rational expectations associated with a sufficiently large information set. In other words, for the current expectations model, the perfect knowledge of current exogenous variables implies a perfect expectation of the current endogenous variable.

\section{Partial ignorance of the future}

The rational expectation model is nevertheless more interesting when future variables are partially unknown. Suppose that, among the $\mathrm{K}$ explanatory variables $\mathrm{x}_{\mathrm{t}}, \tilde{\mathrm{K}}$ are perfectly known at time $\mathrm{t}-1$, while the $\tilde{\mathrm{K}}=\mathrm{K}-\tilde{\mathrm{K}}$ others are not. Without loss of generality, the first category of variables is taken as the first $\tilde{\mathrm{K}}$ components of the vector $\mathrm{x}$ and is denoted $\tilde{\mathrm{x}}$. Conformably, the $\tilde{\mathrm{K}}$ remaining variables are considered to belong to the second category and are denoted $\tilde{x}$. It follows that :

$$
\begin{aligned}
& y_{t}=E\left[\tilde{x}_{t} \mid I_{t-1}\right] \frac{a \tilde{b}}{1-a}+E\left[\tilde{x}_{t} \mid I_{t-1}\right] \frac{a \tilde{b}}{1-a}+\tilde{x}_{t} \tilde{b}+\tilde{x}_{t} \tilde{b}, \\
& y_{t}=\tilde{x}_{t} \frac{\sigma}{1-a}+E\left[\tilde{x}_{t} \mid I_{t-1}\right] \frac{a \tilde{b}}{1-a}+\tilde{x}_{t} \tilde{b} .
\end{aligned}
$$

The model has to be completed by a specification of the expectations of the exogenous $\tilde{x}_{t}$. We assume here a linear scheme with an autoregressive form of order one :

$$
\text { (2.15) } \mathrm{E}\left[\tilde{\mathrm{x}}_{\mathrm{t}} \mid \mathrm{I}_{\mathrm{t}-1}\right]=\mathrm{H}_{0}+\tilde{\mathrm{x}}_{\mathrm{t}} \mathrm{H}_{1}+\tilde{\mathrm{x}}_{\mathrm{t}-1} \mathrm{H}_{2}+\tilde{\mathrm{x}}_{\mathrm{t}-1} \mathrm{H}_{3}+\mathrm{y}_{\mathrm{t}-1} \mathrm{H}_{4}
$$

where $\mathrm{H}_{0}, \mathrm{H}_{1}, \mathrm{H}_{2}, \mathrm{H}_{3}$ and $\mathrm{H}_{4}$ are matrices having respective sizes of $1 \times \tilde{\mathrm{K}}, \tilde{\mathrm{K}} \times \tilde{\mathrm{K}}$, $\tilde{\mathrm{K}} \times \widetilde{\widetilde{K}}, \tilde{\mathrm{K}} \times \widetilde{\mathrm{K}}$ and $1 \times \widetilde{\mathrm{K}}$. Under specification (2.15), one obtains a dynamic model describing simultaneously $y$ and $\tilde{x}$ :

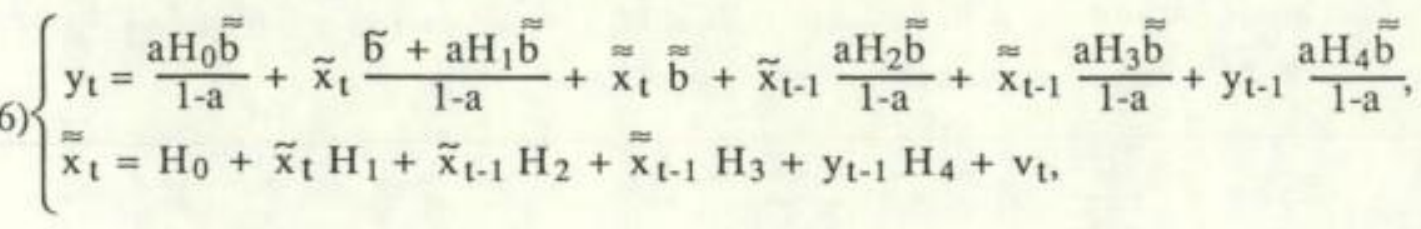


with $\mathrm{E}\left[\mathrm{v}_{\mathrm{t}} \mid \mathrm{I}_{\mathrm{t}-1}\right]=0$.

This system is a joint autoregressive representation of $(y, \tilde{\mathbf{x}})$ conditional on the predetermined variables $\tilde{\mathbf{x}}$. Such an expression leads itself to a statistical treatment involving parameter estimation and tests of the restrictions imposed by the rational expectation hypothesis. The next section is devoted to a discussion of the latter.

\section{2.b. Comparison of the constrained and unconstrained reduced forms}

Model (2.16) may be directly compared to the unconstrained reduced form :

$$
\text { (2.17) }\left\{\begin{array}{l}
\mathrm{y}_{\mathrm{t}}=\pi_{0}+\tilde{\mathrm{x}}_{\mathrm{t}} \pi_{1}+\tilde{\mathrm{x}}_{\mathrm{t}} \pi_{2}+\tilde{\mathrm{x}}_{\mathrm{t}-1} \pi_{3}+\tilde{\mathrm{x}}_{\mathrm{t}-1} \pi_{4}+\mathrm{y}_{\mathrm{t}-1} \pi_{5}, \\
\tilde{\mathrm{x}}_{\mathrm{t}}=\mathrm{H}_{0}+\tilde{\mathrm{x}}_{\mathrm{t}} \mathrm{H}_{1}+\tilde{\mathrm{x}}_{\mathrm{t}-1} \mathrm{H}_{2}+\tilde{\mathrm{x}}_{\mathrm{t}-1} \mathrm{H}_{3}+\mathrm{y}_{\mathrm{t}-1} \mathrm{H}_{4}+\mathrm{v}_{\mathrm{t}}
\end{array}\right.
$$

Under assumption (2.15) concerning the expectations of $\tilde{x}_{t}$, the existence of a rational expectations model explaining the formation of $\mathrm{y}_{\mathrm{t}}$ depends on the expression of the reduced coefficients. More precisely, such a model is possible if and only if there exist real values, a, $\tilde{b}$ and $\overline{\mathrm{b}}$ satisfying the following relations :

$$
\pi_{0}=\frac{\mathrm{aH}_{0} \tilde{\mathrm{b}}}{1-\mathrm{a}}, \pi_{1}=\frac{5+\mathrm{aH}_{1} \tilde{\mathrm{b}}}{1-\mathrm{a}}, \pi_{2}=\tilde{\mathrm{b}}, \pi_{3}=\frac{\mathrm{aH}_{2} \tilde{\mathrm{b}}}{1-\mathrm{a}}, \pi_{4}=\frac{\mathrm{aH}_{3} \tilde{\mathrm{b}}}{1-\mathrm{a}}, \pi_{5}=\frac{\mathrm{aH}_{4} \tilde{\mathrm{b}}}{1-\mathrm{a}} .
$$

This set of relations gives the system of constraints. It can be written in a shorter way by defining $\mathrm{c}=\frac{1-\mathrm{a}}{\mathrm{a}}$ and $\mathrm{d}=\frac{\tilde{\mathrm{b}}}{1-\mathrm{a}}$. The condition for existence of a rational expectations model then becomes :

$$
\text { (2.18) } \begin{aligned}
& \exists \mathrm{c}, \mathrm{d}, \tilde{\mathrm{b}}: \mathrm{c} \pi_{0}=\mathrm{H}_{0} \tilde{\mathrm{b}}, \mathrm{c} \pi_{1}=\mathrm{d}+\mathrm{H}_{1} \tilde{\mathrm{b}}, \pi_{2}=\tilde{\mathrm{b}}, \mathrm{c} \pi_{3}=\mathrm{H}_{2} \tilde{\overline{\mathrm{b}}}, \\
& \text { c } \pi_{4}=\mathrm{H}_{3} \tilde{\mathrm{b}}, \mathrm{c} \pi_{5}=\mathrm{H}_{4} \tilde{\mathrm{b}} .
\end{aligned}
$$

The constraints are expressed in terms of both the unconstrained parameters $\pi_{0}$, $\pi_{1}, \pi_{2}, \pi_{3}, \pi_{4}, \pi_{5}, \mathrm{H}_{0}, \mathrm{H}_{1}, \mathrm{H}_{2}, \mathrm{H}_{3}$ and $\mathrm{H}_{4}$ and the auxiliary parameters $\mathrm{c}, \mathrm{d}$ and $\mathrm{b}$. The latter can be interpreted only under the null hypothesis of rational expectations. 
Furthermore, the constraints are simultaneously linear with respect to both types of parameters. This particularly simple form allows for the development of a Wald test of the rational expectations hypothesis that only makes use of linear least squares estimation procedures. Such an approach has been introduced by Szroeter (1983), Gouriéroux and Monfort (1988) and Gouriéroux, Monfort and Renault (1988) for mixed hypotheses.The steps are the following :

a) Determine the OLS estimators $\hat{\pi}$ and $\hat{\mathrm{H}}$ of the unconstrained reduced form parameters.

b) Estimate by OLS the regression model given by :

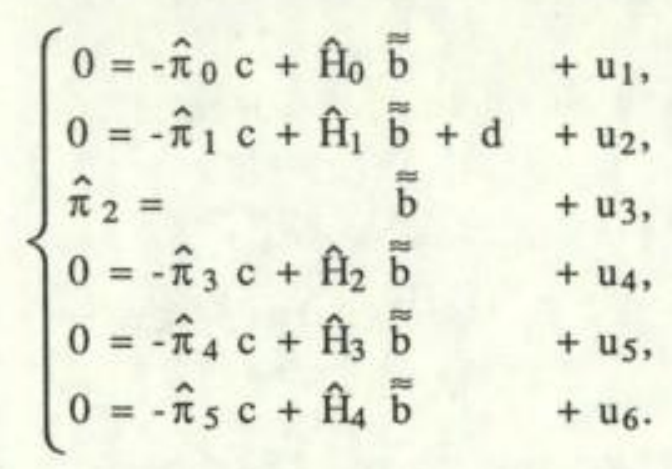

This yields estimators of the auxiliary parameters $c, d$ and $\tilde{b}$ that are consistent under the rational expectations hypothesis.

c) Compute the asymptotic variance-covariance matrix of the error terms $\mathrm{u}_{1}, \ldots \mathrm{u}_{6}$ of the regression. Re-estimate the regression model by taking into account the correlations among the errors, i.e. apply the quasi-generalized least squares method. It may be shown [See Gouriéroux, Monfort and Renault (1988)] that the second step estimators of c, $\mathrm{d}$ and $\tilde{\mathrm{b}}$ have asymptotic optimality properties. Also, the Wald statistic of the rational expectation hypothesis is equal to the sum of the squared residuals corresponding to the last regression [Szroeter (1983)].

In other words, a natural way to examine whether a rational expectations specification holds consists in first using an unconstrained vector autoregressive representation (VAR) [See for instance Sims (1980)] and then examining the satisfaction of the constraints due to the rationality hypothesis. Technically, as far as a linear current expectations model is concerned, this approach only necessitates simple statistical methods of the linear least squares type.

\section{2.c. Comparison of various expectation schemes}

Model (2.12) is given by : 


$$
y_{t}=a E\left[y_{t} \mid I_{t-1}\right]+x_{t} b
$$

Its expression summarizes in a single formula two quite different ideas. The first one is the impact of expectations on real values which may be singled out as :

$$
y_{t}=a_{t-1} \tilde{y}_{t}+x_{t} b
$$

where ${ }_{t-1} \tilde{y}_{t}$ is the expectation of the endogenous variable $y_{t}$ formed at time $t-1$. The second one is the rational expectations hypothesis, i.e. the optimality of the expectation scheme with respect to the available information. Formally :

$$
t-1 \tilde{y}_{t}=E\left[y_{t} \mid I_{t-1}\right]
$$

In this section we keep the first part of the model and modify the second part. A discussion of the consequences of such a modification on the evolution of the endogenous process will then be pursued. In order to facilitate the discussion, we restrict it to the case of a single explanatory exogenous variable $\mathrm{x}$. Furthermore, the latter is assumed to admit an autoregressive representation :

$$
x_{t}=\rho x_{t-1}+\varepsilon_{t}
$$

where $\rho$ is a real number with modulus strictly smaller than 1 and $\varepsilon=\left(\varepsilon_{t}\right)$ is an independant white noise with variance $\sigma^{2}$.

\section{The rational expectation model}

When the expectation is rational and based on the information set $\mathrm{I}_{\mathrm{t}-1}=\left\{\mathrm{x}_{\mathrm{t}-1}, \mathrm{y}_{\mathrm{t}-1}\right.$, $\mathrm{x}_{\mathrm{t}-2}, \mathrm{y}_{\mathrm{t}-2}, \ldots \mathrm{t}$, one has :

$$
t_{t-1} \tilde{y}_{t}=E\left[y_{t} \mid I_{t-1}\right]=\frac{b}{1-a} E\left[x_{t} \mid I_{t-1}\right]=\frac{b}{1-a} \rho x_{t-1}
$$

because the optimal prediction of $x_{t}$ is $\rho x_{t-1}$. It follows that :

$$
y_{t}=a_{t-1} \tilde{y}_{t}+b x_{t}=\frac{a b \rho}{1-a} x_{t-1}+b x_{t} .
$$


Let us now introduce the lag-operator $\mathrm{L}$ that, when applied to a current variable $\left(\mathrm{x}_{\mathrm{t}}\right.$ or $\mathrm{y}_{t}$ ), gives the variable lagged one period (respectively $\mathrm{x}_{\mathrm{t}-1}$ or $\mathrm{y}_{\mathrm{t}-1}$ ). The joint evolution of $y_{t}$ and $x_{t}$ may then be written as :

$$
\left\{\begin{array}{l}
y_{t}=\left(\frac{a b \rho L}{1-a}+b\right) x_{t}, \\
(1-\rho L) x_{t}=\varepsilon_{t} .
\end{array}\right.
$$

Subsequently, the endogenous process may be expressed in terms of the innovation $\varepsilon$ of the exogenous process :

$$
\text { (2.19) } y_{t}=\left(\frac{a b \rho L}{1-a}+b\right)(1-\rho L)^{-1} \varepsilon_{t} \text {. }
$$

Equation (2.19) shows that $y$ has an autoregressive-moving average representation ARMA $(1,1)$. This process is stationary for all real values of the structural parameters a and $\mathrm{b}$ (with $\mathrm{a} \neq 1$ ).

On the other hand, it is interesting to examine the effect of an exogenous shock on the endogenous variable. The usual way to do this is to define an exogenous shock by means of the innovation process [see Sims (1980)]. To a sustained shock $\Delta \varepsilon$ to the components of the noise correspond the following modifications :

$$
\begin{array}{ll}
\text {. on the exogenous } \mathrm{x}_{\mathrm{t}} & : \Delta \mathrm{x}=\frac{1}{1-\rho} \Delta \varepsilon \\
\text {. on the expectation }{ }_{\mathrm{t}-1} \tilde{\mathrm{y}}_{\mathrm{t}} & : \Delta \tilde{y}=\frac{\mathrm{b} \rho}{(1-\mathrm{a})(1-\rho)} \Delta \varepsilon ; \\
\text {. on the endogenous } \mathrm{y}_{\mathrm{t}} & : \Delta \mathrm{y}=\frac{1}{1-\rho}\left(\frac{\mathrm{ab} \rho}{1-\mathrm{a}}+\mathrm{b}\right) \Delta \varepsilon .
\end{array}
$$

Hence a modification of the evolution scheme of the exogenous process has a double effect on the endogenous process. The first effect is direct since it comes from the term $\mathrm{bx}_{\mathrm{t}}$. The second effect is indirect because it is transmitted through the expectation. Translated into a formula, this distinction is expressed by :

$$
\frac{\Delta y}{\Delta \varepsilon}=\frac{\begin{array}{c}
\text { abp } \\
\text { indirect } \\
\text { effect }
\end{array}}{1-\rho} \frac{1}{b \frac{1}{1-\rho}},
$$


or equivalently :

$$
\text { (2.20) } \frac{\Delta \mathrm{y}}{\Delta \mathrm{x}}=\frac{\mathrm{ab} \rho}{1-\mathrm{a}}+\mathrm{b} .
$$

Note that the size of the indirect effect depends on the parameter $\rho$ describing the dynamics of the exogenous process.

\section{The adaptive expectations model}

Another classical expectation scheme is the adaptive one. It was first introduced into a model by Fischer (1930) and its main properties have been systematically presented by Arrow (1959) and Nerlove (1958).

Following the adaptive scheme (see chapter 1 ), the expectation ${ }_{t-1} \tilde{y}_{t}$ is a weighted average of the last expectation and the most recent observation of the variable. Letting $\lambda$ denote the weight :

$$
\mathrm{t}_{\mathrm{t}-1} \tilde{\mathrm{y}}_{\mathrm{t}}=\lambda_{\mathrm{t}-2 \tilde{\mathrm{y}}_{\mathrm{t}-1}+(1-\lambda) \mathrm{y}_{\mathrm{t}-1},} \quad 0 \leq \lambda \leq 1,
$$

or equivalently :

$$
t_{t-1} \tilde{y}_{t}-t_{t-2} \tilde{y}_{t-1}=(1-\lambda)\left(y_{t-1}-t_{t-2} \tilde{y}_{t-1}\right), \quad 0 \leq \lambda \leq 1 .
$$

The second form refers to the updating formula (2.3). Under the adaptive expectations hypothesis, the structural form of the model implies :

$$
\mathrm{y}_{\mathrm{t}}-\lambda \mathrm{y}_{\mathrm{t}-1}=\mathrm{a}\left(\mathrm{t}-1 \tilde{\mathrm{y}}_{\mathrm{t}}-\lambda_{\mathrm{t}-2} \tilde{\mathrm{y}}_{\mathrm{t}-1}\right)+\left(\mathrm{x}_{\mathrm{t}}-\lambda \mathrm{x}_{\mathrm{t}-1}\right) \mathrm{b}
$$

Finally, we obtain :

$$
(1-(a+\lambda-a \lambda) L) y_{t}=b(1-\lambda L) x_{t}=\frac{b(1-\lambda L)}{1-\rho L} \varepsilon_{t}
$$

The last equation shows an autoregressive-moving average structure. However it does not always lead to a stationary solution y. 


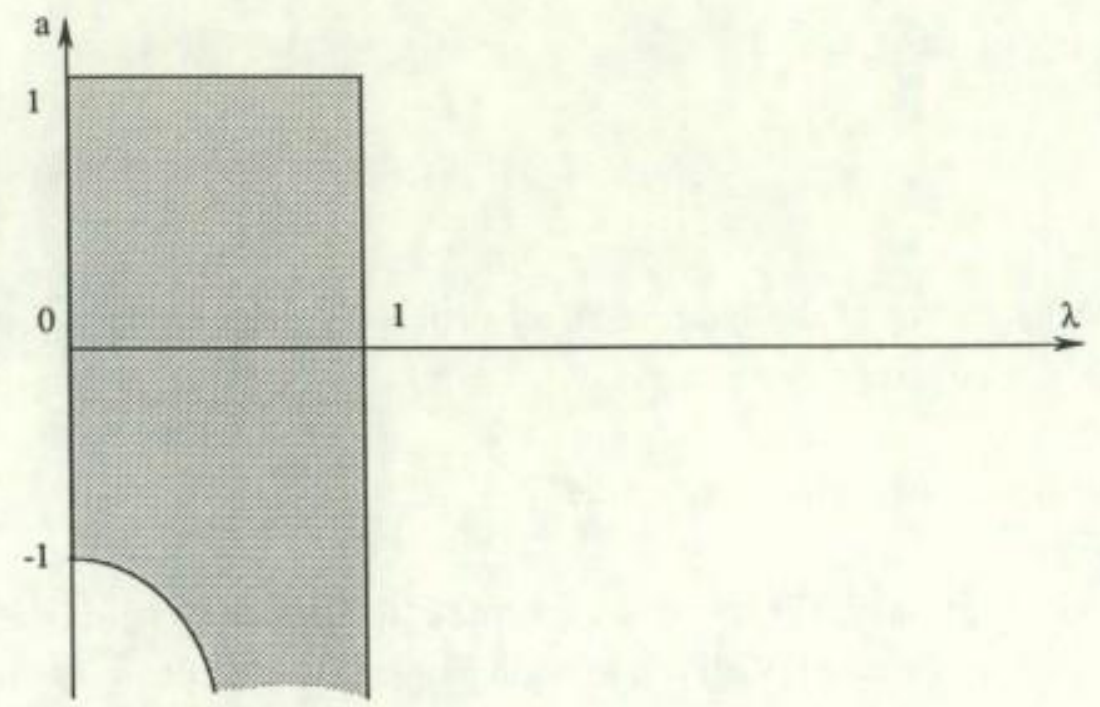

Figure 6

The condition for stationarity requires the value of the parameter $\lambda+\mathrm{a}(1-\lambda)$ to be strictly included in the real interval $(-1,1)$. Equivalently, parameter a has to be such that $1-\frac{2}{1-\lambda}<\mathrm{a}<1$. Figure 6 represents the admissible zone for stationarity. Larger values of the smoothing constant $(1-\lambda)$ lead to larger intervals of admissible values for a.

When the stationarity condition is meet, the effect of a sustained shock on the exogenous process is given by :

$$
\begin{aligned}
& \frac{\Delta y}{\Delta x}=\frac{b(1-\lambda)}{1-(\lambda+a(1-\lambda))}=\frac{b}{1-a}, \\
& \frac{\Delta y}{\Delta x}=\frac{a b}{1-a}+b . \\
& \begin{array}{c}
\text { indirect direct } \\
\text { effect } \quad \text { effect }
\end{array}
\end{aligned}
$$

Here again appears a distinction between the direct effect of $\mathrm{x}$ and the indirect effect passing through the expectation. However, since the adaptive expectation has been chosen independently from the exogenous process, the indirect effect does not depend on $\rho$. Neither does it depend on the smoothing constant $\lambda$. 


\section{The limit case where both schemes are alike}

The adaptive scheme makes use of the information available at time t-1. Indeed the expectation may be rewritten as :

$$
t-1 \tilde{y}_{t}=\sum_{i=0}^{\infty}(1-\lambda) \lambda^{i} y_{t-i-1} \text {. }
$$

It depends on all lagged endogenous variables. However it is generally not optimal. Optimality would be attained if the following relations occured simultaneously :

$$
\left\{\begin{array}{l}
\mathrm{t}_{\mathrm{t}-1} \tilde{y}_{\mathrm{t}}=(1-\lambda) \lambda^{\mathrm{i}} \mathrm{y}_{\mathrm{t}-1}+\lambda_{\mathrm{t}-2} \tilde{y}_{\mathrm{t}-1} \\
\mathrm{t}-1 \tilde{y}_{t}=E\left[\mathrm{y}_{\mathrm{t}} \mid \mathrm{I}_{\mathrm{t}-1}\right]
\end{array}\right.
$$

or equivalently if :

$$
E\left[y_{t} \mid I_{t-1}\right]=(1-\lambda) y_{t-1}+\lambda E\left[y_{t-1} \mid I_{t-2}\right]
$$

In the present context, the prediction error on $y_{t}$ is proportional to $\varepsilon_{\mathrm{l}}$ :

$$
y_{t}-E\left[y_{t} \mid I_{t-1}\right]=C \varepsilon_{t}
$$

Thus the condition for optimality of the adaptive expectation may be reformulated, after replacing the conditional expectation, as :

$$
y_{t}-C \varepsilon_{t}=(1-\lambda) y_{t-1}+\lambda\left(y_{t-1}-\varepsilon_{t-1}\right)
$$

or

$$
y_{t}-y_{t-1}=C \varepsilon_{t}-\lambda C \varepsilon_{t-1} \text {. }
$$

In words, the endogenous process should be such that the differenciated series is a stationary moving-average process of order 1 .

Compare now the latter condition to the expression (equation (2.19)) of the rational expectation solution. It appears that the equivalence of adaptive and rational schemes is only possible in the limit case $\rho=1$, i.e. when the exogenous process is a random walk. Moreover, it is necessary that the smoothing constant satisfies : 


$$
\lambda=\frac{a b \rho}{1-a}
$$

This result was established by Muth (1960). It emphasizes the fundamental difference between the rational and adaptive frameworks. In the adaptive case, the coefficient $\lambda$ is generally chosen without referring to the dynamics of the exogenous process, while in the rational case - even when it has an adaptive interpretation - the expectation formation has to be linked to the structural parameters of the model ( $a, b$ and $\rho$ in the present model). An important consequence of this distinction concerns economic policy. Suppose that the economic authority uses the process $\mathrm{x}$ as an instrument for influencing $\mathrm{y}$. In our context, its choice will involve the fixation of a value for the correlation parameter $\rho$. Under rational expectations, variations in $\rho$ affect the way agents predict future values of $y$ [see Lucas (1976)]. Their expectation scheme is thus sensitive to changes in the exogenous dynamics. In turn, under adaptive expectations, whatever the value of $\rho$, expectations of future y's remain the same. The adaptive scheme does not capture changes in economic policy.

\section{Learning processes}

It is commonly postulated that the decisions of economic agents are based to a large degree on their views about future events. However, controversies arise as soon as the choice of an expectations model is considered. The rationale of the prediction mechanism of 'real' agents is not yet fully elucidated (will it ever be ?).

A comparison of diverse expectation schemes (rational, adaptive, perfect, etc.) may be carried out at a theoretical level and then confronted with empirical data. Unfortunately all test procedures generally treat jointly the structural relations, linking actual variables and expectations, and the expectation scheme. Another way to investigate the plausibility of a given expectation scheme will be outlined in this section. The basic idea is to examine whether there exists a theoretical explanation of the choice of the given scheme. More precisely, the rational expectation hypothesis implicitly includes the idea that agents know the transition probabilities from the past to the present. It thus naturally raises the problem of how agents can aquire such knowledge. Learning processes provide a possible answer to this problem.

The conditions for existence of a learning process are the following. Firstly the relations among variables must hold with some degree of dynamic stability (especially if 
the variables are assumed stationary). Secondly the agents must have enough time (theoretically an infinite period) to complete the learning process.

All learning models given in the literature (see e.g. Bray (1982), Bray and Savin (1986), Fourgeaud, Gouriéroux and Pradel (1986)) are based on the same principle. At time $t$, the agent makes use of a generally suboptimal expectation mechanism. This leads to a certain prediction that influences the realization of the endogenous variable. At time $t+1$, the agent observes an additional endogenous variable that may be compared to the earlier prediction. On the basis of this comparison, the agent measures his/her expectation error and uses this information in order to modify the way he/she forms expectations.

In what follows, we describe a learning model along these lines. Furthermore, the deviation from one expectation modification to another is assumed very large (actually infinite) compared to the duration between the observations.

Let us return to the model presented in subsection $2 \mathrm{c}$, i.e. :

$$
\left\{\begin{array}{l}
y_{t}=a_{t-1} \tilde{y}_{t}+x_{t} b \\
x_{t}=\rho x_{t-1}+\varepsilon_{t},
\end{array}\right.
$$

and assume that the agent forms his/her expectation using the following formula :

$$
t-1 \tilde{y}_{t}(1)=C_{1} x_{t-1} \text {, }
$$

where $C_{1}$ is a given real number. The realization of $y_{t}$ is then such that :

$$
\mathrm{y}_{\mathrm{t}}=\mathrm{a} \mathrm{C}_{1} \mathrm{x}_{\mathrm{t}-1}+\mathrm{x}_{\mathrm{t}} \mathrm{b}
$$

By observing during a sufficently long period the relations occuring among $\mathrm{y}_{t}$, $x_{t-1}$ and $x_{t}$, the agent should perceive that the prediction of $y_{t}$ is not $C_{1} x_{t-1}$ but :

$$
E\left[y_{t} \mid I_{t-1}\right]=a C_{1} x_{t-1}+x_{t-1} \rho b \text {. }
$$

The agent is thus spontaneously induced to modify his/her way of forming expectations. The earlier scheme will be replaced by :

$$
t-1 \tilde{y}_{t}(2)=C_{2} x_{t-1}
$$


where $C_{2}=a C_{1}+\rho$ b. Again this new rule will be revealed erroneous and will be modified, and so on.

Let ${ }_{t-1} \tilde{y}_{t}(k)=C_{k} x_{t-1}$, denote the successive expectation formulations used by the learning agent. Iteration of the preceding argument yields :

$$
C_{k}=a C_{k-1}+\rho b, \forall k
$$

The sequence of coefficients satisfies a recursive linear equation of order 1 . A particular solution to this equation is given by $\bar{C}=\frac{b \rho}{1-a}$. This is exactly equal to the coefficient associated with the rational expectation. The evolution of the sequence $\left(\mathrm{C}_{\mathrm{k}}\right)$ is described by :

(2.22) $\mathrm{C}_{\mathrm{k}}=\frac{\mathrm{b} \rho}{1-\mathrm{a}}+\mu \mathrm{a}^{\mathrm{k}}, \quad \mu \in \mathrm{R}$.

Two cases can be distinguished :

a) if $|\mathrm{a}|<1$, the sequence $\left(\mathrm{C}_{\mathrm{k}}\right)$ converges to $\overline{\mathrm{C}}=\frac{\mathrm{b} \rho}{1-\mathrm{a}}$.

Following the learning process, the agent is asymptotically rational;

b) if $\mid$ a $\mid \geq 1$, the learning process does not converge and may not be used as a justification for the rational expectations hypothesis.

The learning process that has been described here is of course highly simplified. It could be made more sophisticated by introducing, for instance, continuous updatings, i.e. by allowing changes in the coefficients $\mathrm{C}_{\mathrm{k}}$ at any point in time. Technically this leads to convergence conditions that are much harder to derive but which remain fundamentally of the same form. One might also think of introducing costs involved in information acquisition. Intuitively these costs would prevent convergence to rationality. Therefore learning could lead to rational expectations only in the limit case of zero costs. 


\section{References}

ARROW, K.J. (1959) : 'Towards a theory of price adjustment', in The Allocation of Economic Resources, M. Abramowitz et al. (Eds), Stanford University Press, 49-51.

BRAY, M. (1982) : 'Learning, estimation and the stability of rational expectations', Journal of Economic Theory, 26, 318-340.

BRAY, M. AND N. SAVIN (1986) : 'Rational expectations equilibria, learning and model specification', Econometrica, 54, 1129-1160.

FISHER, I. (1930): The Theory of Interest as Determined by Impatience to Spend Income and the Opportunity to Invest it, MacMillan, New-York.

FOURGEAUD, C., C. GOURIÉROUX and J. PRADEL (1986) : 'Learning procedures and convergence to rationality', Econometrica, 54, 845-868.

GOURIÉROUX, C. AND A. MONFORT (1988) : 'A general theory for asymptotic tests', to appear in Econometrica.

GouriÉROUX, C., A. MONFORT and E. RENAULT (1988) : 'Tests d'hypothèses bilinéaires', to appear in Book in Honour of E. Malinvaud.

GROSSMAN, S. (1981) : 'An introduction to the theory of rational expectations under asymmetric information', Review of Economic Studies, 4, 103-124.

LUCAS, R.E. (1976) : ‘Econometric policy evaluation : a critique', in The Phillips Curve and Labor Markets, Karl Brunner (ed.), supplement to the Journal of Monetary Economics, 1, 19-46.

MUTH, J.R. (1960) : 'Optimal properties of exponentially weighted forecasts', Journal of the American Statistical Association, 55, 229-305.

MUTH, J.R. (1961) : 'Rational expectations and the theory of price movements', Econometrica, 24, 315-335.

NeRLOVE, M. (1958) : 'Adaptive expectations and Cobweb phenomena', Quarterly Journal of Economics, 73, 227-240.

RADNER, R. (1983) : 'Comment on convergence to rational expectations equilibrium', in Individual Forecasting and aggregate outcomes : 'Rational Expectations' Examined, R. Frydman and E.S. Phelps (eds), Cambridge University Press, Cambridge.

SHEFFRIN, S. (1983) : Rational Expectations, Cambridge University Press, Cambridge.

SIMS, C.A. (1980) : ‘Macroeconomics and reality', Econometrica, 48, 1551-1567. 
SzROETER, J. (1983) : 'Generalized Wald methods for testing nonlinear implicit and overidentifying restrictions', Econometrica, 51, 335-353.

WALLIS, K. (1980) : 'Econometric implications of the rational expectations hypothesis', Econometrica, 48, 49-73. 


\section{Chapter 3}

\section{A MODEL WITH FUTURE EXPECTATIONS}

\section{Examples}

The Muth model is a rational expectation model involving a current endogenous expected variable. More precisely, the structural form of the model consists of an equation explaining the endogenous variable $\mathrm{y}_{\mathrm{t}}$ in terms of the expectation $\mathrm{E}\left[\mathrm{y}_{\mathrm{t}} \mid \mathrm{I}_{\mathrm{t}-1}\right]$ and various exogenous variables among which some are observable and some are not. As shown in chapter 2 , this equation has a unique solution. This uniqueness property greatly simplifies the analysis. It is also useful for practical purposes.

In this chapter we consider a modified version of the model. Formally, the change introduced in the original model might seem a priori rather small since it consists in replacing the current expectation $\mathrm{E}\left[\mathrm{y}_{\mathrm{t}} \mid \mathrm{I}_{\mathrm{t}-1}\right]$ by the future expectation $\mathrm{E}\left[\mathrm{y}_{\mathrm{t}+1} \mid \mathrm{I}_{\mathrm{t}}\right]$. However, as will be shown, this modification has a fundamental impact on the resolution of the model. Indeed a rational expectation model including future expectations admits multiple solutions. A detailed analysis of the whole set of solutions is thus required for this type of model.

\section{1.a. Hyperinflation models}

Models involving future rational expectations have been proposed in the literature to describe hyperinflation, i.e. large and rapid increases in the price level. These movements are normally accompained by other economic phenomena, either linked to them or occurring simultaneously, such as a large supply of money.

The extreme situation of Hungary during the period August 1945 - July 1946, described by Shiller (1978), illustrates this point. The nominal money supply was then multiplied by a factor of $10^{25}$ while the price level increased by a factor of $4 \times 10^{27}$. In this particular case, the inflation rate was larger than the rate of growth of the money supply. A possible explanation of this fact lies in the reduced liquidity preference of agents who wished to cover the expected loss of their purchasing power due to inflation.

To describe such complex phenomena, simultaneous equations models are needed. They must provide explanations of the main linkages existing between the 
relevant economic variables such as prices, the money supply and quantities produced, as well as the equilibrium formation on the different markets. The expectations generally concern the prices.

A first step in solving the model consists in specifying a partially reduced form equation which expresses the current price in terms of expected prices and exogenous factors. The solution to this equation provides the price path. It then becomes possible to determine the evolution of all the other variables, with reference to the price path obtained.

Hyperinflation models are generally constructed on the same basis as the usual macromodels, therefore they present the same advantages and disadvantages as these macromodels. So, they are often highly aggregated and thus do not explicitly refer to the behavior of individual agents. Also, these models only take into account a small number of variables and conceal some indirect effects that could be of great importance. Moreover, linearity with respect to all variables is one of the most common features. It is justified by practical needs, especially those presented by estimation and multiplicators analysis. From this point of view, effectiveness often dominates realism. In particular, when expectations are incorporated as explanatory variables, they are usually included in a linear way.

In a linear rational expectations model, the agents' views on future events are thus only captured by the first-order conditional moments. Consequently, such models reflect neither the influences of the variability that could arise among individual views, nor the potential effects of the expected variability. Indeed the inclusion of effects such as these would require the taking into account of second-order conditional moments.

The previous remarks are related to hyperinflation models as originally formulated by Cagan (1956) and developed under the rational expectations hypothesis by a large number of authors [e.g. Blanchard (1979), Sargent and Wallace (1973, 1975), Shiller (1978)]. However, they are not specific to this type of model, since they apply to any macromodel including expectations. In order to provide various illustrations of rational expectations models including future expectations, we will now give a formal presentation of Taylor's model and discuss its underlying assumptions in details. We will end the section with the presentation of an asset pricing model.

\section{1.b. The Taylor model}

We take here a slightly simplified version of the Taylor (1977) model. It is a stochastic macromodel describing the simultaneous equilibria in the aggregated goods 
(output) market and the money market. Price expectations are introduced by means of the demand function for goods. The two markets are linked through a real balance effect. The model has the following form :

$$
\left\{\begin{array}{l}
\mathrm{y}_{\mathrm{t}}=-\mathrm{a}_{1}\left[\mathrm{r}_{\mathrm{t}}-\left(\mathrm{t}_{\mathrm{p}} \tilde{\mathrm{p}}_{\mathrm{t}+1}-\mathrm{p}_{\mathrm{t}}\right)\right]+\mathrm{a}_{2}\left(\mathrm{~m}_{\mathrm{t}}-\mathrm{p}_{\mathrm{t}}\right)+\mathrm{u}_{1 \mathrm{t}} \\
\mathrm{y}_{\mathrm{t}}=\mathrm{b}_{0}+\mathrm{b}_{1}\left(\mathrm{~m}_{\mathrm{t}}-\mathrm{p}_{\mathrm{t}}\right)+\mathrm{u}_{2 \mathrm{t}}, \\
\mathrm{m}_{\mathrm{t}}=\mathrm{y}_{\mathrm{t}}+\mathrm{p}_{\mathrm{t}}-\mathrm{c}_{1} \mathrm{r}_{\mathrm{t}}+\mathrm{c}_{2}\left(\mathrm{~m}_{\mathrm{t}}-\mathrm{p}_{\mathrm{t}}\right)+\mathrm{u}_{3 \mathrm{t}} \\
\mathrm{m}_{\mathrm{t}}=\mathrm{u}_{4} \mathrm{t}
\end{array}\right.
$$

where $\mathrm{y}_{\mathrm{t}}, \mathrm{m}_{\mathrm{t}}, \mathrm{p}_{\mathrm{t}}$ and $\mathrm{r}_{\mathrm{t}}$ denote respectively the log of the output, the $\log$ of the nominal money stock, the log of the price of goods and the nominal interest rate. $\tilde{\mathrm{p}}_{\mathrm{t}+1}$ is the expectation of the log of the future price, formed in the current period. The deviation $\tilde{\mathrm{p}}_{\mathrm{t}+1}-\mathrm{p}_{\mathrm{t}}$ appears as the expectation of $\log \mathrm{P}_{\mathrm{t}+1}-\log \mathrm{P}_{\mathrm{t}}$, where $\mathrm{P}$ represents the price of the goods. Furthermore, we have :

$$
\begin{aligned}
\log \mathrm{P}_{\mathrm{t}+1}-\log \mathrm{P}_{\mathrm{t}} & =\log \frac{\mathrm{P}_{\mathrm{t}+1}}{\mathrm{P}_{\mathrm{t}}} \\
& =\log \left(1+\frac{\mathrm{P}_{\mathrm{t}+1}-\mathrm{P}_{\mathrm{t}}}{\mathrm{P}_{\mathrm{t}}}\right) .
\end{aligned}
$$

When $\frac{\mathrm{P}_{\mathrm{t}+1}-\mathrm{P}_{\mathrm{t}}}{\mathrm{P}_{\mathrm{t}}}$ is small, the previous expression may be approximated by $\frac{\mathrm{P}_{\mathrm{t}+1}-\mathrm{P}_{\mathrm{t}}}{\mathrm{P}_{\mathrm{t}}}$. This argument justifies the use of $\tilde{\mathrm{p}}_{\mathrm{t}+1}-\mathrm{p}_{\mathrm{t}}$ as a proxy for the expected inflation rate (between $\mathrm{t}$ and $\mathrm{t}+1$ ).

The model includes four endogenous variables $\mathrm{y}_{\mathrm{t}}, \mathrm{m}_{\mathrm{t}}, \mathrm{p}_{\mathrm{t}}$ and $\mathrm{r}_{\mathrm{t}}$. The exogenous variables influencing the demand and the supply are summarized by the residual terms $\mathrm{u}_{1 \mathrm{t}}, \mathrm{u}_{2 \mathrm{t}}, \mathrm{u}_{3 \mathrm{t}}, \mathrm{u}_{4 \mathrm{t}}$.

The first equation represents the aggregate demand function. It depends negatively $\left(a_{1}>0\right)$ on the expected real interest rate, i.e. the difference between the nominal interest rate and expected inflation, and positively on the real balances $\left(a_{2}>0\right)$. This may be interpreted as a preference for holding goods when the real money balances are considered to be excessive. The second equation describes the supply of goods, which, in addition to the exogenous effects represented by $\mathrm{u}_{2 \mathrm{t}}$, depends positively on real balances $\left(b_{1}>0\right)$. The demand for money in (3.1) has been formulated following a 'Cambridgetype equation' : $\mathrm{M}_{\mathrm{t}}=\mathrm{k} \mathrm{P}_{\mathrm{t}} \mathrm{Y}_{\mathrm{t}}$ (where capitals denote the variables themselves, not their logs). The proportionality coefficient $k$, linking the demand for money to output, depends 
both on the interest rate and real balances. The money supply is assumed to be exogenous.

The structural form (3.1) may be easily transformed into a partially reduced form, such that each endogenous variable is expressed in terms of the expected future price and exogenous variables. One obtains a four-equation model giving respectively $\mathrm{y}_{\mathrm{t}}, \mathrm{m}_{\mathrm{t}}, \mathrm{p}_{\mathrm{t}}$ and $\mathrm{r}_{\mathrm{t}}$ in terms of ${ }_{\mathrm{t}} \tilde{\mathrm{p}}_{\mathrm{t}+1}, \mathrm{u}_{1 \mathrm{t}}, \mathrm{u}_{2 \mathrm{t}}, \mathrm{u}_{3 \mathrm{t}}$ and $\mathrm{u}_{4 \mathrm{t}}$. The resolution may be performed recursively by analysing first the price evolution equation and secondly the consequences of the price evolution on the three other endogenous variables. In the model examined here, the price equation only involves the expected price and exogenous terms and may be solved without considering explicit forms of the other endogenous variables. On the other hand $\mathrm{y}_{\mathrm{t}}, \mathrm{m}_{\mathrm{t}}$ and $\mathrm{r}_{\mathrm{t}}$ can be determined only after having found the expression for the expected price.

From the structural form, we deduce the price evolution equation :

$$
\mathrm{p}_{\mathrm{t}}=\mathrm{a}_{\mathrm{t}} \tilde{\mathrm{p}}_{\mathrm{t}+1}+\mathrm{u}_{\mathrm{t}}
$$

where $\mathrm{a}$ is a reduced form parameter obtained from the structural parameters by the relation :

$$
a=\frac{-a_{1} c_{1}}{c_{1} b_{1}+a_{1} c_{2}-a_{1}+a_{1} b_{1}-a_{2} c_{1}}
$$

and $\mathrm{u}_{\mathrm{t}}$ is a linear combination of $\mathrm{u}_{1 \mathrm{t}}, \mathrm{u}_{2 \mathrm{t}}, \mathrm{u}_{3 \mathrm{t}}$ and $\mathrm{u}_{4 \mathrm{t}}$ with coefficients depending on the values taken by the structural parameters.

At this stage, the derivations have been made independently of any assumption about the expectation scheme. Let us now incorporate into the model the rational expectations hypothesis. Equation (3.2) becomes :

$$
p_{t}=a E\left[p_{t+1} \mid I_{t}\right]+u_{t}
$$

where $\mathrm{I}_{\mathrm{t}}$ denotes the available information set at time $\mathrm{t}$.

\section{1.c. Some remarks on the price equation}

Before going further and solving equation (3.3), we will examine more closely the initial structural form of our model. In fact, the following remarks are not specific to the 
Taylor model. They apply to a large class of models suggested in the literature which lead to a price evolution equation having a formal expression similar to (3.2) [see e.g. Cagan (1956), Lucas (1973), Sargent and Wallace (1973a, 1973b, 1975), Shiller (1978)...]. Furthermore, these remarks mainly concern the underlying structural form called the ad hoc model by Sargent and Wallace (1975), here (3.1), and not the expectation scheme (whether rational or not) chosen by the model builder.

a) Consider a hyperinflation model. It seems reasonable to postulate, at least as a first approximation, exponential evolutions for the price level and money supply :

$$
\mathrm{P}_{\mathrm{t}}=\mathrm{P}_{0} \mathrm{~g}_{0}^{\mathrm{t}} \quad, \quad \mathrm{M}_{\mathrm{t}}=\mathrm{M}_{0} \mathrm{~g}_{1}^{\mathrm{t}} \text {. }
$$

By taking logs, we obtain :

$$
\left\{\begin{array}{l}
\mathrm{p}_{\mathrm{t}}=\log \mathrm{P}_{0}+\mathrm{t} \log \mathrm{g}_{0} \\
\mathrm{~m}_{\mathrm{t}}=\log \mathrm{M}_{0}+\mathrm{t} \log \mathrm{g}_{1} .
\end{array}\right.
$$

Thus, as far as a hyperinflation model is concerned, solutions to the price (in log) equation should be sought among explosive (non-stationary) paths.

b) On the other hand, certain variables should not present an explosive behavior. For instance, consider the real interest rate $\mathrm{r}_{\mathrm{t}}-\left(\mathrm{t}_{\mathrm{p}} \tilde{\mathrm{p}}_{\mathrm{t}+1}-\mathrm{p}_{\mathrm{t}}\right)$. This variable has a more appealing interpretation as an adjustment factor.

Now assume non-explosive exogenous variables and consider, for instance, the demand for goods. This demand includes 'stationary' as well as 'non stationary' terms. Such a formulation is feasible only if the explosive series, here $\mathrm{m}_{\mathrm{t}}$ and $\mathrm{p}_{\mathrm{t}}$, are cointegrated [Engle and Granger (1987)]. This condition is obviously very strong and should be investigated empirically before concluding the formulation of any hyperinflation model .

c) Let us pursue the analysis further and consider the money supply equation. It seems realistic to impose the restriction that $\mathrm{y}_{\mathrm{t}}$ and $\mathrm{r}_{\mathrm{t}}$ are either stationary variables or explosive variables but with velocities smaller than the velocities of prices and money. In terms of the model, this implies that the growth rates of the price and of the money supply $\mathrm{g}_{0}$ and $\mathrm{g}_{1}$, have to be equal. However, as noted at the beginning of this chapter, this does not reflect one of the characteristics of hyperinflation, namely a rate of inflation which is higher than the rate of increase in the money supply. 
The previous remarks are basically formulated as econometric comments. They may however be put in a different way. As suggested by Malinvaud (1982, Chapter 8), we will now refer to the underlying economic theory. Consider for instance the Cambridge equation. It is essentially derived from a growth theory, i.e, a long-term theory. Consequently, the relations between the growth rates $g_{0}$ and $g_{1}$ must be seen as relations between long-term rates. On the other hand, hyperinflation is essentially a short-term phenomenon. It follows that the structural models describing this phenomenon should be based on adjustment models and not on long-term models. This confusion between short- and long-term models is the most important source of the unsatisfactory properties emphasized in the previous discussion. To overcome this problem, Malinvaud (1982) has suggested the inclusion of a reduced form price evolution equation in the original specification of the model. In order to have stationary movements, it is preferable to use the inflation rate instead of the log of the price. The resulting equation is :

$$
\Delta \mathrm{p}_{\mathrm{t}}=\mathrm{a} E\left[\Delta \mathrm{p}_{\mathrm{t}+1} \mid \mathrm{I}_{\mathrm{t}}\right]+\mathrm{u}_{\mathrm{t}}
$$

with $\Delta \mathrm{p}_{\mathrm{t}}=\mathrm{p}_{\mathrm{t}}-\mathrm{p}_{\mathrm{t}-1}$ and $\mathrm{u}_{\mathrm{t}}$ being a variable summarizing the short-term factors. In terms of resolution, equation (3.4) is analogous to (3.3), however there are important differences in interpretation. Developing the first-order differences in (3.4) yields :

$$
p_{t}=\frac{a}{1+a} E\left[p_{t+1} \mid I_{t}\right]+\frac{1}{1+a} p_{t-1}+\frac{u_{t}}{1+a}
$$

It follows that the equation includes not only a future expectation but also a lagged endogenous term. Note however that the effects of these two variables are linked because of the constraint on the structural parameters : the sum of the corresponding coefficients is equal to 1 .

It is also important to note that the meaning of $\mathrm{u}_{\mathrm{t}}$ in (3.4) is quite different from the meaning of this term in (3.1). Here the residual term depends on factors explaining the short-term movements of prices. Usually these factors are separated into two classes : factors in the first class correspond to cost modifications (cost inflation), while factors in the second class describe disequilibria between supply and demand (demand inflation). In model ( 3.1$)$, the factors summarized by the residual variables $u_{1 t}, u_{2 t}, u_{3 t}, u_{4 t}$ are implicitly associated with behavioral changes. They do not include, for instance, variables representing disequilibria (such as demand inflation). Intuitively, this would be incompatible with assumptions concerning equilibrium made in specifying model (3.1). In order words, the difficulty comes from the fact that the model does not take into 
account the possibility of the existence of a long-term equilibrium together with short-term disequilibria.

\section{1.d. The evolution of an asset price}

Another classical example of a rational expectations model concerns dynamic asset pricing. Let us at first consider a deterministic framework and denote $\mathrm{p}_{\mathrm{t}}$ the unit asset price at time $t, d_{t}$ the unit dividend for period $[t, t+1]$, and $r$ the discount rate. The dynamic equilibrium condition is :

$$
\mathrm{p}_{\mathrm{t}}=\frac{1}{1+\eta} \mathrm{p}_{\mathrm{t}+1}+\mathrm{d}_{\mathrm{t}}
$$

It states that the dividend exactly compensates the actualized price difference from one period to the next.

In an uncertain environment, one often specifies, by analogy, a relation of the same type with the future price replaced by its expectation :

(3.6) $\mathrm{p}_{\mathrm{t}}=\frac{1}{1+\eta} \mathrm{E}\left[\mathrm{p}_{\mathrm{t}+1} \mid \mathrm{I}_{\mathrm{t}}\right]+\mathrm{d}_{\mathrm{t}}$.

It is thus implicitly assumed that the dividend $\mathrm{d}_{\mathrm{t}}$ and the discount rate $\eta$ are known at time $t$. It is also implicitly supposed that the equilibrium condition in ancertain environment is directly derived from the equilibrium condition given in the deterministic case by replacing the unknown variables - here $\mathrm{p}_{t+1}$ - by their (conditional) expectations. This use of the certainty-equivalent principle requires some restrictive conditions on the underlying structural model. We will not make this point explicit here. It will be further detailed in Chapter 6.

\section{A description of the solution methods}

We start here with a reduced equation which is analogous to the price equations (3.3) and (3.4). However we adopt the following general notations :

$\mathrm{y}_{\mathrm{t}}$ is the endogenous variable at time $\mathrm{t}$;

$\mathrm{u}_{\mathrm{t}}$ is the summary of all the exogenous factors at time $\mathrm{t}$;

$\mathrm{I}_{\mathrm{t}}$ is the information set available at time $\mathrm{t}$. 
The basic equation is :

(3.7) $y_{t}=a E\left[y_{t+1} \mid I_{t}\right]+u_{t}$.

The evolution of the residual term $\left(\mathrm{u}_{\mathrm{t}}\right)$ is assumed to be given. A solution of equation (3.7) is a stochastic process $\left(y_{t}\right)$ compatible with this equation. In order to ensure that the expectation plays a real role in the model, we restrict the reduced parameter a to be different from zero.

As will be shown, equation (3.7) admits an infinite number of solutions. Among the solution methods proposed in the literature, we will first present those that lead to the determination of particular solutions, and then describe those that give the general solution.

\section{2.a. The 'forward' - 'backward' approach}

The solution method suggested by Blanchard (1979) is based on very intuitive reasoning. It consists of a recursive solution technique. Depending on whether the recursive substitutions are made in a forward or backward - looking approach, the resulting solution is called the forward or backward solution.

\section{a) The forward approach}

Applying forward recursive substitutions to equation (3.7) yields :

$$
\begin{aligned}
y_{t} & =a E\left[y_{t+1} \mid I_{t}\right]+u_{t} \\
& =a^{2} E\left[y_{t+2} \mid I_{t}\right]+u_{t}+a E\left[u_{t+1} \mid I_{t}\right] \\
& \vdots \\
& : \\
& =a^{i} E\left[y_{t+i} \mid I_{t}\right]+u_{t}+a E\left[u_{t+1} \mid I_{t}\right]+\ldots+a^{i-1} E\left[u_{t+i-1} \mid I_{t}\right] .
\end{aligned}
$$

If the series of the variables $a^{i} \mathrm{E}\left[\mathrm{u}_{\mathrm{t}+\mathrm{i}} \mid \mathrm{I}_{\mathrm{t}}\right]$ converges, then equation (3.7) admits the particular solution given by :

$$
y_{t}^{F}=\sum_{i=0}^{\infty} a^{i} E\left[u_{t+i} \mid I_{t}\right] .
$$

For this solution, the current endogenous variable depends on the expectations, formed at time $t$, of all the future exogenous variables. 
The series defining the forward-solution does not always exist. To develop this point, let us consider a residual term $\left(u_{t}\right)$ corresponding to a stationary process. The importance of the general term of the series may be measured by :

$$
\begin{aligned}
& E\left[a^{i} E\left[u_{t+1} \mid I_{t}\right]\right]^{2}=a^{2 i} E\left(E\left[u_{t+i} \mid I_{t}\right]\right)^{2} \\
& \quad=a^{2 i}\left\{V\left(E\left[u_{t+i} \mid I_{t}\right]\right)+\left(E E\left[u_{t+i} \mid I_{t}\right]\right)^{2}\right\} \\
& \leq a^{2 i}\left\{V u_{t+i}+\left(E u_{t+i}\right)^{2}\right\},
\end{aligned}
$$

by using the variance analysis equation (see chapter 1 ). Since $\left(\mathrm{u}_{t}\right)$ is a stationary process, the quantity $\mathrm{Vu}_{\mathrm{t}+\mathrm{i}}+\left(\mathrm{E} \mathrm{u}_{\mathrm{t}+\mathrm{i}}\right)^{2}$ is a constant. It follows that, as soon as the coefficient a has a modulus smaller than 1 , the series defining the forward solution converges in quadratic mean.

Property (3.9) : A sufficient condition for existence of the forward solution is the stationarity of the exogenous process $\left(u_{t}\right)$ with the constraint lal $<1$.

For instance, assume that the exogenous process can be represented by an autoregressive model of order 1 :

$$
u_{t}=\rho u_{t-1}+\varepsilon_{t} \quad,|\rho|<1,
$$

where $\left(\varepsilon_{t}\right)$ is an independent white noise, i.e. a sequence of independent variables having the zero mean and same variance. It follows that $u_{t+1}=\rho u_{t}+\varepsilon_{t+1}$. Now suppose that the available information $I_{t}$ is only composed of the current and past values of $u$. Then $u_{t}$ belongs to this information set while $\varepsilon_{t+1}$ is orthogonal to it. Consequently the optimal forecast of $\mathrm{u}_{\mathrm{t}+1}$ made with the information set $\mathrm{I}_{\mathrm{t}}$ is proportional to $\mathrm{u}_{\mathrm{t}}$ :

$$
E\left[u_{t+1} \mid I_{t}\right]=\rho u_{t} \text {. }
$$

The same argument may be used for higher order horizons. Recursive substitutions yield :

$$
u_{t+i}=\rho^{i} u_{t}+\rho^{i-1} \varepsilon_{t+1}+\rho^{i-2} \varepsilon_{t+2}+\ldots+\varepsilon_{t+i},
$$

and thus :

$$
E\left[u_{t+i} \mid I_{t}\right]=\rho^{i} u_{t} .
$$


The forward solution has the following form :

$$
y_{t}^{F}=\sum_{i=0}^{\infty} a^{i} \rho^{i} u_{t},
$$

or equivalently

$$
y_{t}^{F}=\frac{1}{1-a \rho} u_{t} .
$$

For this solution, the expectation of the future endogenous variable is :

$$
E\left[y_{t+1}^{F} \mid I_{t}\right]=\frac{1}{1-a \rho} E\left[u_{t+1} \mid I_{t}\right]=\frac{\rho u_{t}}{1-a \rho} \text {. }
$$

The forward solution has, in some applications, an interesting economic interpretation. Consider for instance equation (3.6) describing the evolution of an asset price. The forward solution leads to the following price sequence :

$$
\text { (3.10) } \mathrm{p}_{\mathrm{t}}^{\mathrm{F}}=\sum_{\mathrm{i}=0}^{\infty} \frac{1}{(1+\eta)^{\mathrm{i}}} \mathrm{E}\left[\mathrm{d}_{\mathrm{t}+\mathrm{i}} \mid \mathrm{I}_{\mathrm{t}}\right]=\mathrm{E}\left[\mathrm{V}_{\mathrm{t}} \mid \mathrm{I}_{\mathrm{t}}\right]
$$

where $V_{t}=\sum_{i=0}^{\infty} \frac{1}{(1+\eta)^{i}} d_{t+i} \cdot V_{t}$ is the discounted sum of all dividends payed between $t$ and $\infty ; \mathrm{p}_{\mathrm{t}}^{\mathrm{F}}$ is thus the expectation of this discounted sum, i.e. the present value of the firm.

In the previous example it is interesting to interpret the asymptotic behaviour of $\frac{1}{(1+\eta)^{\mathrm{i}}} \mathrm{E}\left[\mathrm{p}_{\mathrm{t}+\mathrm{i}} \mid \mathrm{I}_{\mathrm{t}}\right]$. If this quantity converges (for $\left.\mathrm{i} \rightarrow \infty\right)$ toward a strictly positive value, the agents would expect an asymptotic selling price that always remains advantageous. Hence they would be inclined to keep their assets. This would lead to the paradoxal situation in which equilibrium at finite times would become impossible because of the lack of asset suppliers. In such a case of a generation that lives indefinitely, it is then logical to impose the following condition :

$$
\lim _{i \rightarrow \infty} \frac{1}{(1+\eta)^{i}} E\left[p_{t+i} \mid I_{t}\right]=0 .
$$


This condition is often described as the transversality condition associated with an underlying intertemporal optimization problem. When this condition is imposed, the forward solution becomes the unique admissible solution.

\section{b) The backward approach}

To solve equation (3.7) in a backward manner requires an expression of the future variable $y_{t+1}$ in terms of current variables. One thus has to 'extract' the realization $y_{t+1}$ out of the expectation $\mathrm{E}\left[\mathrm{y}_{\mathrm{t}+1} \mid \mathrm{I}_{\mathrm{t}}\right]$. In practice this is done by examining whether there exists a perfect foresight solution, i.e. a solution such that $\mathrm{y}_{\mathrm{t}+1}=\mathrm{E}\left[\mathrm{y}_{\mathrm{t}+1} \mid \mathrm{I}_{\mathrm{t}}\right]$. When it does exist, equation (3.7) yields :

$$
\begin{aligned}
& y_{t}=a y_{t+1}+u_{t} \\
& \Leftrightarrow y_{t+1}=\frac{1}{a} y_{t}-\frac{1}{a} u_{t} \\
& \Leftrightarrow y_{t}=\frac{1}{a} y_{t-1}-\frac{1}{a} u_{t-1}
\end{aligned}
$$

This is an equation without expectations. It may be analysed directly. Carrying out successive substitutions results in the following series :

$$
\text { (3.11) } \mathrm{y}_{\mathrm{t}}^{\mathrm{B}}=-\sum_{\mathrm{i}=1}^{\infty} \frac{1}{\mathrm{a}^{\mathrm{i}}} \mathrm{u}_{\mathrm{t}-\mathrm{i}} \text {. }
$$

If equation (3.11) describes a convergent series, it is a solution to the perfect foresight model associated with equation (3.7). Moreover, it is a solution to equation (3.7) itself when $y_{t+1}^{B}$ is perfectly predictible. This condition is met when the available information $I_{t}$ includes the current and past values of the exogenous variables that affect the residual term u.

Property (3.12) : If the series, having a general term $\frac{1}{\mathrm{a}^{\mathrm{i}}} \mathrm{u}_{\mathrm{t}-\mathrm{i}}$ converges (in square mean) and the information set $\mathrm{I}_{\mathrm{t}}$ includes $\mathrm{u}_{\mathrm{t}}, \mathrm{u}_{\mathrm{t}-1}, \ldots$ then $\mathrm{y}_{\mathrm{t}}^{\mathrm{B}}=-\sum_{\mathrm{i}=1}^{\infty} \frac{1}{\mathrm{a}^{\mathrm{i}}} \mathrm{u}_{\mathrm{t}-\mathrm{i}}$ is a solution - called the backward solution - to the rational expectations model (3.7). 
The backward solution may be written in a condensed way by using the lag operator L :

$$
y_{t}^{B}=-\sum_{i=1}^{\infty} \frac{1}{a^{i}} L^{i} u_{t}=-\frac{L}{a-L} u_{t} .
$$

Suppose now that the exogenous process $\left(u_{t}\right)$ is stationary. It follows that the backward solution exists if and only if the root of the autoregressive part (a-L) has a modulus larger than 1, i.e. if and only if $|a|>1$. At first sight, the existence domains of the forward and backward solutions seem complementary. However, as will be shown in the next section, the forward solution has a wider domain (remember that property (3.9) only gives a sufficient condition for existence).

Finally, note that the backward solution is a very special one (when it does exist) because it is built on the perfect foresight assumption, thus it does not allow for forecast errors. In a stochastic model, this is a very strong restriction on the agents' behavior. To some extent, this solution may be seen as the deterministic limit case of the rational expectations model.

\section{2.b. Linear solutions}

\section{a) The evolution of the exogenous process}

In dynamic models, it is often useful to complete the basic formulation concerning the evolution of the endogenous process by a relation describing the evolution of the exogenous variables. Indeed the initial equation gives the current endogenous variable in terms of lagged endogenous terms and some exogenous variables, but it does not assume anything about neither the dynamics of the exogenous process itself, nor the specification of the information sets.

Let us focus on the evolution of the exogenous process. When no particular formulation is implied by the economic theory embodied in the model, one frequently retains a descriptive model based on a stationary time-series having an ARMA (autoregressive - moving average) form or on non-stationary time-series having an ARIMA form (i.e. with roots of the autoregressive part equal to 1). These formulations allow for a large range of possible behaviors. In all the cases, the process denoted u may be written as a weighted average of the current and lagged innovations of its components. More precisely, we have : 
(3.13) $u_{t}=\sum_{j=0}^{\infty} h_{j} \varepsilon_{t-j}$,

where $\left(\varepsilon_{t}\right)$ is an independent white noise vector having a size equal to the number (denoted $\mathrm{p}$ ) of exogenous variables that are taken into account in the underlying structural model. The coefficients $h_{j}, j=0 \ldots \infty$, are row - vectors of size $1 \times p$.

Formulation (3.13) makes sense if the coefficients $h_{j}$ are such that : $\sum_{j=0}^{\infty} h_{j} h_{j}{ }^{\prime}<\infty$, where the symbol ' means transposition. With this condition satisfied, the process $u$ defined by (3.13) is stationary. To extend the presentation to non-stationary processes, i.e. to cases where $\sum_{j=0}^{\infty} h_{j} h_{j}{ }^{\prime}=\infty$, it is sufficient to make a choice of initial values. For instance, one can take zero values for the noise before an initial date $\mathrm{t}=0$ and then obtain :

(3.14) $u_{t}=\sum_{j=0}^{t} h_{j} \varepsilon_{t-j}=\sum_{j=0}^{\infty} h_{j} \tilde{\varepsilon}_{t-j}$,

with $\tilde{\varepsilon}_{\mathrm{t}}= \begin{cases}\varepsilon_{\mathrm{t}}, & \text { for } \mathrm{t} \geq 0, \\ 0, & \text { for } \mathrm{t}<0 .\end{cases}$

With these restrictions, one gets a non-stationary process. In particular, formula (3.14) incorporates the case of ARIMA processes with initial conditions set at zero.

The previous moving-average formulations may also be summarized with the use of the lag-operator L. Equation (3.14) becomes :

(3.15) $\mathrm{u}_{\mathrm{t}}=\mathrm{h}(\mathrm{L}) \tilde{\varepsilon}_{\mathrm{t}}$, where $\mathrm{h}(\mathrm{L})=\sum_{\mathrm{j}=0}^{\infty} \mathrm{h}_{\mathrm{j}} \mathrm{Lj}$.

\section{b) Determination of the linear solutions}

In addition to the ARMA or ARIMA representation of the exogenous process, we assume here that the information set available at time $t$ is composed of the past and current exogenous variables. Equivalently, it can be taken as being composed of the past and current innovations. 
Since the information set is now precisely specified, it is possible to make explicit the derivation of the expectations. For instance, in the case of a non-stationary process with zero values before the initial date, the expected innovations are given by :

$$
E\left[\tilde{\varepsilon}_{t+j} \mid I_{t}\right]= \begin{cases}0, & \text { for } j>0 \\ \tilde{\varepsilon}_{t+j}, & \text { for } j \leq 0 .\end{cases}
$$

We can now go back to model (3.7) and examine whether it has solutions with a structure analogous to that chosen for the residual term u. In other words, we look for solutions of equation (3.7) that can be written as :

$$
y_{t}=C(L) \tilde{\varepsilon}_{t},
$$

where $C(L)=\sum_{j=0}^{\infty} c_{j} L$ is an operator that has to be determined. The coefficients denoted $c_{j}$ measure the effects on $y_{t+j}$ of shocks affecting the current exogenous variables. These shocks are transmitted through the innovations [see Sims (1980)].

Let us now compute the expectations of the desired linear solutions. First, observe that the future endogenous variable may be written as :

$$
y_{t+1}=C(L) \tilde{\varepsilon}_{t+1}=c_{0} \tilde{\varepsilon}_{t+1}+\frac{C(L)-c_{0}}{L} \tilde{\varepsilon}_{t} .
$$

Then, using the formula giving the expected innovations, one obtains :

$$
E\left[y_{t+1} \mid I_{t}\right]=c_{0} E\left[\tilde{\varepsilon}_{t+1} \mid I_{t}\right]+E\left[\frac{C(L)-c_{0}}{L} \tilde{\varepsilon}_{t} \mid I_{t}\right]=\frac{C(L)-c_{0}}{L} \tilde{\varepsilon}_{t} .
$$

Replacing the expectation in equation (3.7) by this expression yields :

$$
\begin{aligned}
& y_{t}=a E\left[y_{t+1} \mid I_{t}\right]+u_{t} \\
& \Leftrightarrow C(L) \tilde{\varepsilon}_{t}=a \frac{C(L)-c_{0}}{L} \tilde{\varepsilon}_{t}+h(L) \tilde{\varepsilon}_{t} .
\end{aligned}
$$

If strict multicollinearity does not exist among the exogenous variables of the model, then the components of the noise are not linearly linked and a term-by-term identification may be performed to give : 


$$
\begin{aligned}
& C(L)=a \frac{C(L)-c_{0}}{L}+h(L), \\
& \Leftrightarrow C(L)(L-a)=-a c_{0}+L h(L) \\
& \Leftrightarrow C(L)=-\frac{a c_{0}}{L-a}+L \frac{h(L)}{L-a} .
\end{aligned}
$$

The solution method that has been followed is actually the undetermined coefficients procedure suggested for instance by Muth (1961) and Mac Callum (1976). Note that the use of lag operator polynomials greatly simplifies the technical derivations.

The linear solutions are characterized by the moving-average operator $\mathrm{C}(\mathrm{L})$. They depend not only on the evolution of the exogenous process $[\mathrm{h}(\mathrm{L})]$, on the structural parameter of the conditional model [a], but also on p auxiliary parameters, components of the row-vector $c_{0}$. Consequently there exists an infinite number of such solutions.

Property (3.16) : Consider the following rational expectations model :

$\mathrm{y}_{\mathrm{t}}=\mathrm{a} \mathrm{E}\left[\mathrm{y}_{\mathrm{t}+1} \mid \mathrm{I}_{\mathrm{t}}\right]+\mathrm{u}_{\mathrm{t}}$.

If the exogenous process verifies:

$\mathrm{u}_{\mathrm{t}}=\mathrm{h}(\mathrm{L}) \tilde{\varepsilon}_{\mathrm{t}}$,

and the information set available at time $t$ is given by :

$\mathrm{I}_{\mathrm{t}}=\left\{\tilde{\varepsilon}_{\mathrm{t}}, \widetilde{\varepsilon}_{\mathrm{t}-1}, \widetilde{\varepsilon}_{\mathrm{t}-2}, \ldots\right\}$,

then the model has an infinity of linear solution written as :

$y_{t}=\left[-\frac{a c_{0}}{L-a}+\frac{L h(L)}{L-a}\right] \tilde{\varepsilon}_{t}, c_{0} \in R^{P}$.

\section{c) The role of the backward solution}

The linear solutions have been obtained under the condition that the innovations are equal to zero before the initial date $t=0$. In this framework, the backward solution always exists. It is given by :

$$
y_{t}^{B}=\frac{-L}{a-L} u_{t}=\frac{L h(L)}{L-a} \widetilde{\varepsilon}_{t},
$$

This expression clearly shows that the linear solutions described by Property (3.16) may be rewritten as : 


$$
y_{t}=-\frac{a c_{0}}{L-a} \tilde{\varepsilon}_{t}+y_{t}^{B}
$$

The first term includes the current exogenous innovation, while the backward solution only includes past values of $\tilde{\varepsilon}$.

The linear solutions constitute an affine space containing the backward solution. The dimension of this space is equal to $\mathrm{p}$, which denotes the number of exogenous variables of the underlying structural model.

\section{d) Linear stationary solutions}

Stationarity will be introduced as a limit case of the previous approach. We will first assume that the exogenous process is stationary and then search for the linear stationary solutions. As will be shown, further restrictions need to be imposed to the solutions obtained above.

Consider an exogenous process admitting the following representation :

$$
\mathrm{u}_{\mathrm{t}}=\sum_{\mathrm{j}=0}^{\infty} \mathrm{h}_{\mathrm{j}} \varepsilon_{\mathrm{t}-\mathrm{j}}
$$

with $\sum_{j=0}^{\infty} h_{j} h_{j}^{\prime}<\infty$.

We now investigate whether any of the previously obtained linear solutions exhibit asymptotic stationary behavior. For this purpose, we must discuss the convergence of the series $\sum_{j=0}^{\infty} c_{j} c_{j}$. Since the $c_{j}$ 's are the coefficients of the development of the following operator :

$$
C(L)=\frac{1}{a-L}\left[-a c_{0}+L h(L)\right] \text {, }
$$

it appears that two cases must be distinguished. 
First case : $|\mathbf{a}|>1$

The moving-average development of $\frac{1}{\mathrm{a}-\mathrm{L}}$ always leads to a convergent series. Therefore whatever the value of $c_{0}$, the linear solutions are asymptotically stationary.

\section{Second case : $|a|>1$}

The development of $\frac{1}{\mathrm{a}-\mathrm{L}}$ always corresponds to a divergent series. The condition $\sum_{j=0}^{\infty} c_{j} c_{j}<\infty$ will only be satisfied when the coefficient a is also a root of the numerator $-\mathrm{ac}_{0}+\mathrm{L} \mathrm{h}(\mathrm{L})$. Otherwise the explosive denominator may not be neutralized and stationarity is impossible. Consequently, the only admissible choice for the auxiliary parameter is :

$$
\mathrm{c}_{0}=\mathrm{h}(\mathrm{a}) \text {. }
$$

Among all linear solutions, one is stationary and corresponds to :

$$
C(L)=\frac{1}{a-L}(-a h(a)+L h(L))
$$

The following property summarizes the preceding analysis.

Property (3.17) : $\quad$ Consider the following rational expectations model :

$\mathrm{y}_{\mathrm{t}}=\mathrm{a} \mathrm{E}\left[\mathrm{y}_{\mathrm{t}+1} \mid \mathrm{I}_{\mathrm{t}}\right]+\mathrm{u}_{\mathrm{t}}$.

If the stationary exogenous process is defined by :

$\mathrm{u}_{\mathrm{t}}=\mathrm{h}(\mathrm{L}) \varepsilon_{\mathrm{t}}$,

and the information set at time $t$ is given by :

$\mathrm{I}_{\mathrm{t}}=\left\{\varepsilon_{\mathrm{t}}, \varepsilon_{\mathrm{t}-1}, \varepsilon_{\mathrm{t}-2}, \ldots\right\}$,

then :

a) If $\mid \mathrm{al}>1$, the model has an infinity of linear stationary solutions written as :

$$
y_{t}=\left(-\frac{a c_{0}}{a-L}+\frac{L h(L)}{a-L}\right) \varepsilon_{t}, c_{0} \in R^{P}
$$


b) If lal $\leq 1$, the model has a unique linear stationary solution written as :

$$
y_{t}=\left(\frac{L h(L)-a h(a)}{a-L}\right) \varepsilon_{t} \text {. }
$$

\section{e) A robust solution}

When lal $<1$, the sufficient condition given by property (3.9) is fulfilled. Consequently, in this case the existence of the forward solution is ensured. Furthermore it is the unique linear stationary solution ${ }^{1}$ :

$$
y_{t}^{F}=\frac{L h(L)-a h(a)}{a-L} \varepsilon_{t} .
$$

On the other hand, when lal $>1$, this solution also exists because it corresponds to a precise choice of $c_{0}$, namely $c_{0}=h(a)$, which is obviously admissible. However, the forward-looking representation of this solution fails since the series no longer exists.

Thus this solution plays a very special role : it is the only linear stationary solution that exists for all values of the structural parameter a. This robustness property has sometimes been overstated by taking this solution as equivalent to the model itself. Such an assertion is generally invalid. Strong restrictions on the model would be needed to preclude all the other solutions. It remains evident that the 'forward' solution has a privileged status, especially when $|\mathrm{a}|<1$.

\section{2.c. The general solution}

\section{a) The homogeneous equation approach}

Except for the expectation term, the model described in this chapter looks like a linear difference equation. The method introduced by Gouriéroux, Laffont and Monfort (1982) starts from this observation. It applies to the rational expectations model a solution technique analogous to the technique that is traditionally used for difference equations. More precisely, the general solution is obtained by a two-step procedure. The first step involves the determination of a particular solution. The second step corresponds to the resolution of the associated homogeneous equation.

\footnotetext{
${ }^{1}$ For a formal proof of this assertion see for instance Gouriéroux, Laffont and Monfort (1982).
} 
Let $\left(y_{t}^{0}\right)$ be a particular solution to equation (3.7) and take another solution $\left(y_{t}\right)$ to the same equation. The two following relations then hold simultaneously :

$$
\left\{\begin{array}{l}
y_{t}=a E\left[y_{t+1} \mid I_{t}\right]+u_{t}, \\
y_{t}^{o}=a E\left[y_{t+1}^{o} \mid I_{t}\right]+u_{t} .
\end{array}\right.
$$

We substract the second relation from the first and use the linearity property of the conditional expectation operator to get :

$$
z_{t}=a E\left[z_{t+1} \mid I_{t}\right] \text {, }
$$

where $z_{t}=y_{t}-y_{t}^{0}$ denotes the difference between the two solutions. The stochastic process $\left(z_{t}\right)$ thus also satisfies a rational expectation equation. However, this equation appears to be homogeneous, i.e. it corresponds to a zero residual term.

The homogeneous equation is equivalent to :

$$
a^{t} z_{t}=E\left[a^{t+1} z_{t+1} \mid I_{t}\right]
$$

Consequently the process $\left(\mathrm{M}_{\mathrm{t}}=\mathrm{a}^{\mathrm{t}} \mathrm{z}_{\mathrm{t}}\right)$ is such that the rational expectation $\mathrm{E}\left[\mathrm{M}_{\mathrm{t}+1} \mid \mathrm{I}_{\mathrm{t}}\right]$ coincides with the naive one $\mathrm{M}_{\mathrm{l}}$. As defined in Chapter 1 , this property is characteristic of martingales. The described procedure leads to the following property.

Property (3.18) : $\quad$ If $\left(\mathrm{y}_{\mathrm{t}}^{\mathrm{o}}\right)$ is a particular solution to model (3.7), then all the other solutions are given by :

$$
\mathrm{y}_{\mathrm{t}}=\mathrm{y}_{\mathrm{t}}^{\mathrm{o}}+\frac{1}{\mathrm{a}^{\mathrm{t}}} \mathrm{M}_{\mathrm{t}} \text {, }
$$

where $\left(\mathrm{M}_{\mathrm{t}}\right)$ is any martingale.

\section{b) The approach based on prediction errors}

Another way to obtain the general solution has been proposed by Broze, Gouriéroux and Szafarz (1985). This method implicitly appeared in some earlier works (Pesaran (1981), Gouriéroux, Laffont and Monfort (1982)). It has the advantage of being easily generalizable to models having a more general structure than equation (3.7) (see Chapter 4). 
The basic idea is inspired by the backward solution approach. The latter only leads to a particular solution because of the perfect foresight assumption that has been introduced. Here, this restriction is avoided and the prediction error made explicit. More precisely, for any process $\left(y_{t}\right)$, the realization at time $t+1$ can be expressed by means of the expectation made at time $t$ and the corresponding prediction error denoted $\varepsilon_{t+1}^{0}$ :

$$
y_{t+1}=E\left[\begin{array}{lll}
y_{t+1} & \mid I_{t}
\end{array}\right]+\varepsilon_{t+1}^{o}
$$

Since expectations are rationally formed, the process $\left(\varepsilon_{t}^{o}\right)$ has to fulfill the characteristic property of a rational prediction error. In other words, $\varepsilon_{t}^{o}$ has to be orthogonal to the past :

$$
\mathrm{E}\left[\varepsilon_{\mathrm{t}}^{0} \mid \mathrm{I}_{\mathrm{t}-1}\right]=0, \forall \mathrm{t} \text {. }
$$

On the other hand, $\varepsilon_{t}^{0}$ is obviously included in $I_{t}$. It follows that the process $\left(\varepsilon_{t}^{0}\right)$ is a martingale difference.

Let now consider the model :

$$
y_{t}=a E\left[\begin{array}{llll}
y_{t+1} & \mid & I_{t}
\end{array}\right]+u_{t} .
$$

The expectation may be replaced by using the prediction error :

$$
y_{t}=a\left(y_{t+1}-\varepsilon_{t+1}^{o}\right)+u_{t} .
$$

An equivalent form is given by :

$$
\mathrm{y}_{\mathrm{t}}=\frac{1}{\mathrm{a}} \mathrm{y}_{\mathrm{t}-1}-\frac{1}{\mathrm{a}} \mathrm{u}_{\mathrm{t}-1}+\varepsilon_{\mathrm{t}}^{\mathrm{o}} \text {. }
$$

This equation describes the solution of equation (3.7). The only remaining problem concerns the possible choices of the prediction error. The following property gives an answer to this problem. 
Property (3.19) : a) Any solution y to equation (3.7) satisfies the following difference equation :

$$
\mathrm{y}_{\mathrm{t}}=\frac{1}{\mathrm{a}} \mathrm{y}_{\mathrm{t}-1}-\frac{1}{\mathrm{a}} \mathrm{u}_{\mathrm{t}-1}+\varepsilon_{\mathrm{t}}^{0},
$$

where $\varepsilon_{\mathrm{t}}^{o}$ denotes the prediction error.

b) Conversely, if $\varepsilon_{t}^{0}$ is an arbitrary martingale difference and y is a solution to the previous difference equation, then $\mathrm{y}$ is a solution to equation (3.7).

Proof

The first part has been proved in the text. In order to establish the second part, we take the conditional expectation of both sides of the difference equation with respect to the information set $\mathrm{I}_{\mathrm{t}-1}$ :

$$
\begin{aligned}
E\left[y_{t} \mid I_{t-1}\right] & =\frac{1}{a} y_{t-1}-\frac{1}{a} u_{t-1}+E\left[\varepsilon_{t}^{0} \mid I_{t-1}\right] \\
& =\frac{1}{a} y_{t-1}-\frac{1}{a} u_{t-1} .
\end{aligned}
$$

The transition from the first line to the second is a consequence of the assumption that $\varepsilon_{\mathrm{t}}{ }^{\mathrm{O}}$, as a martingale difference, is orthogonal to the past information.

We now substract side by side the previous expression from the difference equation and obtain :

$$
\varepsilon_{t}^{o}=y_{t}-E\left[y_{t} \mid I_{t-1}\right]
$$

This shows that the arbitrarily chosen martingale difference is necessarily equal to the error made in predicting the endogenous process $\mathrm{y}$.

Replacing $\varepsilon_{\mathrm{t}}^{\mathrm{o}}$ by its expression in the difference equation yields : 


$$
\mathrm{y}_{\mathrm{t}}=\frac{1}{\mathrm{a}} \mathrm{y}_{\mathrm{t}-1}-\frac{1}{\mathrm{a}} \mathrm{u}_{\mathrm{t}-1}+\mathrm{y}_{\mathrm{t}}-\mathrm{E}\left[\mathrm{y}_{\mathrm{t}} \mid \mathrm{I}_{\mathrm{t}-1}\right]
$$

or equivalently :

$$
y_{t-1}=a E\left[y_{t} \mid I_{t-1}\right]+u_{t-1} \text {. }
$$

The latter exactly corresponds to equation (3.7) written for the lagged endogenous variable.

In conclusion, the approach based on prediction errors provides a direct method for eliminating the expectation term in the original model.

\section{Properties of the solution set}

\section{3.a. Impact of a terminal condition}

Suppose that the value taken by the solution is known at a given date $t_{0}$. It follows from eq. (3.7) that :

$$
y_{t_{0}-1}=a E\left[y_{t_{0}} \mid I_{t_{0}-1}\right]+u_{t_{0}-1} \text {. }
$$

The value of the endogenous variable at time $t_{0}-1$ is unambiguously determined since the exogenous variable and the value of $\mathrm{y}_{\mathrm{t}_{0}}$ are known. Step by step, the same argument applies to every date before $t_{0}$. The knowledge of $y_{t_{0}}$ thus fixes all past values of the endogenous process : $\mathrm{y}_{\mathrm{t}_{0}-1}, \mathrm{y}_{\mathrm{t}_{0}-2}, \ldots . \mathrm{A}$ terminal condition leads to the determination of a unique solution (since $t_{0}$ is viewed as a terminal date, we only pay attention to the dates that precede $t_{0}$ ).

\section{3.b. Impact of an initial condition}

Again assume a known value for $\mathrm{y}_{\mathrm{t}_{0}}$. We now examine the behavior of the endogenous process after $t_{0}$. With the use of the prediction error approach, we have :

$$
\mathrm{y}_{\mathrm{t}_{0}+1}=\frac{1}{\mathrm{a}} \mathrm{y}_{\mathrm{t}_{0}}-\frac{1}{\mathrm{a}} \mathrm{u}_{\mathrm{t}_{0}}+\varepsilon_{\mathrm{t}_{0}+1}^{\mathrm{o}} \text {, }
$$


where $\varepsilon_{t_{0+1}}^{o}$ is an arbitrary variable orthogonal to the information set $I_{t_{0}}$. To any admissible $\varepsilon_{t_{0+1}}^{o}$ corresponds a possible value $\mathrm{y}_{\mathrm{t}_{0}+1}$. In consequence, there exists an infinite number of future values $y_{t_{0}+1}$ compatible with the value given for time $t_{0}$.

Consider the next value $y_{t_{0}+2}$. Following the same method we obtain :

$$
\begin{aligned}
\mathrm{y}_{\mathrm{t}_{0}+2} & =\frac{1}{\mathrm{a}} \mathrm{y}_{\mathrm{t}_{0}+1}-\frac{1}{\mathrm{a}} \mathrm{u}_{\mathrm{t}_{0}+1}+\varepsilon_{\mathrm{t}_{0}+2}^{\mathrm{o}} \\
= & \frac{1}{\mathrm{a}^{2}} \mathrm{y}_{\mathrm{t}_{0}}-\frac{1}{\mathrm{a}} \mathrm{u}_{\mathrm{t}_{0}+1}-\frac{1}{\mathrm{a}^{2}} \mathrm{u}_{\mathrm{t}_{0}}+\varepsilon_{\mathrm{t}_{0}+2}^{\mathrm{o}}+\frac{1}{\mathrm{a}} \varepsilon_{\mathrm{t}_{0}+1}^{\mathrm{o}} .
\end{aligned}
$$

The non-uniqueness property is now reflected by two arbitrary variables, $\varepsilon_{t_{0+1}}^{o}$ and $\varepsilon_{t_{0}+2}^{0}$, that are orthogonal to $\mathrm{I}_{\mathrm{t}_{0}}$ and $\mathrm{I}_{\mathrm{t}_{0}+1}$ respectively .

The multiplicity of solutions grows with time (after $t_{0}$ ). For a given $y_{t_{0}}$, the evolution of the multiplicity may be intuitively represented as shown on figure 7 .

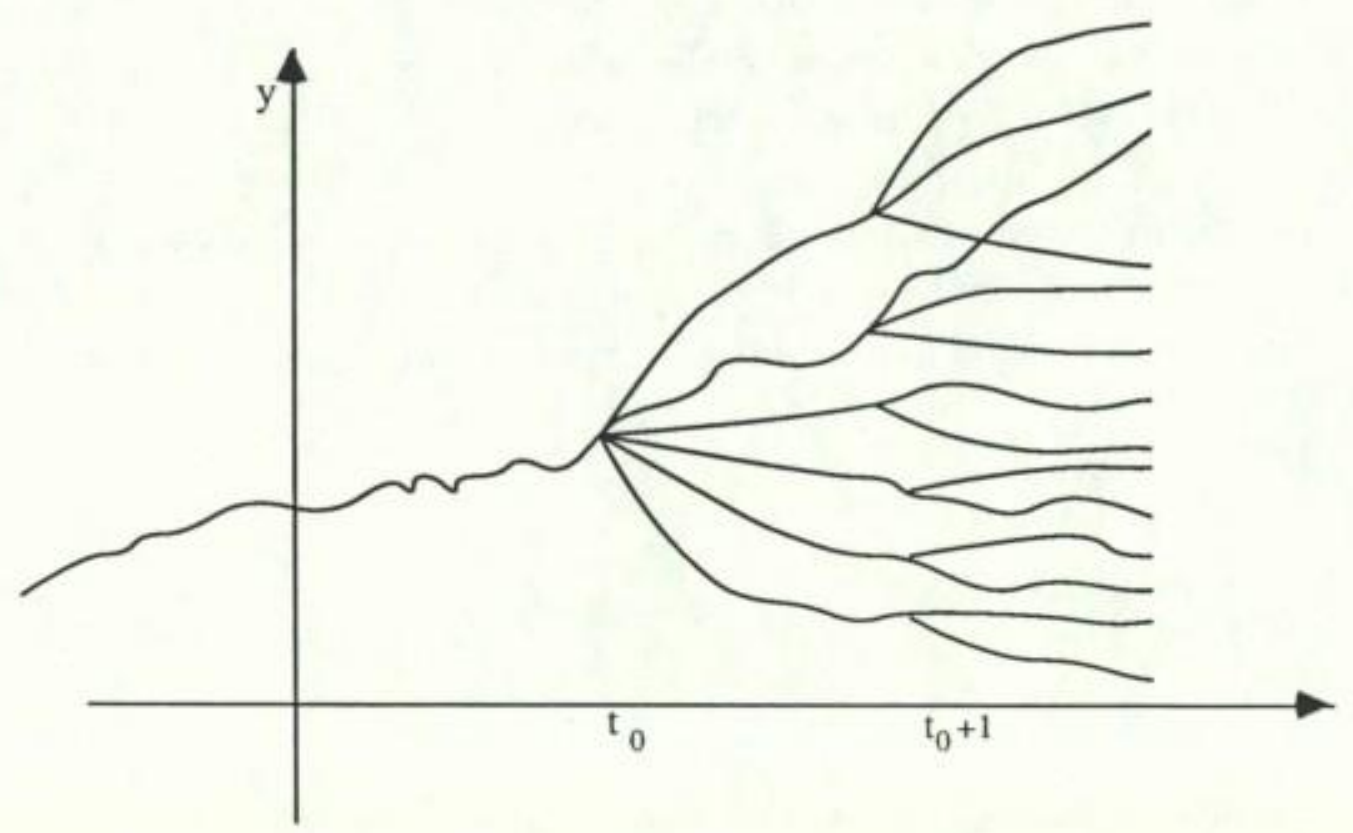

Figure 7 
Note that this phenomenon is specific to rational expecations models. It does not occur in deterministic models or even in the perfect foresight version of our model. The latter is given by :

$$
y_{t}=a y_{t+1}+u_{t} \text {. }
$$

In such a case, it is well-known that knowledge of $\mathrm{y}_{\mathrm{t}_{0}}$ is sufficient for determining all values of the endogenous process. Past and future values have, in this respect, exactly the same status. In other words, in a random environment, rationality introduces an asymmetry between the past and future : past values are known for sure while future values are only (optimally) predicted.

\section{3.c. Sunspots}

Till now, we have often chosen as the information set the set generated by the current and past values of the exogenous variables entering the underlying structural model. It is also possible to enlarge the information set and include, for instance, sunspots.

In our terminology, sunspots are variables independent from the exogenous variables that influence the demand and supply functions. They are extraneous to the original structural model. However, as will be shown, their presence in the information sets can affect the evolution of the endogenous process.

To simplify the presentation, we will restrict ourselves to the linear solutions of model (3.7). Sunspots may be introduced by means of a white noise process $\left(\tilde{\varepsilon}_{21}\right)$ distinct from the innovation $\left(\widetilde{\varepsilon}_{1}\right)$ of the exogenous process. We thus assume that :

$$
I_{t}=\left\{\tilde{\varepsilon}_{t}, \tilde{\varepsilon}_{t-1}, \ldots\right\}
$$

where $\tilde{\varepsilon}_{\mathrm{t}}=\left(\tilde{\varepsilon}_{1 \mathrm{t}}, \tilde{\varepsilon}_{2 \mathrm{t}}\right), \forall \mathrm{t}$,

and :

$$
\mathrm{u}_{\mathrm{t}}=\mathrm{h}(\mathrm{L}) \tilde{\varepsilon}_{\mathrm{t}}=\mathrm{h}_{1}(L) \tilde{\varepsilon}_{1 \mathrm{t}}+\mathrm{h}_{2}(\mathrm{~L}) \tilde{\varepsilon}_{2 \mathrm{t}}=\mathrm{h}_{1}(L) \tilde{\varepsilon}_{1 \mathrm{t}} .
$$


In other words, the condition $\mathrm{h}_{2}(\mathrm{~L})=0$ says that the residual variable $\mathrm{u}_{\mathrm{t}}$ only depends on the innovations $\tilde{\varepsilon}_{1}$. It is not influenced by the extraneous noise $\widetilde{\varepsilon}_{2}$. Furthermore, we impose that $\tilde{\varepsilon}_{2}$ is independent from $\tilde{\varepsilon}_{1}$.

The expression of the linear solution may be deduced from property (3.16) :

$$
\mathrm{y}_{\mathrm{t}}=\left[\frac{-\mathrm{a} \mathrm{c}_{0}^{1}}{\mathrm{~L}-\mathrm{a}} \tilde{\varepsilon}_{1 \mathrm{t}}+\frac{\mathrm{L} \mathrm{h}_{1}(\mathrm{~L})}{\mathrm{L}-\mathrm{a}} \tilde{\varepsilon}_{1 \mathrm{t}}\right]+\frac{-\mathrm{a} \mathrm{c}_{0}^{2}}{\mathrm{~L}-\mathrm{a}} \tilde{\varepsilon}_{2 \mathrm{t}} .
$$

The solution can thus effectively depend on the extraneous variables, although these have no real influence on the demand and supply functions. To some extent, this result may be interpreted in terms of 'self-fulfilling expectations' phenomena. The thought that some sunspots influence the price sequence will lead to the incorporation of these variables in the information sets. Then the expectations formed with the use of these sets will reflect the presence of the extraneous variables. Since expectations influence the price itself, the whole price path will be submitted to a real effect of the sunspots. This will reassure the agents in their belief that sunspots play a crucial role in price determination.

Moreover, the independence assumption leads to :

$$
\begin{aligned}
V y_{t} & =V\left[\frac{-a c_{0}^{1}}{L-a} \tilde{\varepsilon}_{1 t}+\frac{L h_{1}(L)}{L-a} \tilde{\varepsilon}_{1 t}\right]+V\left[\frac{a c_{0}^{2}}{L-a} \tilde{\varepsilon}_{2 t}\right] \\
& \geq V\left[\frac{-a c_{0}^{1}}{L-a} \tilde{\varepsilon}_{1 t}+\frac{L h_{1}(L)}{L-a} \tilde{\varepsilon}_{1 t}\right] .
\end{aligned}
$$

Taking into account extraneous variables gives a larger variability to the solution. This kind of inequality may be used to test for the presence of sunspots. It is especially interesting in financial theory where sunspots can be interpreted in terms of excess volatility [see Shiller $(1979,1981)$, Leroy and Porter (1981)]. Nevertheless, the role of sunspots and self-fulfilling expectations on the one hand, and speculative bubbles on the other hand, has not yet been fully elucidated [see Leroy (1984), Adam and Szafarz (1987)].

\section{3.d. Stationary solutions}

We have previously analyzed the set of the linear stationary solutions of equation (3.7). It has been pointed out that two cases are to be distinguished according to the value 
taken by the modulus of the structural parameter a. In this subsection we intend to stress the non-uniqueness problem that arises when lal $>1$.

To put the problem in a simple fashion, we here assume that $\mid \mathrm{al}>1$ and that $\mathrm{u}$ is an independent white noise (with identically distributed components). Let us consider a mapping $f$ such that $f\left(u_{t}\right)$ admits second order moments and define the process $\varepsilon^{0}$ as :

$$
\varepsilon_{t}^{o}=f\left(u_{t}\right)-E f\left(u_{t}\right)
$$

This process obviously has independent, identically distributed components. Furthermore it is a martingale difference. Then from property (3.19), the following relation provides solutions to equation (3.7) :

$$
\mathrm{y}_{\mathrm{t}}=\frac{1}{\mathrm{a}} \mathrm{y}_{\mathrm{t}-1}-\frac{1}{\mathrm{a}} \mathrm{u}_{\mathrm{t}-1}+\mathrm{f}\left(\mathrm{u}_{\mathrm{t}}\right)-\mathrm{E} \mathrm{f}\left(\mathrm{u}_{\mathrm{t}}\right)
$$

Recursive substitutions yield :

$$
y_{t}=\sum_{j=0}^{\infty} \frac{1}{a^{j}}\left[-\frac{u_{t-j-1}}{a}+f\left(u_{t-j}\right)-E f\left(u_{t-j}\right)\right] .
$$

This formula describes stationary solutions that are generally non-linear. Linear stationary solutions only occur for choices of a linear mapping $f$.

This remark shows how severe non-uniqueness may be. Whatever the value of a, the model has a non-parametrizable set of solutions. In the case lal $>1$, the model still has a non-parametrizable set of stationary solutions. However the additional assumption of linearity leads to a parametrizable set. This set appears much more tractable for further developments, whether empirical or analytical.

\section{3.e. Variability of the linear stationary solutions}

We consider the case lal $>1$ together with the minimal information sequence (i.e. no sunspots). There exists an infinity of linear stationary solutions given by :

$$
y_{t}=\left[-\frac{a c_{0}}{L-a}+\frac{L h(L)}{L-a}\right] \varepsilon_{t} \text {, with } c_{0} \in R^{P} \text {. }
$$


Let us now introduce the following processes:

$$
y_{t}^{o}=\frac{L h(L)}{L-a} \varepsilon_{t}
$$

and

$$
y_{t}^{j}=-\frac{a}{L-a} \varepsilon_{j t} \quad, j=1, \ldots p,
$$

where $\varepsilon_{\mathrm{jt}}$ denotes the $\mathrm{j}^{\text {th }}$ component of $\varepsilon_{\mathrm{t}}$. The linear stationary solutions may then be rewritten as :

$$
y_{t}=\sum_{j=1}^{p} c_{0 j} y_{t}^{j}+y_{t}^{o},
$$

where $c_{0 j}$ is the $\mathrm{j}^{\text {th }}$ component of the row-vector $c_{0}$. The coefficients $c_{0 j}$ may be arbitrarily chosen. We will henceforth examine whether there exist particular values of these coefficients that would lead to the minimal variability solution [see Taylor (1977)].

Since we have restricted the analysis to solutions that are combinations of current and past values of the noise $\varepsilon$, the sequences $y^{o}$ and $y j, j=1 \ldots p$, are centered and the minimization problem becomes :

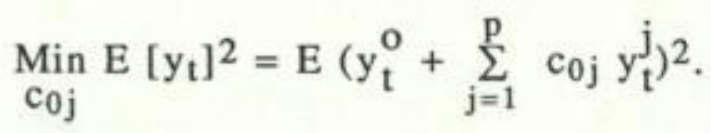

In this form, the problem appears as the classical (theoretical) least squares problem. Consequently, it has a unique solution. The optimal choice for the coefficients is provided by the values opposite to the regression coefficients of $y_{t}^{0}$ on $y_{t}^{j}, j=1 \ldots p$ : 


$$
\left(\begin{array}{c}
\hat{c}_{1} \\
\hat{c}_{2} \\
\vdots \\
\hat{c}_{p}
\end{array}\right)=-\left(\begin{array}{cccc}
v_{t_{t}}^{1} & \ldots & \ldots & \operatorname{Cov}\left(y_{t}^{1}, y_{t}^{p}\right) \\
\cdot & v_{t}^{2} & \ldots & . \\
\cdot & \cdots & \cdots & . \\
\operatorname{Cov}\left(y_{t}^{p}, y_{t}^{1}\right) & \ldots & \cdots & v y_{t}^{p}
\end{array}\right)^{-1}\left(\begin{array}{c}
\operatorname{Cov}\left(y_{t}^{0}, y_{t}^{1}\right) \\
\operatorname{Cov}\left(y_{t}^{0}, y_{t}^{2}\right) \\
\ldots \\
\operatorname{Cov}\left(y_{t}^{0}, y_{t}^{p}\right)
\end{array}\right)
$$

The minimum variance solution is given by :

$$
\hat{y}_{t}=y_{t}^{o}+\sum_{j=1}^{p} \hat{c}_{o j} y_{t}^{j}
$$

The value $\hat{y}_{t}$ is interpreted as the residual of the preceding regression. It is thus orthogonal to all the variables $\mathrm{y}_{\mathrm{t}}^{\mathrm{j}}, \mathrm{j}=1, \ldots \mathrm{p}$.

Any other linear stationary solution may of course be written as :

$$
y_{t}=\hat{y}_{t}+\sum_{j=1}^{p}\left(c_{0 j}-\hat{c}_{0 j}\right) y_{t}^{j}
$$

The variance of this is :

$$
V y_{t}=V \hat{y}_{t}+\left(c_{0}-\hat{c}_{0}\right)^{\prime} V y_{t}\left(c_{0}-\hat{c}_{0}\right)
$$

where $\mathrm{c}_{0}=\left(\mathrm{c}_{01}, \ldots, \mathrm{c}_{0 \mathrm{p}}\right)^{\prime}, \hat{\mathrm{c}}_{0}=\left(\hat{\mathrm{c}}_{01}, \ldots, \hat{\mathrm{c}}_{0 \mathrm{p}}\right)^{\prime}$ and

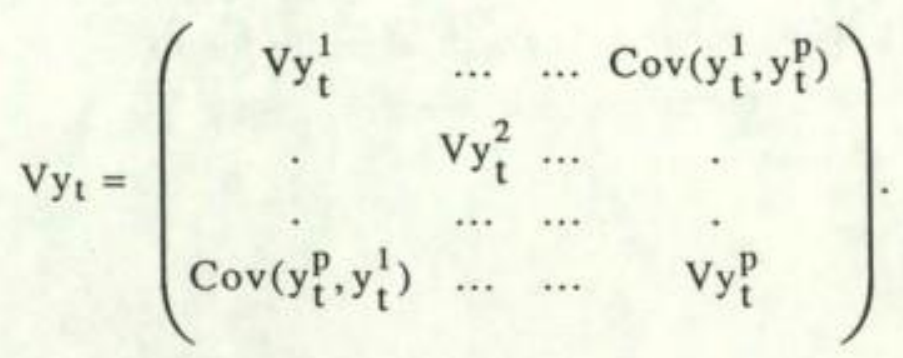

In particular, this result may be applied to the solution corresponding to $c_{0}=0$ (the backward solution) : 


$$
v y_{t}^{B}=v \hat{y}_{t}+\hat{c}_{0}^{\prime} v y_{t} \hat{c}_{0}
$$

Thus, with reference to the backward solution, the general formula for the variance of any linear stationary solution becomes :

$$
\text { (3.20) } \mathrm{Vy}_{\mathrm{t}}=\left(\mathrm{V}_{\mathrm{t}}^{\mathrm{B}}-\hat{\mathrm{c}}_{0}^{\prime} \mathrm{Vy_{ \textrm {t } }} \hat{\mathrm{c}}_{0}\right)+\left(\mathrm{c}_{0}-\hat{\mathrm{c}}_{0}\right)^{\prime} \mathrm{V} \mathrm{y}_{\mathrm{t}}\left(\mathrm{c}_{0}-\hat{\mathrm{c}}_{0}\right)
$$

Equation (3.20) provides a decomposition of the variability into two terms : the first term is the minimal variability and the second one is the deviation from this minimal variability.

A priori, it seems reasonable to accord a special status to the solution denoted $\hat{y}$. It corresponds to the intuition that agents predict future values in such a way that the corresponding solution is the less erratic one. The choice of this solution could be compatible with a 'no bubble' assumption (in the case $\mid \mathrm{al}>1$ ).

Indeed, all the other linear stationary solutions have a larger variability. Along these lines, the additional term $\left(\mathrm{c}_{0}-\hat{\mathrm{c}}_{0}\right)^{\prime} \mathrm{Vy}_{\mathrm{t}}\left(\mathrm{c}_{0}-\hat{\mathrm{c}}_{0}\right)$ could be viewed as a measure of the size of the corresponding bubble. Nevertheless this argument only makes sense when the structural parameter is such that $\mathrm{lal}>1$ and when no sunspots are introduced, which is not the usual situation in the 'bubble' literature. Therefore the minimum variability criterion has not yet found convincing applications.

\section{Learning processes}

In Chapter 2 (section3), we have described a very simple learning process that may be used to evaluate the relevance of the rational expectation hypothesis as a limiting case. In this framework, the agents are assumed to use a naïve revision scheme to update their expectations. Actually, this scheme is very crude. Also, it implicitely assumes that a very long time occurs between two successive updatings.

A more sophisticated approach (Bray and Savin (1986), Fourgeaud, Gouriéroux and Pradel (1986), Kiefer (1988a,b), Marcet and Sargent $(1986,1988)$ ) consists in assuming that the agents are 'learning' with the use of a regression model. When applied to the hyperinflation model given by equation (3.7), the procedure may be summarized as follows. 
- The 'true model', i.e. $y_{t}=a \tilde{y}_{t+1}+u_{t}$ (where $\tilde{y}_{t+1}$ denotes the expectation of $\left.y_{t+1}\right)$, is not known by the learning agents.

- The agents build their predictions on the basis of a regression model (called the 'misspecified auxiliary model') with an observable instrumental variable denoted $x$ (chosen one-dimensional for simplicity) : $y_{\tau}=\alpha x_{\tau-1}+\varepsilon_{\tau}$.

- At the beginning of period $t$, the observed variables are $\mathrm{y}_{1}, \ldots, \mathrm{y}_{\mathrm{t}-1}, \mathrm{x}_{0}, \mathrm{x}_{1}, \ldots$, $x_{t}$. The prediction of $y_{t+1}$ is then given by:

$$
\tilde{y}_{t+1}=\hat{\alpha}_{t} x_{t-1}
$$

where $\hat{\alpha}_{\mathrm{t}}=\frac{\sum_{\tau=1}^{t-1} y_{\tau} x_{\tau-1}}{\sum_{\tau=1}^{t-1} x_{\tau-1}^{2}}$.

- According to the 'true' model the current of value $y_{t}$ is then given by :

$$
y_{t}=a \hat{\alpha}_{t} x_{t-1}+u_{t}
$$

- At the beginning of period $t+1$, the agents rebuild their predictions by using the regression model :

$$
\tilde{y}_{t+2}=\hat{\alpha}_{t+1} x_{t} \text {. }
$$

Thanks to (3.22), $\hat{\alpha}_{t+1}$ may be expressed as a revised estimate of $\hat{\alpha}_{t}$ by the following formula :

$$
\hat{\alpha}_{t+1}=\frac{\sum_{\tau=1}^{t-2} x_{\tau}^{2}+a x_{t} x_{t-1}}{\sum_{\tau=1}^{t-1} x_{\tau}^{2}} \hat{\alpha}_{t}+\frac{u_{t} x_{t-1}}{\sum_{\tau=1}^{t-1} x_{\tau}^{2}}
$$

The previous procedure describes the behaviour of the learning agents. The problem is now to know whether the learning process converges toward rationality. At this level, it is required to specify the relation existing between the instrumental variable $\mathrm{x}$ 
and the exogenous variable $\mathrm{u}$ appearing in the 'true' model. Fourgeaud, Gouriéroux and Pradel (1986) assume that the following stationary relations hold :

$$
\begin{aligned}
& \text { (3.25) } \mathrm{u}_{\mathrm{t}+1}=\mathrm{c} \mathrm{x}_{\mathrm{t}}+\mathrm{v}_{\mathrm{t}+1} \text {, with } \mathrm{c}=\frac{\mathrm{E}\left(\mathrm{u}_{\mathrm{t}+1} \mathrm{x}_{\mathrm{t}}\right)}{\mathrm{E}\left(\mathrm{x}_{\mathrm{t}}^{2}\right)}, \mathrm{E}\left(\mathrm{v}_{\mathrm{t}+1} \mathrm{x}_{\mathrm{t}}\right)=0, \\
& \text { (3.26) } \mathrm{x}_{\mathrm{t}+1}=\mathrm{r} \mathrm{x}_{\mathrm{t}}+\mathrm{w}_{\mathrm{t}+1} \text {, with } \mathrm{r}=\frac{\mathrm{E}\left(\mathrm{x}_{\mathrm{t}+1} \mathrm{x}_{\mathrm{t}}\right)}{\mathrm{E}\left(\mathrm{x}_{\mathrm{t}}^{2}\right)}, \mathrm{E}\left(\mathrm{w}_{\mathrm{t}+1} \mathrm{x}_{\mathrm{t}}\right)=0 .
\end{aligned}
$$

Under these assumptions (and some standard regularity conditions), the authors have proved that, if lal $<1$, the sequence $\left(\hat{\alpha}_{1}\right)$ converges to $c /(1$-ar) for any initial value. Also, the sequence $\left(y_{t}\right)$ generated by the 'true model' - together with the expectation scheme (3.21) - tends in probability to a special solution of the corresponding rational expectation model :

$$
(3.27) \mathrm{y}_{\mathrm{t}}^{*}=\mathrm{aE}\left[\mathrm{y}_{\mathrm{t}+1}^{*} \mid \mathrm{x}_{\mathrm{t}}\right]+\mathrm{u}_{\mathrm{t}} \text {. }
$$

The special solution to model (3.27) which is the limit to the learning process is given by :

$$
\text { (3.28) } \mathrm{y}_{\mathrm{t}}^{*}=\frac{\mathrm{a} \mathrm{c}}{1-\mathrm{ar}} \mathrm{x}_{\mathrm{t}}+\mathrm{u}_{\mathrm{t}} \text {. }
$$

The rate of convergence of the coefficients $\left(\hat{\alpha}_{t}\right)$ may be examined under various assumptions about the instruments $x$, the exogenous process $u$ and the value of the coefficient a. The following figures give the evolution of $\left\|\hat{\alpha}_{\ell}\right\|^{2}$ obtained by Monte-Carlo experiments. The instrument $\mathrm{x}$ is drawn in a i.i.d. centered uniform distribution (with a given length of the variation interval). The exogenous variable $u_{t}$ is a linear function of $\mathrm{x}_{\mathrm{t}}: \mathrm{u}_{\mathrm{t}}=\mu+\mathrm{v} \mathrm{x}_{\mathrm{t}}$, with $\mu=0$ and $\mathrm{v}=1$ (so that $\mathrm{c}=\mathrm{r}=0$ ). The simulations have been performed for different values of a between 0 and 1 . For these values, the convergence is observed. Furthermore, as a goes closer to 1 , the convergence becomes slower. 

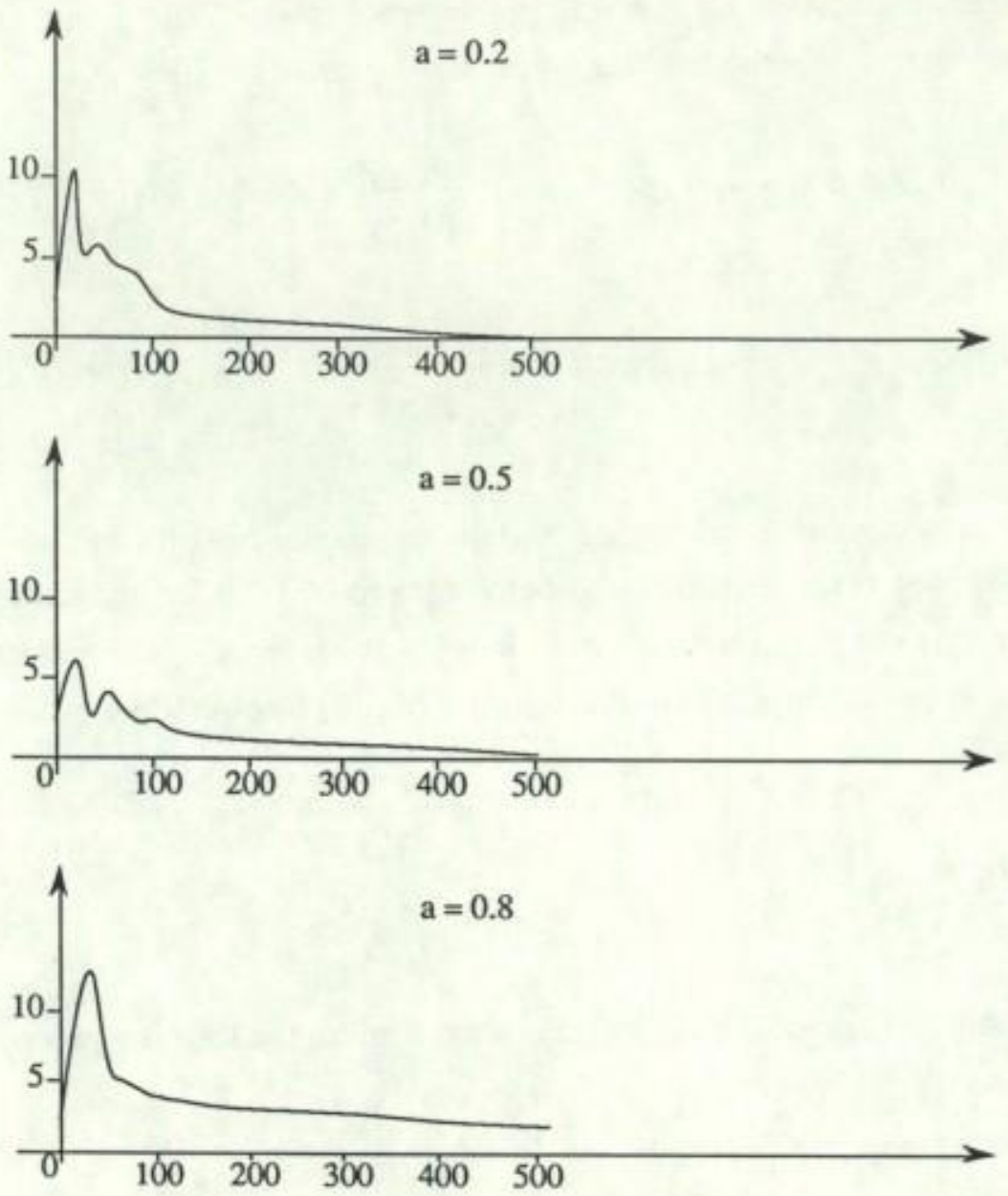

Figure 8 


\section{References}

ADAM, M.C. AND A. SZAFARZ (1987) : 'Speculative bubbles in monetary and financial models of asset pricing : Evaluating their explanatory power', Discussion paper CEME 8712, University of Brussels.

BLANCHARD, O.J. (1979) : ' Backward and forward solutions for economies with rational expectations', American Economic Review, Papers and Proceedings, 69, 114-118.

BLANCHARD, O.J. AND C.M. KAHN (1980) : 'The solution of linear difference models under rational expectations', Econometrica, 48, 1305-1311.

BLANCHARD, O.J. AND M. WATSON (1982) : 'Bubbles, rational expectations and financial markets', in Crises in the Economic and Financial Structure, P. Wachtel (ed.), Lexington Book.

BRAY, M. AND N. SAVIN (1986) : 'Rational expectations equilibria, learning and model specification', Econometrica, 54, 1129-1160.

BROZE, L., C. GouriÉROUX AND A. SZAFARZ (1985) : 'Solutions of dynamic linear rational expectations models', Econometric Theory, 1, 341-368.

BURMEISTER, E., R. FLOOD AND P. GARBER (1983) : 'On the equivalence of solutions in rational expectations models', Journal of Economic Dynamics and Control, 5, 311-321.

CAGAN, P. (1956) : 'The monetary dynamics of hyperinflation', in Studies in the Quantity Theory of Money, M. Friedman Ed., Chicago University Press.

CHOW, C. (1980) : 'Econometric policy evaluation and optimization under rational expectations', Journal of Economic Dynamics and Control, 2, 47-59.

DIBA, B.T. AND H.I. GROSSMAN (1988) : 'The theory of rational bubbles in stock prices', The Economic Journal, 98, 746-754.

ENGLE, R. AND C. GRANGER (1987) : 'Co-integration and error correction : representation, estimation and testing', Econometrica, 55, 251-276.

EVANS, G. (1986) : 'Selection criteria for models with non-uniqueness', Journal of Monetary Economics, 18, 147-157.

FELDMAN, M. (1987a) : 'An example of convergence to rational expectations with heterogenous beliefs', International Economic Review, 28, 635-650.

FELDMAN, M. (1987b) : 'Bayesian learning and convergence to rational expectations', Journal of Mathematical Economics, 16, 297-313. 
FLOOD, R.P. AND P. GARBER (1980) : 'Market fundamentals versus price-level bubbles : The first test', Journal of Political Economy, 8, 745-770.

FOURGEAUd, C. , C. GoURIÉROUX AND J. PRADEL (1986) : 'Learning procedures and convergence to rationality', Econometrica, 54, 845-868.

GOURIÉROUX, C., J.J. LAFFONT AND A. MONFORT (1982) : 'Rational expectations in dynamic linear models : analysis of the solutions', Econometrica, 50, 409-425.

HANSEN, L. AND T. SARGENT (1980) : 'Formulating and estimating linear rational expectations models', Journal of Economic Dynamics and Control, 2, 7-46.

KIEFER, N. (1988a) : 'Optimal collection of information by partially informed agents', Discussion Paper, Cornell University.

KIEFER, N. (1988b) : 'A value function arising in the economics information', Discussion Paper, Cornell University.

LEROY, S. (1984) : 'Efficiency and variability of asset prices', American Economic Review, 74, 183-187.

LEROY, S. AND R. PORTER (1981) : 'The present-value relation : Tests based on implied variance bounds', Econometrica, 49, 555-574.

LUCAS, R. (1973) : 'Some international evidence on output inflation trade-offs', American Economic Review, 63, 326-364.

MAC CALLUM, B.T. (1976) : 'Rational expectations and the estimation of econometric models : an alternative procedure', International Economic Review, 17, 484-490.

MAC CALLUM, B.T. (1983) : 'On non-uniqueness in rational expectations models : an attempt at perspective', Journal of Monetary Economics, 11, 134-168.

MALINVAUD, E. (1982) : Théorie macroéconomique, Dunod.

MARCET AND SARGENT (1986) : 'Convergence of least squares learning mechanisms in self referential linear stochastic models', Federal Reserve Bank, Minneapolis.

MARCET AND SARGENT (1988) : 'Least squares learning and the dynamics of hyperinflation', in Economic Complexity : Chaos, Sunspots, Bubbles and Nonlinearity, W. Barnett, J. Geweke and K. Shell (eds), Cambridge University Press.

MUTH, J.F. (1961) 'Rational expectations and the theory of price movements', Econometrica, 29, 315-335.

PESARAN, M. (1981) : 'Solution of linear rational expectations models', Journal of Econometrics, 16, 375-398.

PESARAN, M. (1985): The Limits to Rational Expectations, Basil Blackwell, Oxford.

SARGENT, T. (1979) : Macroeconomic Theory, Academic Press, New York. 
SARGENT, T. AND N. WALLACE (1973a) : 'Rational expectations and the dynamics of hyperinflation', International Economic Review, , 328-350.

SARGENT, T. AND N. WALLACE (1973b) : 'The stability of models of money and growth with perfect foresight', Econometrica, 41, 1043-1048.

SARGENT, T. AND N. WALLACE (1975) : 'Rational expectations, the optimal monetary instruments and the optimal money supply', Journal of Political Economy, 83, 241-254.

SCARTH, W.M. (1985) : 'A note on non-uniqueness in rational expectations models', Journal of Monetary Economics, 15, 247-254.

SHEFFRIN, S. (1983) : Rational Expectations, Cambridge University Press.

SHILLER, R. (1978) : 'Rational expectations and the dynamic structure of macroeconomic models', Journal of Monetary Economics, 4, 1-44.

SHILLER, R. (1979) : 'The volatility of long term interest rates and expectations models of the term structure', Journal of Political Economy, 87, 1190-1219.

SHILLER, R. (1981) : 'Do stock prices move too much to be justified by subsequent changes in dividends ?', American Economic Review, 71, 421-436.

SIMS, C.A. (1980) : 'Macroeconomics and reality', Econometrica, 48, 1551-1567.

TAYLOR, J. (1977) : 'Conditions for a unique solution in stochastic macroeconomic models rational expectations', Econometrica, 45, 1377-1387.

Whiteman, C.H. (1983) : Linear Rational Expectations Models : A User's Guide, University of Minnesota Press, Minneapolis. 
Chapter 3 


\section{CHAPTER 4}

\section{DYNAMIC COMPLICATIONS}

Among the solution methods described in chapters 2 and 3, some may be extended to treat the case of (univariate or multivariate) models involving various expectations. The martingale differences approach allows for the substitution of any expectation in terms of a realization and a prediction error. Starting from the initial structural model, this method leads to a dynamic equation including observable variables and prediction errors. This equation is then used for completely solving the model. This chapter will begin with some examples. It will be emphasized that, when some dynamic complications arise, it is necessary to impose some constraints on the successive prediction errors. An illustration will give an intuitive idea of the general result concerning the solution set of any linear univariate rational expectations model. After having described this general result, we will apply it to the search for stationary solutions.

\section{Some examples}

\section{1.a. A model with various expectations of the current endogenous variable}

We here consider an extension of the Muth model. The equation includes various expectations of the current endogenous variable formed at different past dates. For instance, when two such expectations are included, the model is given by :

$$
\text { (4.1) } y_{t}=a E\left[y_{t} \mid I_{t-1}\right]+b E\left[y_{t} \mid I_{t-2}\right]+u_{t} \text {. }
$$

A projection method, similar to the one used to solve the Muth model, may be applied [Aoki and Canzoneri (1980), Visco (1981, 1984)]. Since two expectations are to be replaced, we need two projections. Consequently, we take the expectations of both sides of (4.1), firstly conditional on the information set available at time $t-1$, and then conditional on the information set available at time $\mathrm{t}-2$. We obtain a two-equation system :

$$
\begin{aligned}
& \int E\left[y_{t} \mid I_{t-1}\right]=a E\left[y_{t} \mid I_{t-1}\right]+b E\left[y_{t} \mid I_{t-2}\right]+E\left[u_{t} \mid I_{t-1}\right] \\
& \left\{E\left[y_{t} \mid I_{t-2}\right]=a E\left[y_{t} \mid I_{t-2}\right]+b E\left[y_{t} \mid I_{t-2}\right]+E\left[u_{t} \mid I_{t-2}\right]\right. \text {. }
\end{aligned}
$$


This system determines uniquely the expectations of the endogenous variable as functions of the expectations of the exogenous variables. Indeed we have :

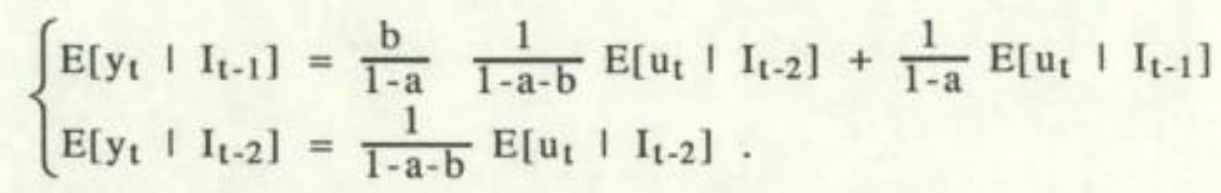

It follows that model (4.1), like the Muth model, has a unique solution. Explicitly this solution is written as

$$
y_{t}=\frac{b}{(1-a)(1-a-b)} E\left[u_{t} \mid I_{t-2}\right]+\frac{a}{1-a} E\left[u_{t} \mid I_{t-1}\right]+u_{t}
$$

Of course, the dynamics of the endogenous process is only known after the evolution of the exogenous process has been specified. Consider for instance, for $u$, an autoregressive model of order 1 :

$$
\mathrm{u}_{\mathrm{t}}=\rho \mathrm{u}_{\mathrm{t}-1}+\varepsilon_{\mathrm{t}}, \quad|\rho|<1 \text {. }
$$

If the information set $\mathrm{I}_{\mathrm{t}}$ is composed of the past and current values of the exogenous process, then :

$$
E\left[u_{t} \mid I_{t-1}\right]=\rho u_{t-1},
$$

and

$$
E\left[u_{t} \mid I_{t-2}\right]=\rho^{2} u_{t-2} \text {. }
$$

The solution becomes :

$$
y_{t}=\frac{b \rho^{2}}{(1-a)(1-a-b)} u_{t-2}+\frac{a \rho}{1-a} u_{t-1}+u_{t} .
$$

In this expression, two effects may be separated : the direct effect of the exogenous dynamics (term $\mathrm{u}_{\downarrow}$ ) and the effect passing through the expectations (terms in $\mathrm{u}_{\mathrm{t}-1}$ and $\mathrm{u}_{\mathrm{t}-2}$ ). 


\section{1.b. A model with a two-periods-ahead future expectation}

The model considered in Chapter 3 is here modified by replacing the one-periodahead expectation by a two-periods-ahead one. It becomes :

(4.2) $y_{t}=a E\left[y_{t+2} \mid I_{t}\right]+u_{t}$.

To solve this model, the prediction error over two periods is introduced :

$$
v_{t, 2}=y_{t}-E\left[y_{t} \mid I_{t-2}\right]
$$

Substituting for the expectation in (4.2) yields :

$$
y_{t}=a\left(y_{t+2}-v_{t+2,2}\right)+u_{t}
$$

As shown in Chapter 1, any prediction error may be decomposed as a sum of revision (or updating) terms :

$$
v_{t, 2}=\varepsilon_{t}^{0}+\varepsilon_{t-1}^{1},
$$

where : $\varepsilon_{t}^{0}=y_{t}-E\left[y_{t} \mid I_{t-1}\right]$,

$$
\varepsilon_{t-1}^{1}=E\left[y_{t} \mid I_{t-1}\right]-E\left[y_{t} \mid I_{t-2}\right]
$$

We then obtain :

$$
y_{t}=a\left(y_{t+2}-\varepsilon_{t+2}^{0}-\varepsilon_{t+1}^{1}\right)+u_{t},
$$

or equivalently :

$$
\text { (4.3) } \mathrm{y}_{\mathrm{t}}=\frac{1}{\mathrm{a}} \mathrm{y}_{\mathrm{t}-2}-\frac{1}{\mathrm{a}} \mathrm{u}_{\mathrm{t}-2}+\varepsilon_{\mathrm{t}}^{0}+\varepsilon_{\mathrm{t}-1}^{1} \text {, }
$$

where $\varepsilon^{0}$ and $\varepsilon^{1}$ are martingale differences. 
Conversely, for any given martingale differences $\varepsilon^{0}$ and $\varepsilon^{1}$ and any process y satisfying the latter equation, we directly obtain the two-periods-ahead prediction by taking the expectation conditional on $\mathrm{I}_{\mathrm{t}-2}$ :

$$
\begin{aligned}
& E\left[y_{t} \mid I_{t-2}\right]=\frac{1}{a} y_{t-2}-\frac{1}{a} u_{t-2}+E\left[\varepsilon_{t}^{0} \mid I_{t-2}\right]+E\left[\varepsilon_{t-1}^{1} \mid I_{t-2}\right] \\
& =\frac{1}{a} y_{t-2}-\frac{1}{a} u_{t-2} .
\end{aligned}
$$

This equation exactly coincides with the initial rational expectations model.

In summary, all solutions of model (4.2) are given by equation (4.3) where $\varepsilon^{0}$ and $\varepsilon^{1}$ are arbitrary martingale differences. Since two such arbitrary processes are required for an exhaustive description of the solution set, we will say that this set has a dimension equal to two (in terms of arbitrary martingale differences).

\section{1.c. A model with one current expectation and one future expectation}

In Chapter 3, we have presented a slightly simplified version of the Taylor (1977) model. Actually, the original model considered by Taylor is a rational expectations macromodel leading to a price equation having the following form :

$$
\text { (4.4) } y_{t}=a E\left[y_{t+1} \mid I_{t-1}\right]+b E\left[y_{t} \mid I_{t-1}\right]+u_{t} \text {. }
$$

This equation includes two expectations simultaneously. Both expectations are formed at time $\mathrm{t}-1$, however the first one concerns a future variable $\mathrm{y}_{\mathrm{t}+1}$ while the second one concerns the current variable $\mathrm{y}_{\mathrm{t}}$.

Let us now introduce the prediction errors over one and two periods and then decompose them with the use of revision terms. We obtain :

$$
\text { (4.5) } y_{t}=a\left(y_{t+1}-\varepsilon_{t+1}^{0}-\varepsilon_{t}^{1}\right)+b\left(y_{t}-\varepsilon_{t}^{0}\right)+u_{t} \text {, }
$$

where $\varepsilon^{0}$ and $\varepsilon^{1}$ are martingale differences. Thus any solution to (4.4) verifies (4.5).

Alternatively, let us consider a solution to (4.5) where $\varepsilon^{0}$ and $\varepsilon^{1}$ are taken as arbitrary martingale differences. We will examine whether these processes may be interpreted 
as updating terms. For this purpose, we successively compute the expectations of both sides of (4.5) conditional on $\mathrm{I}_{\mathrm{t}}$ and $\mathrm{I}_{\mathrm{t}-1}$. We have :

(4.6) $y_{t}=a\left(E\left[y_{t+1} \mid I_{t}\right]-\varepsilon_{t}^{1}\right)+b\left(y_{t}-\varepsilon_{t}^{0}\right)+u_{t}$,

(4.7) $E\left[y_{t} \mid I_{t-1}\right]=a E\left[y_{t+1} \mid I_{t-1}\right]+b E\left[y_{t} \mid I_{t-1}\right]+E\left[u_{t} \mid I_{t-1}\right]$.

Taking side by side the difference between (4.6) and (4.5) yields :

$$
0=a\left(y_{t+1}-E\left[y_{t+1} \mid I_{t}\right]-\varepsilon_{t+1}^{0}\right) \text {. }
$$

Consequently, the martingale difference $\varepsilon^{0}$ is necessarily the one-period-ahead prediction error process.

Let now substract (4.7) from (4.6) to obtain :

$$
\begin{aligned}
& \quad y_{t}-E\left[y_{t} \mid I_{t-1}\right]=a\left(E\left[y_{t+1} \mid I_{t}\right]-E\left[y_{t+1} \mid I_{t-1}\right]-\varepsilon_{t}^{1}\right) \\
& +b\left(y_{t}-E\left[y_{t} \mid I_{t-1}\right]-\varepsilon_{t}^{0}\right)+u_{t}-E\left[u_{t} \mid I_{t-1}\right] .
\end{aligned}
$$

Taking into account the previously established form of $\varepsilon^{0}$, one obtains :

$$
\varepsilon_{t}^{0}=a\left(E\left[y_{t+1} \mid I_{t}\right]-E\left[y_{t+1} \mid I_{t-1}\right]-\varepsilon_{t}^{1}\right)+u_{t}-E\left[u_{t} \mid I_{t-1}\right]
$$

It follows that $\varepsilon^{1}$ can be interpreted as the updating term $E\left[y_{t+1} \mid I_{t}\right]-E\left[y_{t+1} \mid I_{t-1}\right]$ if and only if $\varepsilon^{0}$ fulfills the relation :

$$
\varepsilon_{\mathrm{t}}^{0}=\mathrm{u}_{\mathrm{t}}-\mathrm{E}\left[\mathrm{u}_{\mathrm{t}} \mid \mathrm{I}_{\mathrm{t}-1}\right]
$$

Thus equation (4.5) represents a too wide formulation for our problem. It provides solutions to model (4.4) only if one of the martingale differences is subject to an additional constraint. More precisely, for model (4.4) the constraint requires the oneperiod-ahead prediction error on $y$ to coincide with the one-period ahead prediction error on $\mathrm{u}$. We incorporate this restriction and derive the equation involving observable variables that is equivalent to the model. It is given by : 


$$
y_{t}=a\left[y_{t+1}-\left(u_{t+1}-E\left[u_{t+1} \mid I_{t}\right]\right)-\varepsilon_{t}^{1}\right]+b\left[y_{t}-\left(u_{t}-E\left[u_{t} \mid I_{t-1}\right]\right)\right]+u_{t},
$$

or

(4.8) $y_{t}=\frac{1-b}{a} y_{t-1}+u_{t}-E\left[u_{t} \mid I_{t-1}\right]+\frac{b-1}{a} u_{t-1}-\frac{b}{a} E\left[u_{t-1} \mid I_{t-2}\right]+\varepsilon_{t}^{1}$,

where $\varepsilon^{1}$ is an arbitrary martingale difference. In terms of this kind of processes, the dimension of the solution set is equal to 1 .

\section{1.d. Some remarks}

Let us now summarize the insights brought by the preceding examples. The first, and probably most obvious, distinction among models concerns the presence or absence of multiple solutions. In our examples, uniqueness occurs for the first model as well as for the Muth model. In turn, non-uniqueness is characteristic of the last two models and the hyperinflation price equation. In the next section, we will analyse the linear rational expectations models in more depth and provide a classification based on the nonuniqueness criterion.

On the other hand, the solution methods used above are different depending on the form of the model. The Muth model and its extension have been solved with the help of a projection technique while the other models have been treated by the martingale difference method. This difference is actually inessential. As will be shown, the martingale difference method applies in all cases. Nevertheless, when a projection technique works, it is often more intuitive and also shorter.

From a more technical point of view, the last two examples show that the key aspect of the martingale difference method lies in the introduction of updating terms. Hence not only prediction errors (as one could think after the reading of Chapter 3 ) play a crucial role in the determination of the solution set. Furthermore the updating terms are sometimes subject to constraints. The next section will begin with a systematic discussion about the necessary constraints that have to be incorporated in the solution phase of the general model. Since the very simple models do not require such constraints, they hide somewhat the presence of this additional level of complexity. By not taking into account this phenomenon, one would enlarge abusively the solution set. As will be shown, the dimension of this set (in terms of martingale differences) varies according to the number and the type of expectations included in the model. 


\section{Solutions to the general univariate model}

\section{2.a. The model}

In the case of a single endogenous variable, the most general linear rational expectations model is given by :

$$
y_{t}=\sum_{k=0}^{K} \sum_{h=1}^{H} a_{k h} E\left[y_{t+h-k} \mid I_{t-k}\right]+\sum_{k=1}^{K} a_{k 0} y_{t-k}+u_{t} .
$$

The current endogenous variable depends on its lagged values $\mathrm{y}_{\mathrm{t}-1}, \ldots, \mathrm{y}_{\mathrm{t}-\mathrm{K}}$, on the exogenous variable $\mathrm{u}_{\mathrm{t}}$ and various expectations. Note that $\mathrm{u}_{\mathrm{t}}$ summarizes all non-endogenous terms, either disturbances or exogenous factors.

The expectations may concern future values $(\mathrm{h}>\mathrm{k})$, current ones $(\mathrm{h}=\mathrm{k})$ or even past ones $(\mathrm{h}<\mathrm{k})$. However in the last case, the expectations are formed at previous dates $(\mathrm{k}>0)$ or simultaneously $(\mathrm{k}=0)$ with the realizations. Only expectations formed later than the current period are excluded for obvious reasons.

We have taken the same upper value for both sums involving the index $\mathrm{k}$. This simplifies the technical derivations and does not restrict the presentation. It suffices to impose zero values for coefficients that affect non-desirable terms.

Index $\mathrm{h}$ has an important meaning. It represents the horizon of the expectations. We assume here that $\mathrm{H}$ is chosen as small as possible (i.e. at least one coefficient $\mathrm{a}_{\mathrm{kH}}$ is different from zero). Therefore $\mathrm{H}$ denotes the maximal horizon of the expectations appearing in model (4.9).

\section{2.b. Expression of the expectations in terms of realizations}

We outline here in a general way the computations that have been used, case by case, in the examples. Any expectation can be expressed by means of the corresponding realization and updating terms :

$$
E\left[y_{t+h-k} \mid I_{t-k}\right]=y_{t+h-k}-\sum_{j=0}^{h-1} \varepsilon_{t+h-k-j}^{j}
$$

We then perform the replacement for each expectation in model (4.9) and obtain : 


$$
y_{t}=\sum_{k=0}^{K} \sum_{h=1}^{H} a_{k h}\left(y_{t+h-k}-\sum_{j=0}^{h-1} \varepsilon_{t+h-k-j}^{j}+\sum_{k=1}^{K} a_{k 0} y_{t-k}+u_{t} .\right.
$$

In this expression, endogenous variables appear in various terms. We group all of the endogenous variables that have the same time index. For this purpose we introduce a new notation $\mathrm{a}_{\mathrm{i}}^{*}$ that represents the sum of all structural coefficients associated with the endogenous variable $\mathrm{y}_{\mathrm{t}+\mathrm{i}}$. We thus define :

$$
a_{i}^{*}=\sum_{\substack{k \in\{0, \ldots K\} \\ i+k \in[0, \ldots H\}}} a_{k, i+k}
$$

and the equation becomes :

$$
\sum_{i=J_{0}}^{J_{1}} a_{i}^{*} y_{t+i}=\sum_{k=0}^{K} \sum_{h=1}^{H} a_{k h} \sum_{j=0}^{h-1} \varepsilon_{t+h-k-j}^{j}-u_{t} .
$$

The integers $\mathrm{J}_{0}$ and $\mathrm{J}_{1}$ are the extreme values taken by index $i$.

$$
\mathrm{J}_{0}=\min \left\{\mathrm{i}: \mathrm{a}_{\mathrm{i}}^{*} \neq 0\right\}, \mathrm{J}_{1}=\max \left\{\mathrm{i}: \mathrm{a}_{\mathrm{i}}^{*} \neq 0\right\}
$$

Equation (4.10) includes $\mathrm{H}$ updating processes $\varepsilon^{0}, \varepsilon^{1}, \ldots \varepsilon^{\mathrm{H}-1}$. Each of them is a martingale difference (see Chapter 1). At this stage only replacements have been made. The remainder of this discussion will concern the constraints that can arise among the updating terms.

In other respects, note that the perfect foresight model associated with model (4.9) could be solved along the same lines. In this case however, all the updating terms necessarily vanish. Thus, equation (4.10) with zero values for all the martingale differences $\varepsilon^{0}, \varepsilon^{1}, \ldots \varepsilon^{\mathrm{H}-1}$ may be seen as the perfect foresight version of the general model. In this case, only $\mathrm{u}_{\mathrm{t}}$ appears on the right-hand-side while the left-hand-side includes the autoregressive term $\sum_{\mathrm{i}=\mathrm{J}_{1}}^{\mathrm{J}_{0}} \mathrm{a}_{\mathrm{i}}^{*} \mathrm{y}_{\mathrm{t}+\mathrm{i}}$ going back to the rational expectation case. It follows that the autoregressive term in (4.10) may be viewed as a summary of the dynamics of the corresponding perfect foresight model. 


\section{2.c. Constraints on the updating terms}

It has been shown previously that any solution to the general model satisfies equation (4.10). In this equation any updating term appears as a distinct martingale difference. Now conversely, we will examine whether any arbitrary choice of martingale differences in (4.10) leads to a solution y of the original model.

As emphasized with the example described in subsection 1c, the martingale differences may not always be taken arbitrarily. Their interpretation as updating terms generally imposes some constraints on the processes denoted $\varepsilon^{0}, \ldots \varepsilon^{\mathrm{H}-1}$. These necessary and sufficient constraints are described in the following property [see Broze, Gouriéroux and Szafarz (1985) for a proof].

Property (4.12) : a) The solutions to equation (4.10) satisfy the rational expectations model (4.9) if the martingale differences fulfill the following constraints

$$
\begin{aligned}
& \varepsilon_{t}^{i}=\sum_{k=0}^{i} \sum_{h=0}^{H} a_{k h} \varepsilon_{t}^{h-k+i}+E\left[u_{t+i} \mid I_{t}\right]-E\left[u_{t+i} \mid I_{t-i}\right], \\
& i=0, \ldots H-J_{1}-1, \text { for } H>J_{1} .
\end{aligned}
$$

b) If $\mathrm{H}=\mathrm{J}_{1}$, the martingale differences may be chosen arbitrarily.

In particular the Cagan model and the example of subsection 1.b. correspond to cases where $\mathrm{H}=\mathrm{J}_{1}$ and therefore do not include constraints.

\section{2.d. Some consequences}

a) Property (4.12) provides the "dimension" of the solution set in terms of martingale differences. Indeed, from the start, $\mathrm{H}$ martingale differences are introduced. Among them, $\mathrm{H}_{-} \mathrm{J}_{1}$ linear constraints must be imposed. After having solved this system, $\mathrm{J}_{1}$ arbitrary martingale differences remain.

b) We have already mentioned that multiplicity of solutions in models involving future rational expectations has two components. The first component results from the internal dynamics of the corresponding perfect foresight model, i.e. the fact that $y_{t}$ generally depends on its lagged values. More precisely, it is clear from (4.10) that lagged endogenous terms enter the model when $J_{1} \neq 0$. However, this first type of non-uniqueness may be avoided by imposing initial conditions on the endogenous 
process. The second component of the multiplicity is due to the presence of martingale differences that may be chosen arbitrarily. This occurs when $J_{1}>0$. This second component cannot be avoided with initial conditions. The class of models that do not lead to such multiplicity is characterized by the next property.

Property (4.13): The rational expectations models for which any solution may be characterized by a finite number of initial values correspond to the case $\mathrm{J}_{1}=0$.

These models include no future expectations. Their general formulation is :

$$
y_{t}=\sum_{k=0}^{K} \sum_{h=1}^{k} a_{k h} E\left[y_{t+h-k} \mid I_{t-k}\right]+\sum_{k=1}^{K} a_{k 0} y_{t-k}+u_{t}
$$

Property (4.14): The rational expectations models which admit a unique solution are characterized by : $\mathrm{J}_{0}=\mathrm{J}_{1}=0$.

Formally the unique solution models are given by :

$$
y_{t}=\sum_{k=1}^{K} a_{k k} E\left[y_{t} \mid I_{t-k}\right]+u_{t} .
$$

They only include current expectations and can be easily solved by using a recursive projection technique as illustrated in example 1.b.

c) One might examine under what condition a backward solution exists. Such a solution corresponds to the case where the rational expectations are taken to be perfect. In other words, a backward solution is a solution for which the martingale differences $\varepsilon^{0}, \ldots \varepsilon^{\mathrm{H}-1}$ are all identically zero. Since constraints are imposed on these processes, the question one has to answer is whether zero values for the martingale differences are compatible with the constraints arising among the updating terms. Considering the system described by property (4.12), it appears that if $\mathrm{H}>\mathrm{J}_{1}$ the previous compatibility implies the condition $\mathrm{E}\left[\mathrm{u}_{\mathrm{t}+\mathrm{i}} \mid \mathrm{I}_{\mathrm{t}}\right]=\mathrm{E}\left[\mathrm{u}_{\mathrm{t}+\mathrm{i}} \mid \mathrm{I}_{\mathrm{t}-1}\right]$ for $\mathrm{i}=0, \ldots \mathrm{H}-1$. This condition imposes a predetermined exogenous process, i.e. a much stronger restriction. Therefore a backward solution can be found only when $\mathrm{H}=\mathrm{J}_{1}$. 


\section{2.e. Some applications}

We have summarized in table 3 the reduced forms of various rational expectations models. For clarity, we have also given the values of the indexes $\mathrm{H}, \mathrm{K}$ and $\mathrm{J}_{1}$.

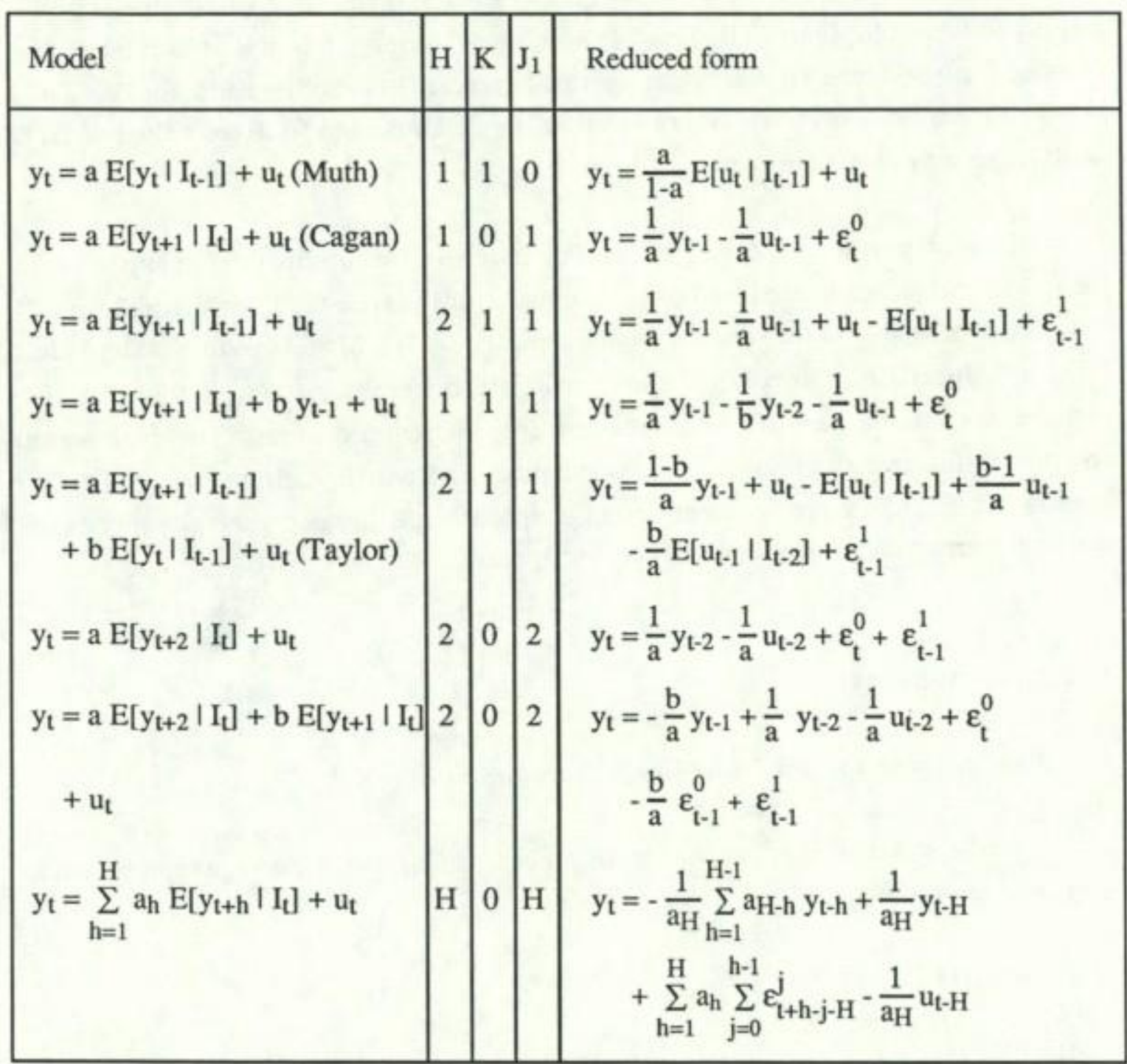

Table 3

In Table 3, all constraints have been incorporated, hence any updating process $\varepsilon^{i}$ that appears should be interpreted as an arbitrary martingale difference.

The models considered here as examples have be chosen in order to recall the main cases used in practical applications and to illustrate the most relevant technical complications that may arise in reducing the models. In fact, the indexes $\mathrm{H}$ and $\mathrm{K}$ refer to 
the model itself, while $\mathrm{J}_{1}$ gives the dimension of the multiplicity (in terms of martingale differences). For instance, one can compare models having the same values for $\mathrm{H}$ and $\mathrm{K}$ and observe that some but not all have different values for $\mathrm{J}_{1}$. Two such situations are present in Table 3. For $H=1$ and $K=1$, the Muth model (line 1) and a future expectations model including a lagged endogenous variable (line 4) are distinct with respect to the multiplicity. The first has a unique solution while the second leads to a reduced form with one arbitrary martingale difference. On the other hand, for $\mathrm{H}=2$ and $\mathrm{K}=1$, the third and fifth models both lead to $\mathrm{J}_{1}=1$. Thus even for fixed values of $\mathrm{H}, \mathrm{K}$ and $\mathrm{J}_{1}$, one may obtain various types of models.

Finally note that the choice of the time index for the information set appearing in the model influences the reduced form. Compare for instance the Cagan model (line 2) with the modified version where $\mathrm{I}_{\mathrm{t}}$ has be replaced by $\mathrm{I}_{\mathrm{t}-1}$ (line 3 ). While both models have a reduced form involving one martingale difference, it is obvious that the endogenous variable has different evolutions (see the reduced forms). The main reason for this is the introduction in the second model of two updating terms (with one constraint). Therefore prediction errors on $\mathrm{u}_{\mathrm{t}}$ appear explicitly and generally this model does not admit a backward solution (because $\mathrm{J}_{1}<\mathrm{H}$ ).

\section{Linear solutions}

\section{3.a. The general form of the linear solutions}

We here assume that the exogenous process has a moving-average representation (possibly non-stationary) :

$$
u_{t}=\Theta(L) \tilde{\varepsilon}_{t},
$$

where $\tilde{\varepsilon}_{t}=\left\{\begin{array}{ll}\varepsilon_{t}, & \text { if } t \geq 0 \\ 0 & \text {, otherwise }\end{array}\right.$, with $\left(\varepsilon_{t}\right)$ being a white noise process.

We are interested in linear solutions to the general model, i.e. in solutions to (4.9) that admit a moving-average formulation of the same type :

$$
y_{t}=A(L) \tilde{\varepsilon}_{t}=a_{0} \varepsilon_{t}+a_{1} \varepsilon_{t-1}+\ldots+a_{t} \varepsilon_{0} .
$$

Obviously, for these solutions, the updating terms must be proportional to the innovation of the exogenous process : 
(4.15) $\varepsilon_{\mathrm{t}}^{\mathrm{j}}=\mathrm{a}_{\mathrm{j}} \varepsilon_{\mathrm{t}}, \forall \mathrm{j}$.

Conversely, to obtain all the linear solutions, it suffices to select among the martingale differences having the previous form the ones that satisfy the constraints .

\section{3.b. (Asymptotic) stationarity of the linear solutions}

We now impose (asymptotic) stationarity of the exogenous process and examine whether some of the linear solutions are also (asymptotically) stationary, i.e. are such that $\sum_{\mathrm{j}=0}^{\infty} \mathrm{a}_{\mathrm{j}}^{2}<\infty$.

As shown in section 2, the constraints linking the martingale differences allow all of them to be expressed in terms of the $\mathrm{J}_{1}$ last differences $\varepsilon^{\mathrm{H}-\mathrm{J}} 1, \ldots \varepsilon^{\mathrm{H}-1}$ that are not restricted. We may then substitute for the first martingale differences in equation (4.10) and obtain a relation of the following type :

$$
\sum_{i=J_{0}}^{J_{1}} a_{i}^{*} y_{t+i}=\sum_{j=H-J_{1}}^{H-1} \sum_{k=k_{j}}^{K_{j}} c_{j k} \varepsilon_{t+J_{1}-k}^{j}+g_{t+J_{1}}(u)
$$

where $\mathrm{g}_{\mathrm{t}}(\mathrm{u})$ is a mapping of the process $\mathrm{u}$ that depends linearly on past and current values of $u$ and of its expectations. As long as a linear stationary representation has been chosen for the exogenous process, the mapping $g_{t}(u)$ has the same form :

$$
\mathrm{g}_{\mathrm{t}}(\mathrm{u})=\Omega(\mathrm{L}) \varepsilon_{\mathrm{t}}
$$

Thus the linear solutions are parametrized by the coefficients denoted $a_{j}, j=H-J_{1}, \ldots . H-1$ and are given by :

$$
\sum_{i=J_{0}}^{J_{1}} a_{i}^{*} y_{t+i}=\sum_{j=H-J_{1}}^{H-1}\left(\sum_{k=k_{j}}^{K_{j}} c_{j k} a_{j} L^{k-J_{1}}\right) \tilde{\varepsilon}_{t}+\Omega(L) \tilde{\varepsilon}_{t+J_{1}}
$$

or equivalently : 
(4.16) $\left(\sum_{i=0}^{J_{1}-J_{0}} a_{J_{1}-i}^{*} L^{i}\right) y_{t}=\left(\sum_{j=H-J_{1}}^{H-1} \sum_{k=k_{j}}^{K_{j}} c_{j k} a_{j} L^{k}+\Omega(L)\right) \widetilde{\varepsilon}_{t}$

Equation (4.16) provides an autoregressive-moving-average form for the linear solutions. Nevertheless, in order to discuss their stationarity, it is necessary to examine the roots of the autoregressive polynomial. More precisely, we must know their position with respect to the unit circle.

Suppose for instance that the autoregressive polynomial has one root, say $\gamma_{1}$, inside the unit circle. It is possible to eliminate this unstable root by imposing that $\gamma_{1}$ is also a root of the moving-average polynomial. This implies the following constraint :

$$
\sum_{j=H-J_{1}}^{H-1} \sum_{k=k_{j}}^{K_{j}} c_{j k} a_{j} \gamma_{1}^{k}-\Omega\left(\gamma_{1}\right)=0
$$

It is thus an additional restriction on the parameters $a_{\mathrm{H}-\mathrm{J}_{1}}, \ldots \mathrm{a}_{\mathrm{H}-1}$. One may of course proceed in the same way to eliminate every unstable root of the autoregressive polynomial. To each unstable root will correspond a new restriction. This yields the next property.

Property (4.18) : Let $\mathrm{N}$ be the number of roots of the equation :

$$
\sum_{i=0}^{J_{1}-J_{0} *} a_{J_{1}-i} \gamma^{i}=0
$$

that lie inside the unit circle.

. If $\mathrm{J}_{1}-\mathrm{N}>0$, the general linear stationary solution includes $\mathrm{J}_{1}-\mathrm{N}$ arbitrary scalar parameters;

- If $\mathrm{J}_{1}=\mathrm{N}$, there exists a unique linear stationary solution;

. If $\mathrm{J}_{1}-\mathrm{N}<0$, no linear stationary solutions exist.

\section{3.c. An example}

Let us consider the following model :

$$
y_{t}=a E\left[y_{t+2} \mid I_{t}\right]+b E\left[y_{t+1} \mid I_{t}\right]+\varepsilon_{t}, a \neq 0
$$


From Table 3, the general solution to this model is given by :

$$
y_{t}=-\frac{b}{a} y_{t-1}+\frac{1}{a} y_{t-2}-\frac{1}{a} \varepsilon_{t-2}+\varepsilon_{t}^{0}-\frac{b}{a} \varepsilon_{t-1}^{0}+\varepsilon_{t-1}^{1}
$$

The linear solutions are deduced from this expression by taking $\varepsilon_{\mathrm{t}}^{0}=\mathrm{a}_{0} \varepsilon_{\mathrm{t}}$ and $\varepsilon_{\mathrm{t}}^{1}=\mathrm{a}_{1} \varepsilon_{\mathrm{t}}$.

After replacements, we obtain :

$$
y_{t}=-\frac{b}{a} y_{t-1}+\frac{1}{a} y_{t-2}-\frac{1}{a} \varepsilon_{t-2}+a_{0} \varepsilon_{t}-\frac{b}{a} a_{0} \varepsilon_{t-1}+a_{1} \varepsilon_{t-1},
$$

or with the use of lag-polynomials :

$$
\left(a+b L-L^{2}\right) y_{t}=\left(a a_{0}+\left(a a_{1}-b a_{0}\right) L-L^{2}\right) \varepsilon_{t}
$$

Various cases are then to be distinguished according to the position of the roots of the autoregressive polynomial $\mathrm{a}+\mathrm{b} \gamma-\gamma^{2}$.

i) If both roots lie outside the unit circle, there exists a double infinity of linear stationary solutions that are parametrized by $a_{0}$ and $a_{1}$.

ii) If only one of these roots lies outside the unit circle, there exists a simple infinity of linear stationary solutions. Letting $\gamma_{1}$ denote the unstable root, the parameters a0 and $\mathrm{a}_{1}$ are constrained by the relation :

$$
\mathrm{a} \mathrm{a}_{0}+\left(\mathrm{a} \mathrm{a}_{1}-\mathrm{b} \mathrm{a}_{0}\right) \gamma_{1}-\gamma_{1}^{2}=0
$$

iii) If both roots lie inside the unit circle, then there exists a unique linear stationary solution. Since $\mathrm{y}_{\mathrm{t}}=\varepsilon_{\mathrm{t}}$ is clearly a solution to the original model, it necessarily coincides with this particular solution.

In this example it is easy to see that the approach followed here to determine the linear stationary solutions has the advantage of immediately providing their ARMA representation. Indeed, the general expression of the linear solution shows an ARMA $(2,2)$ form. Any explosive root that has to be cancelled implies the reduction by one degree of both the autoregressive and moving-average polynomials. Thus case ii) corresponds to an infinity of ARMA $(1,1)$ processes, while case iii) leads to a white noise. The same argument could be put in a more general fashion to discuss the orders of the ARMA solutions of the general model [Evans and Honkapohja (1986), Whiteman (1983), Gouriéroux, Laffont and Monfort (1982)]. 


\section{References}

AOKI M. AND M. CANZONERI (1979) : "Reduced forms of rational expecations models", Quarterly Journal of Economics, 93, 59-71.

BROZE, L., C. GOURIÉROUX and A. SZAFARZ (1985) : "Solutions of dynamic linear rational expectations models", Econometric Theory, 1, 341-368.

D'AUTUME, A. (1988) : "On the solution of linear difference equations with rational expectations", Discussion Paper 134, Laboratoire d'Economie Politique, Ecole Normale Supérieure, Paris.

EVANS, G. (1985) : "The algebra of ARMA processes and the structure of ARMA solutions to a general linear model with rational expectations", INMMS technical report 476, Stanford University.

EVANS, G. (1986) : "Selection criteria for models with non-uniqueness", Journal of Monetary Economics, 18, 147-157.

EVANS, G. AND S. HONKAPOHJA (1986), : "A complete characterization of ARMA solutions to linear rational expectations models", Review of Economic Studies, 53, 227-239.

FAIR, R. AND J. TAYLOR (1983) : "Solution and maximum likelihood estimation of dynamic non-linear rational expectations models", Econometrica, 51, 1169-1184.

GOURIÉROUX, C. , J.J. LAFFONT AND A. MONFORT (1982) : "Rational expecations in linear models : Analysis of solutions", Econometrica, 50, 409-425.

MC CAFFERTY, S. AND R. DRISKILL (1980) : "Problems of existence and uniqueness in nonlinear rational expectations models", Econometrica, 48, 1313-1317.

SARGAN, J.D. (1984) : "Alternative models for rational expectations in some simple irregular cases", Discussion Paper, London School of Economics.

TAYLOR, J. (1977) : "Conditions for a unique solution in stochastic macroeconomic models with rational expectations", Econometrica, 45, 1377-1387.

VISCO, I. (1981) : "On the derivation of reduced forms of rational expecations models", European Economic review, 16, 355-365.

VISCO, I. (1984) : "On linear models with rational expectations : An addendum", European Economic review, 24, 113-115.

Whiteman, C. (1983) : Linear Rational Expectations Models : A User's Guide, Minneapolis, University of Minnesota Press. 


\section{CHAPTER 5}

\section{MULTIVARIATE MODELS}

\section{Dynamic macroeconometric models}

Simulations of economic policies are generally performed using large-scale computerized macroeconometric models. Among the variables appearing in the model, some (the controls) are selected and their values are modified. Then the effects of these shocks on the other variables are evaluated. These effects depend on the amplitude of the initial shocks, on the lag between the date of the shock and the time index of the variable of interest and, of course, on the dynamic specification of the model.

These macroeconometric models are generally simultaneous equations models with a large number of equations and variables. The dynamics is often introduced by means of lagged endogenous and/or exogenous variables. As an example of such a model, we give below the main equations of a core model summarizing the large-scale French model METRIC.

The variables are the following :

\begin{tabular}{|c|c|c|c|}
\hline $\begin{array}{c}\text { Endogenous } \\
\text { variables }\end{array}$ & & $\begin{array}{c}\text { Exogenous } \\
\text { variables }\end{array}$ & \\
\hline $\begin{array}{l}\text { Production : } \\
\text { Imports : } \\
\text { Employment : } \\
\text { Investment : } \\
\text { Capital stock : } \\
\text { Wages : } \\
\text { Domestic price index: } \\
\text { Unemployment rate : } \\
\text { Production capacity : } \\
\text { Degree of production } \\
\text { capacity utilization : }\end{array}$ & $\begin{array}{l}\mathrm{Q} \\
\mathrm{M} \\
\mathrm{N} \\
\mathrm{I} \\
\mathrm{K} \\
\mathrm{W} \\
\mathrm{P} \\
\mathrm{Un} \\
\mathrm{Q}\end{array}$ & $\begin{array}{l}\text { Autonomous demand government } \\
\text { and foreign demand : } \\
\text { Population size : } \\
\text { Foreign prices index : }\end{array}$ & $\begin{array}{l}\frac{\bar{A}}{\bar{N}} \\
\mathrm{P}^{\mathrm{e}}\end{array}$ \\
\hline
\end{tabular}


The model contains 10 equations. The first one is the equilibrium condition on the goods market. Equation (2) is the imports equation : the elasticity of demand is equal to $1+\mathrm{e}_{4}$ in the short run and the price elasticity is constant and equals $e_{2}$. In equation (3) the labor productivity increases at a constant rate and the factors of production are complements. In the investment function (4) the effect of profit and an accelerator phenomenon are simultaneously introduced. The usual Phillips curve is given by equation (5) and relation (6) describes price changes as a function of wages and of a positive effect of excess demand on the goods market. The other equations have clear interpretations.

Equilibrium equation

(1) $Q_{t}=c Q_{t}+I_{t}-M_{t}+\bar{A}_{t}$;

Imports

(2) $\quad \mathrm{M}_{\mathrm{t}}=\tilde{\mathrm{M}}_{0} \mathrm{Q}_{\mathrm{t}}\left(\mathrm{P}_{\mathrm{t}} / \mathrm{P}_{\mathrm{t}}^{\mathrm{e}}\right)^{\mathrm{e}} \mathrm{Uc}_{\mathrm{t}}{ }^{\mathrm{e}_{4}}$;

Employment

(3) $\mathrm{N}_{\mathrm{t}}=\overline{\mathrm{W}}_{0} \exp (-\mathrm{at}) \mathrm{Q}_{\mathrm{t}}$;

Investment

(4) $\mathrm{I}_{\mathrm{t}}=\mathrm{v}_{2}\left(\mathrm{Q}_{\mathrm{t}}-\mathrm{Q}_{\mathrm{t}-1}\right)+\theta\left(\mathrm{Q}_{\mathrm{t}} \frac{\mathrm{W}_{\mathrm{t}} \mathrm{N}_{\mathrm{t}}}{\mathrm{P}_{\mathrm{t}}}\right)$;

Wages

(5) $\quad \log \mathrm{W}_{\mathrm{t}}-\log \mathrm{W}_{\mathrm{t}-1}=\mathrm{g}_{1}\left(\log \mathrm{P}_{\mathrm{t}+1}-\log \mathrm{P}_{\mathrm{t}-1}\right)+\mathrm{g}_{2} \mathrm{Un}_{\mathrm{t}}+\mathrm{g}_{3}, \mathrm{~g}_{2}<0$;

Prices

(6) $\quad \log P_{t}-\log P_{t-1}=f_{1} U c_{t}+f_{2}\left(\log \frac{W_{t} N_{t}}{Q_{t}}-\log \frac{W_{t-1} N_{t-1}}{Q_{t-1}}\right)+f_{3}$;

\section{Unemployment rate}

(7) $\quad \mathrm{Un}_{\mathrm{t}}=1-\mathrm{N}_{\mathrm{t}} / \overline{\mathrm{N}}_{\mathrm{t}}$;

Capital

(8) $\mathrm{K}_{\mathrm{t}}-\mathrm{K}_{\mathrm{t}-1}=\mathrm{I}_{\mathrm{t}}$;

Production capacity

(9) $\overline{\mathrm{Q}}_{\mathrm{t}}=\mathrm{v}_{1} \mathrm{~K}_{\mathrm{t}}$; 


\section{Degree of production capacity utilization}

(10) $\quad \mathrm{Uc}_{\mathrm{t}}=\mathrm{Q}_{\mathrm{t}} / \overline{\mathrm{Q}}_{\mathrm{t}}$.

In such a model, the dynamics is often introduced in a quasi-automatic way in order to have the expected distinction between short run and long run, to obtain a good adequation of the model with the available series and to derive multipliers with natural interpretations. In a second step, it might be useful to have a more precise dynamic specification and in particular to build models distinguishing, for instance, the dynamics associated with expectations from the dynamics associated with growth or adjustment.

In the previous model, expectations might be introduced in several equations. For instance, investment might depend on the expected increase in production, the wage increase might depend on expected inflation,... If expectations are introduced in the model, we obtain a multivariate model in which each endogenous variable is expressed as a function of some other endogenous variables, of some expectations, of lagged exogenous and endogenous variables. Therefore, it seems important to extend the study of the previous chapters to the case of multivariate models with rational expectations. This problem has essentially been considered in the linear case [see e.g. Wallis (1980), Pesaran (1981,1987), Wegge (1984), Kollintzas (1985), Broze, Gouriéroux and Szafarz (1988)]. The one-dimensional solution methods can only be generalized in a simple way if some invertibility restrictions are imposed on the structural coefficient matrices. In practice, this is often not the case. If we examine for instance the core model previously described, we see that a number of variables do not appear in each equation. This implies that several structural coefficients are implicitly constrained to be equal to zero and this may introduce some partial recursivities into the system.

In Section 2, we first consider the straightforward extension of Cagan's model, i.e. of the model with future expectations. In the simple case, it is possible to understand why the univariate results have to be modified in the presence of recursivity.

In Section 3, we give the general form of a multivariate linear model with rational expectations and we discuss the possibility of writing an equivalent more tractable form. The principle is the analog of the state space representation of linear time series. This canonical representation is then used to describe a general solution method for rational expectations models (Section 4).

The results are applied in Section 5 to non-stationary solutions. In particular, we study the case of cointegrated series and establish a representation theorem, giving an equivalent error correction form of the model in the presence of rational expectations. 


\section{A simple case}

A multivariate model that is easy to handle is the straightforward extension of Cagan's model studied in Chapter 3. The endogenous vector $Y_{t}$ with $n$ components is expressed as a linear function of the future expectations $E\left[Y_{t+1} \mid I_{\mathrm{L}}\right]$ and of an additional term $\mathrm{U}_{\mathrm{t}}$ (with $\mathrm{n}$ components) summarizing all exogenous and disturbance effects. This model may be written :

$$
\text { (5.1) } Y_{t}=\pi E\left[Y_{t+1} \mid I_{t}\right]+U_{t} \text {, }
$$

where the matrix $\pi$ of structural coefficients is $\mathrm{n} \mathrm{n}$ and the information set contains past and current values of the various components of $\mathrm{Y}$.

Relation (5.1) may be considered as a simultaneous equation model. Each component $y_{t}^{(j)}$ of the endogenous vector $Y$ depends on the expectations $E\left[y_{t+1}^{(i)} \mid I_{t}\right]$, $\mathrm{i}=1, \ldots, \mathrm{n}$, of all the other components and generally simultaneity occurs since the expectations are held at the present date $\mathrm{t}$.

As an illustration, we can describe explicitly system (5.1) in the two-dimensional case. We obtain :

$$
\left\{\begin{array}{l}
y_{t}^{(1)}=\pi_{11} E\left[y_{t+1}^{(1)} \mid I_{t}\right]+\pi_{12} E\left[y_{t+1}^{(2)} \mid I_{t}\right]+u_{t}^{(1)} \\
y_{t}^{(2)}=\pi_{21} E\left[y_{t+1}^{(1)} \mid I_{t}\right]+\pi_{22} E\left[y_{t+1}^{(2)} \mid I_{t}\right]+u_{t}^{(2)}
\end{array} .\right.
$$

Such a system is more or less easy to solve depending on the values of the structural coefficients. Let us for instance assume that $\pi_{11}=\pi_{12}=\pi_{22}=0$. This condition implies that the matrix $\pi$ is strictly lower triangular and also nilpotent. In this recursive case, we obtain from the first equation :

$$
y_{t}^{(1)}=u_{t}^{(1)}
$$

Then it is possible to deduce the expectation : $\mathrm{E}\left[\mathrm{y}_{\mathrm{t}+1}^{(1)} \mid \mathrm{I}_{\mathrm{t}}\right]=\mathrm{E}\left[\mathrm{u}_{\mathrm{t}+1}^{(1)} \mid \mathrm{I}_{\mathrm{t}}\right]$, and, replacing in the second equation, the explicit expression for $y_{t}^{(2)}$ : 


$$
y_{t}^{(2)}=\pi_{21} E\left[u_{t+1}^{(1)} \mid I_{t}\right]+u_{t}^{(2)}
$$

Therefore, it seems natural in solving system (5.1) to take into account the possible block recursivities.

\section{2.a. The case without recursivities}

The endogenous variables are all simultaneously defined when the structural matrix $\pi$ is nonsingular. In this case, the solution method based on the prediction error (see Chapter 3) may be applied. It leads to the following reduced form :

$$
\mathrm{Y}_{\mathrm{t}}=\pi^{-1} \mathrm{Y}_{\mathrm{t}-1}-\pi^{-1} \mathrm{U}_{\mathrm{t}-1}+\varepsilon_{\mathrm{t}},
$$

where $\left(\varepsilon_{v}\right)$ is a n-dimensional vector with arbitrary martingale difference components.

\section{2.b. The special case of a nilpotent structural matrix}

The assumption that $\pi$ is invertible is quite strong. In many cases, $\pi$ has a large number of zero elements. Often only few expectations are taken into account, even when the model involves many variables. Technically, if $\pi$ is singular, new difficulties emerge. Consider, for instance, the case where $\pi$ is a nilpotent matrix of index $2\left(\pi^{2}=0\right)$. In this case, a forward-looking approach leads to the unique solution of the model :

$$
\begin{aligned}
Y_{t} & =\pi E\left[Y_{t+1} \mid I_{t}\right]+U_{t} \\
& =\pi E\left[\left(\pi E\left[Y_{t+2} \mid I_{t+1}\right]+U_{t+1}\right) \mid I_{t}\right]+U_{t} \\
& =\pi^{2} E\left[Y_{t+2} \mid I_{t}\right]+\pi E\left[U_{t+1} \mid I_{t}\right]+U_{t} \\
& =\pi E\left[U_{t+1} \mid I_{t}\right]+U_{t} .
\end{aligned}
$$

\section{2.c. The general case}

So we have shown that two extreme situations are possible: A n-dimensional solution set on the one hand, a unique solution on the other hand. Actually all the intermediate cases may occur. To obtain a reduced form valid for any matrix $\pi$, we may proceed on the following way. We first isolate a submodel of (5.1) in which a 
nonsingular matrix multiplies the expectation vector. Let $\mathrm{Q}$ be an invertible matrix such that $\mathrm{Q} \pi \mathrm{Q}^{-1}$ is the Jordan form of $\pi$ :

$$
\mathrm{Q} \pi \mathrm{Q}^{-1}=\left[\begin{array}{cc}
\mathrm{P} & \mathrm{O} \\
\mathrm{O} & \mathrm{N}
\end{array}\right] \text {, }
$$

where $\mathrm{N}$ is the block associated with the zero eigenvalue. If $\mathrm{K}_{2}$ denotes the number of zero eigenvalues of $\pi, N$ is a $K_{2}$-square nilpotent matrix and $P$ is a $K_{1}=\left(n-K_{2}\right)$-square invertible matrix. Let us then define :

$$
\mathrm{Y}_{\mathrm{t}}^{*}=\mathrm{QY} \mathrm{Y}_{\mathrm{t}}=\left[\begin{array}{c}
\mathrm{y}_{\mathrm{t}}{ }_{\mathrm{t}} \\
\mathrm{y}_{\mathrm{t}}^{*}
\end{array}\right], \mathrm{U}_{\mathrm{t}}^{*}=\mathrm{QU}_{\mathrm{t}}=\left[\begin{array}{c}
\mathrm{u}_{\mathrm{t}} \\
\mathrm{u}_{\mathrm{t}}
\end{array}\right] \text {, }
$$

where $\mathrm{y}^{* 1}$ and $\mathrm{u}^{* 1}$ are $\mathrm{K}_{1}$-dimensional.

Using this transformation, model (5.1) may be written as :

$$
\text { (5.2) }\left\{\begin{array}{l}
\mathrm{y}_{\mathrm{t}}^{*}=\mathrm{PE}\left[\mathrm{y}_{\mathrm{t}+1}^{*_{1}} \mid \mathrm{I}_{\mathrm{t}}\right]+\mathrm{u}_{\mathrm{t}}^{*} \\
\mathrm{y}_{\mathrm{t}}^{*_{2}}=\mathrm{NE}\left[\mathrm{y}_{\mathrm{t}+1}^{*_{2}} \mid \mathrm{I}_{\mathrm{t}}\right]+\mathrm{u}_{\mathrm{t}}^{*}
\end{array}\right.
$$

In this canonical form, the two blocks are totally separated. Each group of variables cannot be influenced by expectations of variables in the other group.

The reduction of the first group of equations is straightforward since P is invertible and the solution is obtained as in subsection 2.a. In the second group of equations, there is a nilpotent matrix $\mathrm{N}: \mathrm{N}^{\mathrm{K}_{2}}=0$. A forward-looking approach gives a unique solution :

$$
\begin{aligned}
y_{t}^{*}= & N E\left[y_{t+1}^{* 2} \mid I_{t}\right]+u_{t}^{* 2} \\
& =N^{2} E\left[y_{t+2}^{* 2} \mid I_{t}\right]+N E\left[u_{t+1}^{* 2} \mid I_{t}\right]+u_{t}^{* 2} \\
& \vdots \\
& \cdot \\
& =N^{K_{2}} E\left[y_{t+K_{2}}^{*} \mid I_{t}\right]+N^{K_{2}-1} E\left[u_{t+K_{2}-1}^{*} \mid I_{t}\right]+\ldots+u_{t}^{* 2}
\end{aligned}
$$




$$
=\sum_{k=0}^{K_{2}-1} N^{k} E\left[u_{t+k}^{* 2} \mid I_{t}\right] .
$$

The next property summarizes the results. It generalizes the method proposed by Pesaran (1981) when $\pi$ has an equivalent diagonal form.

Property (5.3) : The solutions of model (5.1) are given by :

$\mathrm{Y}_{\mathrm{t}}=\mathrm{Q}^{-1} \mathrm{Y}_{\mathrm{t}}^{*}$,

where $\mathrm{Y}^{*}$ verifies :

$$
\left\{\begin{array}{l}
\mathrm{y}_{\mathrm{t}}^{*_{1}}=\mathrm{P}^{-1} \mathrm{y}_{\mathrm{t}-1}^{*_{1}}-\mathrm{P}^{-1} \mathrm{u}_{\mathrm{t}-1}^{* 1}+\varepsilon_{\mathrm{t}}^{*}{ }^{*} \\
\mathrm{y}_{\mathrm{t}}^{*_{2}}=\sum_{\mathrm{k}=0}^{\mathrm{K}_{2}-1} \mathrm{~N}^{\mathrm{k}} \mathrm{E}\left[\mathrm{u}_{\mathrm{t}+\mathrm{k}}^{*} \mathrm{I}_{\mathrm{t}}\right]
\end{array}\right.
$$

and $\varepsilon^{* 1}$ is a vector with $\mathrm{K}_{1}$ arbitrary martingale difference components.

The two extreme cases mentioned at the beginning may be restated according to the general case. First, when $\pi$ is nonsingular $\left(K_{1}=n\right)$, $n$ arbitrary martingale differences enter the general solution. Secondly, when $\pi$ is nilpotent $\left(K_{1}=0\right)$, we have necessarily $\pi^{\mathrm{n}}=0$ and the solution is unique :

$$
Y_{t}=\sum_{k=0}^{n-1} \pi^{k} E\left[U_{t+k} \mid I_{t}\right] .
$$

In particular, if the model is globally recursive, it is possible after a permutation of variables to have for $\pi$ a strictly lower triangular matrix. In this case, the system may be written as :

$$
\begin{aligned}
& y_{t}^{(1)}=u_{t}^{(1)} \\
& y_{t}^{(2)}=\pi_{21} E\left[y_{t+1}^{(1)} \mid I_{t}\right]+u_{t}^{(2)} \\
& y_{t}^{(3)}=\pi_{31} E\left[y_{t+1}^{(1)} \mid I_{t}\right]+\pi_{32} E\left[y_{t+1}^{(2)} \mid I_{t}\right]+u_{t}^{(3)}
\end{aligned}
$$


and the unique solution may be directly computed by recursive substitutions.

$$
\begin{aligned}
& y_{t}^{(1)}=u_{t}^{(1)} \\
& y_{t}^{(2)}=\pi_{21} E\left[u_{t+1}^{(1)} \mid I_{t}\right]+u_{t}^{(2)}
\end{aligned}
$$

\section{The general model}

\section{3.a. Canonical forms}

The most general form of a linear simultaneous equations model with rational expectations is the following :

(5.4) $\sum_{k=0}^{K} \sum_{h=0}^{H} A_{k h} E\left[Y_{t+h-k} \mid I_{t-k}\right]=U_{t}$,

where $A_{k h}, k=0, \ldots K, h=0, \ldots H$ are $n \times n$ matrices. For a zero horizon $(h=0)$, expectations are equal to the actual variables :

$$
\mathrm{E}\left[\mathrm{Y}_{\mathrm{t}-\mathrm{k}} \mid \mathrm{I}_{\mathrm{t}-\mathrm{k}}\right]=\mathrm{Y}_{\mathrm{t}-\mathrm{k}}, \forall \mathrm{k}
$$

Consequently the corresponding terms in (5.4) give the current endogenous variables for $h=k=0$ and the lagged endogenous variables for $h=0$ and $k \geq 1$. The usual restriction that $\mathrm{A}_{00}$ is regular ensures that the model defines without ambiguity the current terms as functions of lagged values, expectations and disturbances.

In order to determine canonical forms of model (5.4) including for instance less distinct expectation terms, we may introduce a 'state vector' which summarizes these expectations. Let us define the following vector composed of all expectations held at time $\mathrm{t}$ appearing in the model : 
(5.5) $\mathrm{Z}_{\mathrm{t}}=\left[\begin{array}{c}\mathrm{Y}_{\mathrm{t}} \\ \mathrm{E}\left[\mathrm{Y}_{\mathrm{t}+1} \mid \mathrm{I}_{\mathrm{t}}\right] \\ \dot{\mathrm{C}} \\ \mathrm{E}\left[\mathrm{Y}_{\mathrm{t}+\mathrm{H}} \mid \mathrm{I}_{\mathrm{t}}\right]\end{array}\right]$.

The size of $\mathrm{Z}_{\mathrm{t}}$ is $\mathrm{N}=\mathrm{n}(\mathrm{H}+1)$. With the use of (5.5), model (5.4) may be rewritten equivalently as :

$$
\begin{aligned}
& \text { (5.6) }\left[\begin{array}{cccc}
\mathrm{A}_{00} & \mathrm{~A}_{01} & \ldots & \mathrm{A}_{0 \mathrm{H}} \\
0 & \mathrm{Id} & \ldots & 0 \\
\ldots & \ldots & \ldots & \ldots \\
0 & \ldots & \ldots & \mathrm{Id}
\end{array}\right] \mathrm{Z}_{\mathrm{t}}+\sum_{\mathrm{k}=1}^{K}\left[\begin{array}{ccc}
\mathrm{A}_{\mathrm{k} 0} & \mathrm{~A}_{\mathrm{k} 1} \ldots & \mathrm{A}_{\mathrm{kH}} \\
0 &
\end{array}\right] \mathrm{Z}_{\mathrm{t}-\mathrm{k}} \\
& +\left[\begin{array}{cccc}
0 & 0 & \ldots & 0 \\
-\operatorname{Id} & 0 & \ldots & 0 \\
0 & \ldots & -\mathrm{Id} & 0
\end{array}\right] \quad \mathrm{E}\left[\mathrm{Z}_{\mathrm{t}+1} \mid \mathrm{I}_{\mathrm{t}}\right]=\left[\begin{array}{c}
\mathrm{U}_{\mathrm{t}} \\
0 \\
\ldots \\
0
\end{array}\right]
\end{aligned}
$$

or with obvious notations :

(5.7) $\Gamma_{0} \mathrm{Z}_{\mathrm{t}}+\Gamma_{1} \mathrm{Z}_{\mathrm{t}-1}+\ldots+\Gamma_{\mathrm{K}} \mathrm{Z}_{\mathrm{t}-\mathrm{K}}+\Gamma_{-1} \mathrm{E}\left[\mathrm{Z}_{\mathrm{t}+1} \mid \mathrm{I}_{\mathrm{t}}\right]=\mathrm{V}_{\mathrm{t}}$.

This introduction of the state-vector $\mathrm{Z}$ thus leads to an equivalent form of the initial model that only includes a one-period-ahead expectation term. In other words, we have reduced the maximum horizon of the model from $\mathrm{H}$ to 1 . Of course, this is compensated by an increase in the size of the system. Finally we can note that, in the canonical form, coefficient $\Gamma_{0}$ is still a regular matrix.

Property (5.8) : $\quad$ Any linear rational expectations model may be written in a canonical form including lagged terms and only a one-periodahead expectation term.

The previous reduction is specific to rational expectations models. We may now pursue this reduction in the usual way by diminishing the number of lags in the model. To this end, let us introduce a second state-vector denoted by $X$ having the size $n(H+1) K$ : 


$$
\text { (5.9) } \mathrm{X}_{\mathrm{t}}=\left[\begin{array}{l}
\mathrm{z} \\
\mathrm{z}_{\mathrm{t}-1} \\
\mathrm{z}_{\mathrm{t}-\mathrm{K}+1}
\end{array}\right]
$$

From (5.7), we then obtain :

$$
\begin{aligned}
& {\left[\begin{array}{cccc}
\Gamma_{0} & \Gamma_{1} & \ldots & \Gamma_{\mathrm{K}-1} \\
0 & \mathrm{Id} & \ldots & 0 \\
\ldots & \ldots & \ldots & \ldots \\
0 & 0 & \ldots & \mathrm{Id}
\end{array}\right] \mathrm{X}_{\mathrm{t}}+\left[\begin{array}{ccccc}
0 & 0 & \ldots & 0 & \Gamma_{\mathrm{K}} \\
-\mathrm{Id} & 0 & \ldots & \ldots & 0 \\
\ldots & \ldots & \ldots & \ldots & \ldots \\
0 & \ldots & & -\mathrm{Id} & 0
\end{array}\right] \mathrm{X}_{\mathrm{t}-1}} \\
& +\left[\begin{array}{c}
\Gamma_{-1} 0 \ldots . \\
0
\end{array}\right] \mathrm{E}\left[\mathrm{X}_{\mathrm{t}+1} \mid \mathrm{I}_{\mathrm{t}}\right]=\left[\begin{array}{c}
\mathrm{V}_{\mathrm{t}} \\
0 \\
\ldots \\
0
\end{array}\right]
\end{aligned}
$$

Again obvious notations are used to rewrite (5.10) as :

$$
\Lambda_{0} \mathrm{X}_{\mathrm{t}}+\Lambda_{1} \mathrm{X}_{\mathrm{t}-1}+\Lambda_{-1} \mathrm{E}\left[\mathrm{X}_{\mathrm{t}+1} \mid \mathrm{I}_{\mathrm{t}}\right]=\mathrm{W}_{\mathrm{t}}
$$

In this expression only one lagged endogenous variable and one rational expectation are still present. Also, the matrix $\Lambda_{0}$ that multiplies the current endogenous variable is invertible.

Property (5.11) : Any linear rational expectations model may be written in a canonical form including only one lagged term and only a oneperiod-ahead expectation term.

To illustrate the determination of canonical forms, let us consider an example. In order to clarify the derivations, we start from a univariate model :

$$
\begin{aligned}
y_{t}= & a_{10} y_{t-1}+a_{20} y_{t-2}+a_{01} E\left[y_{t+1} \mid I_{t}\right]+a_{02} E\left[y_{t+2} \mid I_{t}\right] \\
& +a_{21} E\left[y_{t-1} \mid I_{t-2}\right]+a_{12} E\left[y_{t+1} \mid I_{t-1}\right]+u_{t} .
\end{aligned}
$$


For this model, the maximum horizon $\mathrm{H}$ is equal to 2 and the maximum $\operatorname{lag} \mathrm{K}$ is also equal to 2 . The first state vector $\mathrm{Z}$ is thus given by :

$$
Z_{t}=\left[\begin{array}{c}
y_{t} \\
E\left[y_{t+1} \mid I_{t}\right] \\
E\left[y_{t+2} \mid I_{t}\right]
\end{array}\right],
$$

and the model may be put in the following form

$$
\begin{aligned}
& {\left[\begin{array}{ccc}
-1 & a_{01} & a_{02} \\
0 & 1 & 0 \\
0 & 0 & 1
\end{array}\right] \mathrm{Z}_{\mathrm{t}}+\left[\begin{array}{ccc}
\mathrm{a}_{10} & 0 & \mathrm{a}_{12} \\
0 & 0 & 0 \\
0 & 0 & 0
\end{array}\right] \mathrm{Z}_{\mathrm{t}-1}} \\
& +\left[\begin{array}{ccc}
\mathrm{a}_{20} & \mathrm{a}_{21} & 0 \\
0 & 0 & 0 \\
0 & 0 & 0
\end{array}\right] \mathrm{Z}_{\mathrm{t}-2}+\left[\begin{array}{rcc}
0 & 0 & 0 \\
-1 & 0 & 0 \\
0 & -1 & 0
\end{array}\right] \mathrm{E}\left[\mathrm{Z}_{\mathrm{t}+1} \mid \mathrm{I}_{\mathrm{t}}\right]=\left[\begin{array}{l}
\mathrm{u}_{\mathrm{t}} \\
0 \\
0
\end{array}\right] .
\end{aligned}
$$

Let us now define the second state-vector $\mathrm{X}$ by :

$$
X_{t}=\left[\begin{array}{c}
Z_{t} \\
Z_{t-1}
\end{array}\right] \text {. }
$$

This vector has 6 scalar components and leads to the system :

$$
\begin{aligned}
& {\left[\begin{array}{rrrrrr}
-1 & a_{01} & a_{02} & a_{10} & 0 & a_{12} \\
0 & 1 & 0 & 0 & 0 & 0 \\
0 & 0 & 1 & 0 & 0 & 0 \\
0 & 0 & 0 & 1 & 0 & 0 \\
0 & 0 & 0 & 0 & 1 & 0 \\
0 & 0 & 0 & 0 & 0 & 1
\end{array}\right] \mathrm{X}_{\mathrm{t}}+\left[\begin{array}{rrrrrr}
0 & 0 & 0 & \mathrm{a}_{20} & \mathrm{a}_{21} & 0 \\
0 & 0 & 0 & 0 & 0 & 0 \\
0 & 0 & 0 & 0 & 0 & 0 \\
-1 & 0 & 0 & 0 & 0 & 0 \\
0 & -1 & 0 & 0 & 0 & 0 \\
0 & 0 & -1 & 0 & 0 & 0
\end{array}\right] \mathrm{X}_{\mathrm{t}-1}} \\
& +\left[\begin{array}{rrrrrr}
0 & 0 & 0 & 0 & 0 & 0 \\
-1 & 0 & 0 & 0 & 0 & 0 \\
0 & -1 & 0 & 0 & 0 & 0 \\
0 & 0 & 0 & 0 & 0 & 0 \\
0 & 0 & 0 & 0 & 0 & 0 \\
0 & 0 & 0 & 0 & 0 & 0
\end{array}\right] \mathrm{E}\left[\mathrm{X}_{\mathrm{t}+1} \mid \mathrm{I}_{\mathrm{t}}\right]=\left[\begin{array}{l}
\mathrm{u}_{\mathrm{t}} \\
0 \\
0 \\
0 \\
0 \\
0
\end{array}\right]
\end{aligned}
$$


This canonical form of the initial model only includes two scalar one-period-ahead expectation terms. Of course, the counterpart of the simplification in the structure of the system lies in its dimension. However, numerous zero-restrictions and normalization restrictions have been introduced on the elements of the coefficient matrices.

\section{3.b. Reduction of the canonical form}

It is obviously equivalent to determine the endogenous processes verifying either the initial model (5.4) or one of its canonical forms, (5.7) or (5.10). In this section we will develop a reduction method for the simplest canonical form, i.e. canonical form (5.10). The next section will go back to the original model and apply a direct method. We thus propose two different (and theoretically equivalent) answers to the problem of solving the initial model.

Let us now focus on system (5.10) which is given by :

$$
\Lambda_{0} \mathrm{X}_{\mathrm{t}}+\Lambda_{1} \mathrm{X}_{\mathrm{t}-1}+\Lambda_{-1} \mathrm{E}\left[\mathrm{X}_{\mathrm{t}+1} \mid \mathrm{I}_{\mathrm{t}}\right]=\mathrm{W}_{\mathrm{t}}
$$

where $\Lambda_{0}$ is invertible.

We will here use the adjoint operator method. This method is carried out in two steps :

i) The first step involves replacement of the expectation in terms of the corresponding realization. Like in the univariate case, we introduce the predictor error process on $\mathrm{X}$ denoted by $\eta$ :

$$
\eta_{\mathrm{t}}=\mathrm{X}_{\mathrm{t}}-\mathrm{E}\left[\mathrm{X}_{\mathrm{t}} \mid \mathrm{I}_{\mathrm{t}-1}\right]
$$

Each component of $\eta$ is a martingale difference. Substituting the expectation in (5.10) yields :

$$
\Lambda_{0} \mathrm{X}_{\mathrm{t}}+\Lambda_{1} \mathrm{X}_{\mathrm{t}-1}+\Lambda_{-1} \mathrm{X}_{\mathrm{t}+1}=\mathrm{W}_{\mathrm{t}}+\Lambda_{-1} \eta_{\mathrm{t}+1}
$$

By lagging this relation and by using operator notation, we have :

$$
\left(\Lambda_{-1}+\Lambda_{0} L+\Lambda_{1} L^{2}\right) X_{t}=W_{t-1}+\Lambda_{-1} \eta_{t}
$$


ii) The second step of the reduction introduces the adjoint matrix, denoted by $\Pi(\mathrm{L})$, of the matrix polynomial $\Lambda_{-1}+\Lambda_{0} L+\Lambda_{1} L^{2}$. By applying the operator $\Pi(L)$ to both sides of equation (5.15) and by rewriting the determinant of $\Lambda_{-1}+\Lambda_{0} L+\Lambda_{1} L^{2}$ as $\mathrm{L}^{\mathrm{G}} \varphi(\mathrm{L})$, with $\varphi(0) \neq 0$, we obtain :

$$
\begin{aligned}
& \mathrm{L}^{\mathrm{G}} \varphi(\mathrm{L}) \mathrm{X}_{\mathrm{t}}=\Pi(\mathrm{L}) \Lambda_{-1} \eta_{\mathrm{t}}+\Pi(\mathrm{L}) \mathrm{W}_{\mathrm{t}-1} \\
& \Leftrightarrow \quad \mathrm{L}^{\mathrm{G}} \varphi(\mathrm{L}) \mathrm{X}_{\mathrm{t}}=\mathrm{L}^{\mathrm{G}} \varphi(\mathrm{L}) \eta_{\mathrm{t}}-\Pi(\mathrm{L})\left[\Lambda_{0} \mathrm{~L}+\Lambda_{1} \mathrm{~L}^{2}\right] \eta_{\mathrm{t}}+\Pi(\mathrm{L}) \mathrm{W}_{\mathrm{t}-1} \\
& \Leftrightarrow \quad \varphi(L)\left(X_{t}-\eta_{t}\right)=-\Pi(L)\left[\Lambda_{0} L+\Lambda_{1} L^{2}\right] \eta_{t+G}+\Pi(L) W_{t+G-1} .
\end{aligned}
$$

Since the series $\varphi(\mathrm{L})$ only includes positive powers of $\mathrm{L}$ and since $\mathrm{X}_{\mathrm{t}}-\eta_{\mathrm{t}}$ only depends on the information set $\mathrm{I}_{\mathrm{t}-1}$, both sides of the last equation depend only on the information set $I_{t-1}$. It follows that the prediction error process $\left(\eta_{t}\right)$ is constrained, not only by the martingale difference restriction, but also by the relation :

$$
\begin{aligned}
& E\left[-\Pi(L)\left[\Lambda_{0} L+\Lambda_{1} L^{2}\right] \eta_{t+G}+\Pi(L) W_{t+G-1} \mid I_{t-1}\right] \\
= & -\Pi(L)\left[\Lambda_{0} L+\Lambda_{1} L^{2}\right] \eta_{t+G}+\Pi(L) W_{t+G-1}, \forall t .
\end{aligned}
$$

It may be shown [Broze, Gouriéroux and Szafarz (1988)] that both conditions (5.14) and (5.16) and the martingale difference property provide a characterization of the solution set of model (5.7). More precisely, we have the following result.

Property (5.17) : All the solutions of the rational expectations model (5.7) are obtained by taking the martingale differences $\eta$ that fulfill (5.16) and by solving all the associated difference equations systems :

$$
\Lambda_{0} \mathrm{X}_{\mathrm{t}-1}+\Lambda_{1} \mathrm{X}_{\mathrm{t}-2}+\Lambda_{-1} \mathrm{X}_{\mathrm{t}}=\mathrm{W}_{\mathrm{t}-1}+\Lambda_{-1} \eta_{\mathrm{t}}
$$

Consequently, for solving a rational expectation system, one needs to solve many difference equation systems. Actually, each of the latter systems is characterized by the process $\eta$ entering its RHS. There are thus as many systems as there are admissible $\eta$ 's, i.e. martingale differences fulfilling (5.16). Generally these restrictions still leave an infinite set of possibilities. Therefore, we obtain an infinite set of difference equation systems and subsequently an infinite set of solutions to the rational expectations model. 
The dimension of this set may be evaluated by enumerating the independent constraints imposed on the components of the vector $\eta$. Let us first write these constraints in an explicit way. We introduce the matrices $D_{0}, D_{1}, \ldots D_{k}, \ldots$ such that :

$$
D_{0}+D_{1} L+\ldots+D_{k} L^{k}+\ldots=-\Pi(L)\left(\Lambda_{0}+\Lambda_{1} L\right)
$$

The constraints imposed by (5.16) are :

$$
\begin{aligned}
& E\left[\left(D_{0}+D_{1} L+\ldots+D_{k} L^{k}+\ldots\right) \eta_{t+G-1}+\Pi(L) W_{t+G-1} \mid I_{t-1}\right] \\
& =\left(D_{0}+D_{1} L+\ldots+D_{k} L^{k}+\ldots\right) \eta_{t+G-1}+\Pi(L) W_{t+G-1} .
\end{aligned}
$$

Since $\eta_{\mathrm{t}}$ is not correlated with past variables, we may deduce the following equivalent system of restrictions :

$$
\left\{\begin{array}{l}
D_{0} \eta_{t+G-1}+\Pi(L) W_{t+G-1}-E\left[\Pi(L) W_{t+G-1} \mid I_{t+G-2}\right]=0 \\
D_{1} \eta_{t+G-2}+E\left[\Pi(L) W_{t+G-1} \mid I_{t+G-2}\right]-E\left[\Pi(L) W_{t+G-1} \mid I_{t+G-3}\right]=0 \\
\cdots \\
D_{G-1} \eta_{t}+E\left[\Pi(L) W_{t+G-1} \mid I_{t}\right]-E\left[\Pi(L) W_{t+G-1} \mid I_{t-1}\right]=0
\end{array}\right.
$$

This system only includes linear constraints on the prediction error $\eta$ by linking it to predictions of exogenous factors. Since all equations in the system hold for any time t, we may bring together the ones that are associated with the current value $\eta_{\mathrm{t}}$. In so doing, we obtain a system in which the LHS is $\left[\mathrm{D}_{0}, \mathrm{D}_{1}, \ldots, \mathrm{D}_{\mathrm{G}-1}\right] \eta_{\mathrm{t}}$. Consequently, the number of independent constraints is equal to the rank of $\left[\mathrm{D}_{0}, \mathrm{D}_{1}, \ldots, \mathrm{D}_{\mathrm{G}-1}\right]$. The value taken by this rank obviously depends on the restrictions imposed on the structural parameters of the model.

\section{3.c. Reduction of the general model}

In its initial form, the general linear multivariate rational expectations model is given by :

$$
\sum_{k=0}^{K} \sum_{h=0}^{H} A_{k h} E\left[Y_{t+h-k} \mid I_{t-k}\right]=U_{t},
$$


where the endogenous vector $\mathrm{Y}_{\mathrm{t}}$ has $\mathrm{n}$ components.

In the previous subsection, we have solved out the initial model by making use of its canonical form. It is possible to introduce along the same lines a direct solution method. To understand this method, let us first examine the endogenous vector $\mathrm{X}_{\mathrm{t}}$ appearing in the canonical form. This vector has $\mathrm{n}(\mathrm{H}+1) \mathrm{K}$ components and has been defined by :

$$
\mathrm{X}_{\mathrm{t}}=\left[\begin{array}{c}
\mathrm{Z}_{\mathrm{t}} \\
\mathrm{Z}_{\mathrm{t}-1} \\
\cdots \\
\mathrm{Z}_{\mathrm{t}-\mathrm{K}+1}
\end{array}\right] \text { with } \mathrm{Z}_{\mathrm{t}}=\left[\begin{array}{c}
\mathrm{Y}_{\mathrm{t}} \\
\mathrm{E}\left[\mathrm{Y}_{\mathrm{t}+1} \mid \mathrm{I}_{\mathrm{t}}\right] \\
\cdots \\
\mathrm{E}\left[\mathrm{Y}_{\mathrm{t}+\mathrm{H}} \mid \mathrm{I}_{\mathrm{t}}\right]
\end{array}\right]
$$

According to this definition, the vector $\eta_{\mathrm{t}}$ representing the prediction error on $\mathrm{X}_{\mathrm{t}}$ is given by :

$$
\eta_{\mathrm{t}}=\left[\begin{array}{c}
\mathrm{Z}_{\mathrm{t}}-\mathrm{E}\left[\mathrm{Z}_{\mathrm{t}} \mid \mathrm{I}_{\mathrm{t}-1}\right] \\
0 \\
\cdots \\
0
\end{array}\right]
$$

with $Z_{t}-E\left[Z_{t} \mid I_{t-1}\right]=\left[\begin{array}{c}Y_{t}-E\left[Y_{t} \mid I_{t-1}\right] \\ E\left[Y_{t+1} \mid I_{t}\right]-E\left[Y_{t+1} \mid I_{t-1}\right] \\ \cdots \\ E\left[Y_{t+H} \mid I_{t}\right]-E\left[Y_{t+H} \mid I_{t-1}\right]\end{array}\right]$.

Thus the components of $\eta_{\mathrm{t}}$ are the updating terms corresponding to the original process $\mathrm{Y}$ (the first one being the prediction error over one period) : 


$$
\begin{aligned}
& \varepsilon_{\mathrm{t}}^{0}=\mathrm{Y}_{\mathrm{t}}-\mathrm{E}\left[\mathrm{Y}_{\mathrm{t}} \mid \mathrm{I}_{\mathrm{t}-1}\right], \\
& \ldots \\
& \varepsilon_{\mathrm{t}}^{\mathrm{h}}=\mathrm{E}\left[\mathrm{Y}_{\mathrm{t}+\mathrm{h}} \mid \mathrm{I}_{\mathrm{l}}\right]-\mathrm{E}\left[\mathrm{Y}_{\mathrm{t}+\mathrm{h}} \mid \mathrm{I}_{\mathrm{t}-1}\right], \mathrm{h} \geq 1 .
\end{aligned}
$$

Therefore, in order to solve directly the initial model, it is natural to replace in model (5.4) the expectations in terms of the realizations. For this purpose we use one-period-ahead prediction errors as well as updating terms. Indeed, for $h \geq 1$, we have :

$$
E\left[Y_{t+h-k} \mid I_{t-k}\right]=Y_{t+h-k}-\sum_{j=0}^{h-1} \varepsilon_{t+h-k-j}^{j}
$$

After replacement in the initial model, we obtain (with the convention $\sum_{j=0}^{-1} \cdot=0$ ) :

$$
\sum_{k=0}^{K} \sum_{h=0}^{H} A_{k h}\left[Y_{t+h-k}-\sum_{j=0}^{h-1} \varepsilon_{t+h-k-j}^{j}\right]=U_{t} .
$$

This form is equivalent to :

(5.18) $\tilde{\mathrm{A}}(\mathrm{L}) \mathrm{Y}_{\mathrm{t}+\mathrm{H}}=\sum_{\mathrm{k}=0}^{\mathrm{K}} \sum_{\mathrm{h}=1}^{\mathrm{H}} \mathrm{A}_{\mathrm{kh}} \sum_{\mathrm{j}=0}^{\mathrm{h}-1} \varepsilon_{\mathrm{t}+\mathrm{h}-\mathrm{k}-\mathrm{j}}^{\mathrm{j}}+\mathrm{U}_{\mathrm{t}}$,

where: $\tilde{A}(L)=L^{-H} A(L)$ and $A(L)=\sum_{k=0}^{K} \sum_{h=0}^{H} A_{k h} L^{k-h}$.

Following the adjoint operator method, we now introduce the matrix $\tilde{\Pi}(\mathrm{L})$ such that $\tilde{\Pi}(L) \tilde{A}(L)=L \tilde{G} \tilde{\varphi}(L)$ Id, with $\tilde{\varphi}(0) \neq 0$. Then by multiplying both sides of $(5.18)$ by $\tilde{\Pi}(\mathrm{L})$, we obtain :

$$
\mathrm{L}^{\tilde{G}} \tilde{\varphi}(\mathrm{L}) \mathrm{Y}_{\mathrm{t}}=\tilde{\Pi}(\mathrm{L}) \mathrm{U}_{\mathrm{t}-\mathrm{H}}+\tilde{\Pi}(\mathrm{L}) \sum_{\mathrm{k}=0}^{\mathrm{K}} \sum_{\mathrm{h}=1}^{\mathrm{H}} \mathrm{A}_{\mathrm{kh}} \sum_{\mathrm{j}=0}^{\mathrm{h}-1} \varepsilon_{\mathrm{t}+\mathrm{h}-\mathrm{H}-\mathrm{k}-\mathrm{j}}^{\mathrm{j}}
$$


The LHS of this system only depends on the information set $\mathrm{I}_{\mathrm{t}-\mathrm{G}} \tilde{\mathrm{G}}$. The same must then be true for the RHS. This constraint leads to the following restrictions imposed on the successive updating terms :

$$
\begin{aligned}
& E\left[\tilde{\Pi}(L) U_{t-H}+\tilde{\Pi}(L) \sum_{k=0}^{K} \sum_{h=1}^{H} A_{k h} \sum_{j=0}^{h-1} \varepsilon_{t+h-H-k-j}^{j} \mid I_{t-\tilde{G}}\right] \\
& =\tilde{\Pi}(L) U_{t-H}+\tilde{\Pi}(L) \sum_{k=0}^{K} \sum_{h=1}^{H} A_{k h} \sum_{j=0}^{h-1} \varepsilon_{t+h-H-k-j^{*}}^{j}
\end{aligned}
$$

Property (5.20) : All the solutions of the rational expectations model (5.4) are obtained by taking the martingale differences $\varepsilon^{0}, \ldots, \varepsilon^{\mathrm{H}-1}$ (interpreted as updating processes) that fulfill (5.19) and solving all the associated difference equation systems :

$$
\widetilde{A}(L) Y_{t}=U_{t}+\sum_{k=0}^{K} \sum_{h=1}^{H} A_{k h} \sum_{j=0}^{h-1} \varepsilon_{t+h-k-j}^{j}
$$

The rank of system (5.19) giving the linear constraints varies according to the structure of the model. Since this rank gives the number of independent constraints imposed on $\varepsilon^{0}, \ldots, \varepsilon^{\mathrm{H}-1}$ and consequently the degree of multiplicity of the solution set of (5.4), we call the degree of multiplicity the number of scalar martingale differences that may be chosen arbitrarily. This number is equal to $\mathrm{n} \mathrm{H}$ minus the rank of system (5.19). The following result concerning the degree of multiplicity can be derived [Broze, Gouriéroux and Szafarz (1988)].

Property (5.21) : If the structural parameters $\mathrm{A}_{\mathrm{kh}}, \mathrm{k}=0, \ldots, \mathrm{K}, \mathrm{h}=0, \ldots, \mathrm{H}$, are only subject to exclusion restrictions, the degree of multiplicity is equal to $\mathrm{n} \mathrm{H}-\mathrm{G}$ where $\mathrm{n}$ is the size of the vector $\mathrm{Y}, \mathrm{H}$ is the maximum horizon of the model and $\mathrm{G}$ is the number of zeroroots of the characteristic equation det $\widetilde{\mathrm{A}}(\mathrm{L})=0$.

Actually it is equivalent to solve directly system (5.4) or to first apply a statevector transformation and then reduce the simpler canonical form. In both cases, the general solution has the same expression. The difference only lies in the technical steps of the derivation. 


\section{3.d. Linear stationary solutions}

We now assume that the exogenous process admits an ARMA representation based on an independent white noise :

$$
\Phi(L) U_{t}=\Theta(L) \varepsilon_{t},
$$

where the degrees of $\Phi$ and $\Theta$ are respectively p and q.

Let us search for the solutions to (5.4) admitting a moving-average form based on the same noise $\varepsilon$, i.e. the solutions that may be written as :

$$
Y_{t=} \sum_{j=0}^{\infty} C_{j} \varepsilon_{t-j}
$$

For these processes, the successive updating terms are given by :

$$
\varepsilon_{\mathrm{i}}^{j^{\prime}}=C_{j} \varepsilon_{\mathrm{t}}
$$

Leaving aside the constraints, we know that any such solution satisfies the following system :

$$
\tilde{A}(L) Y_{t}=U_{t}+\sum_{k=0}^{K} \sum_{h=1}^{H} A_{k h} \sum_{j=0}^{h-1} \varepsilon_{t+h-k-j}^{j}
$$

Consequently it necessarily satisfies :

$$
\begin{aligned}
& \tilde{A}(L) Y_{t}=\Phi^{-1}(L) \Theta(L) \varepsilon_{t}+\sum_{k=0}^{K} \sum_{h=1}^{H} A_{k h} \sum_{j=0}^{h-1} C_{j} \varepsilon_{t+h-k-j}, \\
& \Phi(L) \tilde{A}(L) Y_{t}=\Theta(L) L^{H} \varepsilon_{t}+\Phi(L) \sum_{k=0}^{K} \sum_{h=1}^{H} A_{k h} \sum_{j=0}^{h-1} C_{j} L^{H-h+k+j} \varepsilon_{t} .
\end{aligned}
$$

With reference to this expression, we may compute the orders of the ARMA representation of the process $\mathrm{Y}$. 
Property (5.23) : If the exogenous process $U$ in (5.4) has an ARMA (p, q) representation $\Phi(L) U_{t}=\Theta(L) \varepsilon_{t}$, then all the linear stationary solutions of the model have an ARMA representation such that :

(i) the autoregressive polynomial is $\Phi(\mathrm{L}) \widetilde{\mathrm{A}}(\mathrm{L})$;

(ii) the moving-average polynomial has a degree smaller than or equal to $\operatorname{Max}\{\mathrm{q}+\mathrm{H}, \mathrm{p}+\mathrm{H}+\mathrm{K}-1\}$;

(iii) the parameters $\mathrm{Cj}$ may be expressed as functions of the first $\mathrm{H}$ parameters $\mathrm{C}_{0}, \ldots \mathrm{C}_{\mathrm{H}-1}$ and the structural parameters $\Phi, \Theta$ and A kh.

Actually (iii) allows for taking into account (5.22) as well as the system of constraints (5.19). Note also that property (5.23) does not ensure existence of a linear stationary solution. As we know from Chapter 4, even in the case of a univariate model, such solutions may not exist.

\section{Rational expectations and non-stationary models}

Previously we have often considered stationary solutions of rational expectations models. Obviously such an approach makes sense only when the processes of interest may present a stationary evolution. This will be the case of variables expressing growth rates, for instance the inflation rate or exchange rates movements. Other examples are provided by the variables measuring a disequilibrium, such as the rate of unemployment and the excess production capacity, or more generally, by any variable expressed as a deviation from an equilibrium value.

On the other hand, it is sometimes interesting to formulate models that include real variables instead of growth rates. In particular this is important if one is concerned with the study of the growth paths of the economy. In such a case, the model should necessarily lead to non-stationary solutions.

In the first subsection, we recall the usual modelling for non-stationary series, and some characteristics of joint series of this kind. Subsequently, we introduce the notion of cointegrated series and the error correction representation of a non-stationary dynamic model.

The second subsection is concerned with a rational expectations model for which the corresponding perfect foresight model admits non-stationary solutions. We show that 
the linear solutions of the rational expectations model are also non-stationary. Furthermore, these solutions have the same long-term properties as the solutions of the perfect foresight model. Finally we give the error correction form of the rational expectations model.

\section{4.a. Decomposition of an ARIMA series and cointegration}

\section{(i) The VAR model}

The theory of non-stationary series has mostly been developed for series having a polynomial trend. This approach allows the taking into account of exponential growth, after having log-transformed the original series.

Such polynomial series are usually modelled by means of vector-autoregressive (VAR) representations :

(5.24) $\Phi(L) Y_{t}=\varepsilon_{t}, t \geq 0 ; Y_{t}=0$ for $t<0$.

The components of the vector $\mathrm{Y}_{\mathrm{t}}$ are the observations of the various series at each date. The size of $\mathrm{Y}_{\mathrm{t}}$ is equal to the number, $\mathrm{n}$, of variables appearing in the model. The operator $\Phi(\mathrm{L})$ is a lag-polynomial of order p with matrix coefficients, each of them having the size $\mathrm{n} \times \mathrm{m}$. $\varepsilon$ denotes a $\mathrm{n}$-dimensional white noise having an invertible covariance matrix. It follows that the components of the noise are not multicollinear.

In expression (5.24), each variable $\mathrm{Y}_{\mathrm{it}}$ is given in terms of the current values of the other variables, the past values of all the variables and an error term.

From the autoregressive representation, other equivalent formulations may be deduced. For instance, let us introduce the adjoint matrix of $\Phi(\mathrm{L})$ which is denoted by $\Phi^{*}(\mathrm{~L})$. By multiplying both sides of $(5.24)$ by $\Phi^{*}(\mathrm{~L})$, we obtain :

(5.25) $\operatorname{det} \Phi(\mathrm{L}) \mathrm{Y}_{\mathrm{t}}=\Phi^{*}(\mathrm{~L}) \varepsilon_{\mathrm{t}}, \mathrm{t} \geq 0$.

This system may be written equation by equation. The $\mathrm{i}^{\text {th }}$ equation is :

$$
\operatorname{det} \Phi(\mathrm{L}) \mathrm{Y}_{\mathrm{it}}=\Phi_{\mathrm{i}}^{*}(\mathrm{~L}) \varepsilon_{\mathrm{t}}
$$




$$
\Leftrightarrow Y_{i t}=\frac{\Phi_{i}^{*}(L)}{\operatorname{det} \Phi(L)} \quad \tilde{\varepsilon}_{t} \text {, where } \tilde{\varepsilon}_{t}= \begin{cases}\varepsilon_{t} & \text { if } t \geq 0, \\ 0 & \text { otherwise. }\end{cases}
$$

Consequently the $i^{\text {th }}$ series has an ARMA form. In order to include some non-stationarity in the series, we assume that the autoregressive part of this ARMA form has a root equal to 1 . If the same assumption applies to all the components of $\mathrm{Y}$, then every $\left(\mathrm{Y}_{\mathrm{it}}, \mathrm{i}=1, \ldots \mathrm{n}\right)$, is a non-stationary process, while every differenciated series $\left(\mathrm{Y}_{\mathrm{it}}-\mathrm{Y}_{\mathrm{i}, \mathrm{l}-1}\right), \mathrm{i}=1, \ldots \mathrm{n}$ is stationary. The original system may then be rewritten as :

$$
\text { (5.26) (1-L) } \mathrm{Y}_{\mathrm{t}}=\mathrm{H}(\mathrm{L}) \tilde{\varepsilon}_{\mathrm{t}} \text {, }
$$

where the $\mathrm{i}^{\text {th }}$ row of the operator $\mathrm{H}(\mathrm{L})$ is given by :

$$
\mathrm{H}_{\mathrm{i}}(\mathrm{L})=\frac{\Phi_{\mathrm{i}}^{*}(\mathrm{~L})(1-\mathrm{L})}{\operatorname{det} \Phi(\mathrm{L})}
$$

The elements of this $i^{\text {th }}$ row are taken to be such that $H_{i}(L)$ is not divisible by (1-L). (Otherwise the ARMA representation of the $\mathrm{i}^{\text {th }}$ series would admit a double unit root for its autoregressive part, this situation being excluded here). The series $\left(\mathrm{Y}_{\mathrm{it}}\right)$, $\mathrm{i}=1 \ldots \mathrm{n}$ are then said to be first-order integrated.

\section{(ii) Cointegration}

The previous argument is developed for each component of $\mathrm{Y}_{\mathrm{t}}$. In other words, it is based on a univariate expression of each series $Y_{i t}, i=1, \ldots n$. Cointegration is based on a specific multivariate analysis of the whole vector-series $\mathrm{Y}_{\mathrm{t}}$.

Each series $\mathrm{Y}_{\text {it }}$ is non-stationary with an explosive trend. We may wish to separate the explosive part of $\mathrm{Y}_{\mathrm{t}}$ from its stationary part. The following expression provides such a decomposition :

$$
Y_{t}=\frac{H(1)}{1-L} \tilde{\varepsilon_{t}}+\frac{H(L)-H(1)}{1-L} \tilde{\varepsilon_{t}} .
$$

In this expression, each $\mathrm{H}_{\mathrm{i}}(1)$ is different from zero and the first term is a linear combination of the random walks $\frac{1}{1-L} \widetilde{\varepsilon}_{j t}, j=1, \ldots . n$. Consequently each $Y_{i t}^{e}=\frac{H_{i}(1) \tilde{\varepsilon}_{t}}{1-L}$ is explosive. 
On the other hand, $\mathrm{H}(\mathrm{L})-\mathrm{H}(1)$ is divisible by $1-\mathrm{L}$ and the second component $\mathrm{Y}_{\mathrm{it}}^{\mathrm{S}}=\frac{\mathrm{H}_{\mathrm{i}}(\mathrm{L})-\mathrm{H}_{\mathrm{i}}(1)}{1-\mathrm{L}} \widetilde{\varepsilon}_{\mathrm{t}}$ is stationary.

This decomposition into an explosive part and a stationary part is applicable not only to the initial series $\mathrm{Y}_{\mathrm{t}}$, but also to any linear combination of its components. Let $\alpha^{\prime} \mathrm{Y}_{\mathrm{t}}=\sum_{\mathrm{i}=1}^{\mathrm{n}} \alpha_{\mathrm{i}} \mathrm{Y}_{\mathrm{it}}$ be such a linear combination. We obtain :

$$
\alpha^{\prime} \mathrm{Y}_{\mathrm{t}}=\frac{\alpha^{\prime} \mathrm{H}(1)}{1-\mathrm{L}} \tilde{\varepsilon}_{\mathrm{t}}+\alpha^{\prime} \frac{\mathrm{H}(\mathrm{L})-\mathrm{H}(1)}{1-\mathrm{L}} \tilde{\varepsilon}_{\mathrm{t}}
$$

As already mentioned, the rows of matrix $\mathrm{H}(1)$ are not identically zero. However it is possible that the vector $\alpha^{\prime} H(1)$ is equal to zero. This could happen when $H(1)$ is a singular matrix. In such a case, there would exist some stationary combinations of series that are all non-stationary. We then say that the series are cointegrated. More precisely, Granger (1986) gives the following definitions.

Definition (5.27) : (i) The non-stationary series $\left(\mathrm{Y}_{\mathrm{i}}\right), \mathrm{i}=1, \ldots \mathrm{n}$, are cointegrated if there exists a non-zero linear combination of the components that is stationary.

(ii) When the one-dimensional series are first-order integrated, there is cointegration if and only if matrix $\mathrm{H}(1)$ is singular.

(iii) A cointegration vector is any vector providing a stationary linear cointegration combination. Thus the vectors are defined through the condition : $\mathrm{H}(1)^{\prime} \alpha=0$.

(iii) The error correction form (Davidson, Hendry, Srba and Yeo (1978))

To each cointegration vector $\alpha$ corresponds a relation of the following kind :

(5.28) $\alpha^{\prime} \mathrm{Y}_{\mathrm{t}}=\alpha_{1} \mathrm{Y}_{1 \mathrm{t}}+\ldots+\alpha_{\mathrm{n}} \mathrm{Y}_{\mathrm{nt}}=\mathrm{u}_{\mathrm{t}}$

where $\left(\mathrm{u}_{\mathcal{}}\right)$ denotes a stationary process. Actually, this relation may be decomposed into two relations which respectively concern the explosive components and the stationary components of the series. 
For the explosive components, we have a strictly deterministic relation, i.e. a relation that does not include an error term.

$$
\alpha_{1} \mathrm{Y}_{1 \mathrm{t}}^{\mathrm{e}}+\ldots+\alpha_{\mathrm{n}} \mathrm{Y}_{\mathrm{nt}}^{\mathrm{e}}=0
$$

For the residual components, we have then :

$$
\alpha_{1} \mathrm{Y}_{\mathrm{it}}^{\mathrm{s}}+\ldots+\alpha_{\mathrm{n}} \mathrm{Y}_{\mathrm{nt}}^{\mathrm{s}}=\mathrm{u}_{\mathrm{t}}
$$

In the literature, equation (5.28) is often called the long-term equilibrium relation (a better term would be : 'the relation between dominant components') and $u_{t}$ is consequently called the equilibrium error term.

Usually, the models are built in two steps. First the long-term relations are specified. Then the adjustment factors around the long-term are added. The error correction representation of cointegrated series has the advantage of clearly distinguishing these two steps. Indeed this representation is seen to link the equilibrium error terms and the modifications brought to the various economic variables of the model.

More precisely, if $\mathrm{r}$ denotes the kernel dimension of the matrix $\mathrm{H}(1)$, and if $\Omega=\left[\alpha_{1}, \ldots, \alpha_{\mathrm{r}}\right]$ is a $\mathrm{n} \times \mathrm{r}$ matrix whose row-vectors form a base in the cointegration vector space, then the representation is given by the following result.

Representation Theorem (5.29) : [Engle and Granger (1987)].

There exist a $\mathrm{n} \times \mathrm{r}$ matrix $\Delta$ and an autoregressive polynomial $\tilde{\Phi}(\mathrm{L})$ such that the original model $(5.24)$ is equivalent to :

$$
\Delta \Omega^{\prime} Y_{t}+\tilde{\Phi}(L)\left(Y_{t}-Y_{t-1}\right)=\tilde{\varepsilon}_{t}
$$

$$
\text { where } \tilde{\varepsilon}_{\mathrm{t}}= \begin{cases}\varepsilon_{\mathrm{t}} & \text { if } \mathrm{t} \geq 0 \\ 0 & \text { otherwise. }\end{cases}
$$

This theorem provides a general representation valid for any VAR model. We will now use it to further analyse the solutions of the multivariate rational expectations model and compare them to the solutions of the corresponding perfect foresight model. 


\section{4.b. Application to rational expectations models}

\section{(i) The model and its ARIMA solutions}

Let us consider a general multivariate rational expectations model :

$$
\sum_{h=0}^{H} \sum_{k=0}^{K} A_{k h} E\left[Y_{t+h-k} \mid I_{t-k}\right]=\varepsilon_{t} \text {. }
$$

In order to simplify the derivations, we choose a white noise as the right-hand side of the equation. Nevertheless, this assumption does not affect the generality of the results.

\section{The corresponding perfect foresight model}

The perfect foresight model associated with the previous model is given by :

$$
\sum_{h=0}^{H} \sum_{k=0}^{K} A_{k h} Y_{t+h-k}=\varepsilon_{t} .
$$

or equivalently by :

$$
A(L) Y_{t}=\varepsilon_{t-H} \text {, with } A(L)=\sum_{k=0}^{K} \sum_{h=0}^{H} A_{k h} L^{k-h} \text {. }
$$

It follows that the perfect foresight model is a VAR model (with a lagged noise).

From now on we assume that this model admits non-stationary solutions that are first-order integrated, written as :

$$
\text { (1-L) } Y_{t}=H(L) \varepsilon_{t-H}, t \geq 0
$$

In fact the perfect foresight model, as a VAR model, does not exhibit any particularity. The crucial point of our discussion concerns the comparison with the rational expectations model. 
Let us now go back to the rational expectations model and consider its linear solutions, i.e. the solution having the following form :

$$
Y_{t}=C(L) \varepsilon_{t}, t \geq 0 \text {. }
$$

As we already know, the successive updating terms are given by $C_{0} \varepsilon_{t}, C_{1} \varepsilon_{t}, C_{2} \varepsilon_{t}, \ldots$, and the potential multiplicity comes from the arbitrariness of some of the components of the $\mathrm{C}_{\mathrm{i}}$ 's.

In any case, whatever the dimension of the solutions set, the general result of Property (5.23) shows that the linear solutions of the rational expectations model are all solutions of the following equation :

(5.30) $\mathrm{A}(\mathrm{L}) \mathrm{Y}_{\mathrm{t}}=\mathrm{V}_{\mathrm{t}}, \mathrm{t} \geq 0$.

where the right-hand side $V_{t}$ is a (finite) linear combination of the current and past values of the noise : $V_{t}=\Gamma(L) \varepsilon_{t}$. The coefficients $\Gamma_{0}, \Gamma_{1}, \ldots$ obviously depend on the choice of a particular solution that is made from the updating terms. But independently of that choice, equation (5.30) may be rewritten in an equivalent way as :

(5.31) (1-L) $Y_{t}=H(L) \Gamma(L) \varepsilon_{t}, t \geq 0$.

Thus, as soon as the matrix $\Gamma(1)$ is regular, the kernel of $[H(1) \Gamma(1)]^{\prime}$ coincides with the kernel of $[\mathrm{H}(1)]$ '. Since the cointegration concept is fundamentally based on this kernel, we may deduce the following result.

Property (5.32) : The linear solutions of the rational expectations model for which $\Gamma(1)$ is regular ${ }^{1}$ have the same properties with respect to cointegration as the solution of the corresponding perfect foresight model.

This result provides an interesting interpretation of the non-uniqueness phenomenon. Although there exist mostly multiple solutions, these have important common characteristics. More precisely all solutions satisfy the same long-term equilibrium relation. To some extent, the replacement of perfect foresight by rational expectations or

1 The solutions corresponding to a singular $\Gamma(1)$ will admit more cointegration vectors than the other ones. 
the choice of a particular solution to the rational expectations model (instead of another one), only affects the part of the model which is concerned with describing the adjustments.

Nevertheless it remains that the solutions of the perfect foresight model are not always solutions to the rational expectations model. Thus different adjustments could arise under the perfect foresight assumption and the rationality assumption.

\section{(ii) A representation theorem}

One may also easily obtain a representation theorem for rational expectations models. For this purpose, it suffices to rewrite the original model in the following form :

$$
A(L) Y_{t}=\varepsilon_{t-H}+\sum_{h=0}^{H} \sum_{k=0}^{K} A_{k h}\left(Y_{t+h-k-H}-E\left[Y_{t+h-k-H} \mid I_{t-k-H}\right]\right) .
$$

Then by using the error correction representation given by Theorem (5.29), we have :

$$
\text { (5.33) } \begin{aligned}
\Delta \Omega^{\prime} Y_{t} & +\tilde{\Phi}(L)\left(Y_{t}-Y_{t-1}\right)-\sum_{h=0}^{H} \sum_{k=0}^{K} A_{k h}\left(Y_{t+h-k-H}-E\left[Y_{t+h-k-H} \mid I_{t-k-H}\right]\right) \\
& =\tilde{\varepsilon}_{t-H} .
\end{aligned}
$$

This expression clearly shows the diverse (stationary) elements that enter the adjustment relations :

- firstly the equilibrium error term : $\Omega^{\prime} \mathrm{Y}_{\mathrm{t}}$;

- secondly the variable modifications : $\mathrm{Y}_{\mathrm{t}}-\mathrm{Y}_{\mathrm{t}-1}$;

- and lastly the rational prediction errors $\mathrm{Y}_{\mathrm{t}+\mathrm{h}-\mathrm{k}-\mathrm{H}}-\mathrm{E}\left[\mathrm{Y}_{\mathrm{t}+\mathrm{h}-\mathrm{k}-\mathrm{H}} \mid \mathrm{I}_{\mathrm{t}-\mathrm{k}-\mathrm{H}}\right]$ that come from the specificity of the models we are concerned with. 


\section{(iii) An example}

In order to illustrate the previous results let us consider a two-dimensional model including rational expectations of future variables :

$$
\Psi \mathrm{Y}_{\mathrm{t}}+\mathrm{E}\left[\mathrm{Y}_{\mathrm{t}+1} \mid \mathrm{I}_{\mathrm{t}}\right]=\varepsilon_{\mathrm{t}}
$$

We take here, as autoregressive coefficient $\Psi$, a matrix having the following form :

$$
\Psi=\left[\begin{array}{cc}
\psi_{11} & \alpha\left(1+\psi_{11}\right) \\
\psi_{21} & -1+\alpha \psi_{21}
\end{array}\right], \psi_{11} \neq-1, \psi_{21} \neq 0, \alpha \neq 0 .
$$

\section{Non-stationarity}

In the general framework, we have defined $\mathrm{A}(\mathrm{L})$ as the autoregressive matrix polynomial such that :

$$
A(L)=\sum_{k=0}^{K} \sum_{h=0}^{H} A_{k h} L^{k-h},
$$

In our particular case $\left(K=0, H=1, A_{00}=\Psi, A_{01}=I\right)$, we have :

$$
\begin{aligned}
A(L) & =\Psi L+I \\
& =\left[\begin{array}{cc}
1+\psi_{11} L & \alpha\left(1+\psi_{11}\right) L \\
\psi_{21} L & 1+\left(-1+\alpha \psi_{21}\right) L
\end{array}\right] .
\end{aligned}
$$

The determinant of this matrix is given by :

$$
\begin{aligned}
\operatorname{det} A(L) & =\left(1+\psi_{11} L\right)(1-L)+\alpha \psi_{21} L\left(1+\psi_{11} L\right)-\alpha \psi_{21} L\left(1+\psi_{11} L\right) \\
& =\left(1+\psi_{11} L\right)(1-L) .
\end{aligned}
$$

It obviously has exactly one root equal to 1 since the elements of the adjoint matrix of $A(L)$ are generally not divisible by (1-L). Both series composing the endogenous vectorprocess are non-stationary and first-order integrated. 


\section{Cointegration}

We may now write the perfect foresight model associated with our model as follows :

$$
\left(1+\psi_{11} \mathrm{~L}\right)(1-\mathrm{L})\left[\begin{array}{l}
\mathrm{Y}_{1 \mathrm{t}} \\
\mathrm{Y}_{2 \mathrm{t}}
\end{array}\right]=\left[\begin{array}{cc}
1+\left(-1+\alpha \psi_{21}\right) \mathrm{L} & -\alpha\left(1+\psi_{11}\right) \mathrm{L} \\
-\psi_{21} \mathrm{~L} & 1+\psi_{11} \mathrm{~L}
\end{array}\right] \mathrm{L} \varepsilon_{\mathrm{t}},
$$

or equivalently as :

$$
(1-\mathrm{L})\left[\begin{array}{l}
\mathrm{Y}_{1 \mathrm{t}} \\
\mathrm{Y}_{2 \mathrm{t}}
\end{array}\right]=\frac{1}{1+\psi_{11} \mathrm{~L}}\left[\begin{array}{cc}
1+\left(-1+\alpha \psi_{21}\right) \mathrm{L} & -\alpha\left(1+\psi_{11}\right) \mathrm{L} \\
-\psi_{21} \mathrm{~L} & 1+\psi_{11} \mathrm{~L}
\end{array}\right] \mathrm{L} \varepsilon_{\mathrm{t}}=\mathrm{H}(\mathrm{L}) \mathrm{L} \varepsilon_{\mathrm{t}}
$$

The moving-average matrix evaluated at 1 is given by :

$$
\mathrm{H}(1)=\frac{1}{1+\psi_{11}}\left[\begin{array}{cc}
\alpha \psi_{21} & -\alpha\left(1+\psi_{11}\right) \\
-\psi_{21} & 1+\psi_{11}
\end{array}\right]
$$

The conditions $\psi_{11} \neq-1$ and $\psi_{21} \neq 0$ ensure that the rank of $\mathrm{H}(1)$ is equal to 1 . Consequently the space of the cointegration vectors is generated by $\left[\begin{array}{l}1 \\ \alpha\end{array}\right]$.

\section{The error correction form}

In order to obtain the error correction form of the perfect foresight model, we rewrite the matrix $\mathrm{A}(\mathrm{L})$ in the following terms.:

$$
A(L)=\left[\begin{array}{cc}
1+\psi_{11}-\psi_{11}(1-L) & \alpha\left(1+\psi_{11}\right)-\alpha\left(1+\psi_{11}\right)(1-L) \\
\psi_{21}-\psi_{21}(1-L) & \alpha \psi_{21}+\left(1-\alpha \psi_{21}\right)(1-L)
\end{array}\right]
$$

From this expression, we immediately deduce the error correction form :

$$
\text { (5.34) }\left[\begin{array}{c}
1+\psi_{11} \\
\psi_{21}
\end{array}\right]\left(\mathrm{Y}_{1 \mathrm{t}}+\alpha \mathrm{Y}_{2 \mathrm{t}}\right)-\left[\begin{array}{cc}
\psi_{11} & \alpha\left(1+\psi_{11}\right) \\
-\psi_{21} & \alpha \psi_{21}-1
\end{array}\right]\left(\mathrm{Y}_{\mathrm{t}}-\mathrm{Y}_{\mathrm{t}-1}\right)=\tilde{\varepsilon}_{\mathrm{t}-1} \text {. }
$$


The rational expectations model

The rational expectations model is given by :

$\Psi Y_{t}+E\left[Y_{t+1} \mid I_{t}\right]=\varepsilon_{t}$.

Along the lines of the reduction method, it may be shown that the general solution of this model is provided by :

(5.35) $A(L) Y_{t}=\varepsilon_{t}^{0}+\varepsilon_{t-1}$,

where $\varepsilon^{0}$ denotes an arbitrary two-dimensional martingale difference.

If we restrict ourselves to the linear solutions, we have :

$A(L) Y_{t}=C \varepsilon_{t}+\varepsilon_{t-1}$,

where $\mathrm{C}=\left[\begin{array}{ll}\mathrm{C}_{11} & \mathrm{C}_{12} \\ \mathrm{C}_{21} & \mathrm{C}_{22}\end{array}\right]$ is a matrix from which elements may be chosen arbitrarily. The latter system is equivalent to :

$$
(1-L) Y_{t}=H(L)(C+I d L) \varepsilon_{t}
$$

In order to analyse the cointegration problem for this case, we must consider the rank of the matrix $\mathrm{H}(1)(\mathrm{C}+\mathrm{Id})$. As we know that the rank of $\mathrm{H}(1)$ is equal to 1 , the previous matrix may have either a rank equal to 1 , or a rank equal to 0 . Mostly the rank of $\mathrm{H}(1)(\mathrm{C}+\mathrm{Id})$ is equal to one. Consequently the space of the cointegration vectors is of dimension 1 and is generated by the vector $\left[\begin{array}{l}1 \\ \alpha\end{array}\right]$.

However it could happen that the rank is equal to zero. This corresponds to the case where : $\mathrm{H}(1)(\mathrm{C}+\mathrm{Id})=0$. By expanding the preceding equation, we obtain :

$$
\frac{1}{1+\psi_{11}}\left[\begin{array}{c}
-\alpha \\
1
\end{array}\right]\left(-\psi_{21}, 1+\psi_{11}\right)\left[\begin{array}{cc}
C_{11}+1 & C_{12} \\
C_{21} & C_{22}+1
\end{array}\right]=0
$$

or equivalently : 


$$
\left\{\begin{array}{l}
-\psi_{21}\left(C_{11}+1\right)+\left(1+\psi_{11}\right) C_{21}=0 \\
-\psi_{21} C_{12}+\left(1+\psi_{11}\right)\left(C_{21}+1\right)=0
\end{array}\right.
$$

Thus among the infinity of linear solutions of rational expectations models, some may reveal stationary and lead to a cointegration space of dimension 2 . Nevertheless, this case only occurs in a subset of solutions that has a zero-measure in the set of the linear solutions.

On the other hand, an error correction representation may be obtained for the general solution of the model. It is deduced from system (5.35) :

$$
\left[\begin{array}{c}
1+\psi_{11} \\
\psi_{21}
\end{array}\right]\left(\mathrm{Y}_{1 \mathrm{t}}+\alpha \mathrm{Y}_{2 \mathrm{t}}\right)-\left[\begin{array}{cc}
\psi_{11} & \alpha\left(1+\psi_{11}\right) \\
\psi_{21} & \alpha \psi_{21}-1
\end{array}\right]\left(\mathrm{Y}_{\mathrm{t}}-\mathrm{Y}_{\mathrm{t}-1}\right)-\varepsilon_{\mathrm{t}}^{0}=\varepsilon_{\mathrm{t}-1}
$$

Furthermore, since $\varepsilon_{t}^{0}$ is interpreted as the rational prediction error made in forecasting $\mathrm{Y}_{\mathrm{t}}$ at time $\mathrm{t}-1$, we may rewrite the previous system as :

$$
\left[\begin{array}{c}
1+\psi_{11} \\
\psi_{21}
\end{array}\right]\left(\mathrm{Y}_{1 \mathrm{t}}+\alpha \mathrm{Y}_{2 \mathrm{t}}\right)-\left[\begin{array}{cc}
\psi_{11} & \alpha\left(1+\psi_{11}\right) \\
\psi_{21} & \alpha \psi_{21^{-1}}
\end{array}\right]\left(\mathrm{Y}_{\mathrm{t}}-\mathrm{Y}_{\mathrm{t}-1}\right)-\left(\mathrm{Y}_{\mathrm{t}}-\mathrm{E}\left[\mathrm{Y}_{\mathrm{t}} \mid \mathrm{I}_{\mathrm{t}-1}\right]\right)=\varepsilon_{\mathrm{t}-1}
$$

Finally, for the linear solutions corrresponding to the choice of a prediction error in one relation with $\varepsilon$ ( $\mathrm{C}$ is invertible), it is even possible to derive a representation which no longer includes an error term :

$$
\begin{aligned}
{\left[\begin{array}{c}
1+\psi_{11} \\
\psi_{21}
\end{array}\right]\left(\mathrm{Y}_{1 \mathrm{t}}+\alpha \mathrm{Y}_{2 \mathrm{t}}\right)-} & {\left[\begin{array}{cc}
\psi_{11} & \alpha\left(1+\psi_{11}\right) \\
\psi_{21} & \alpha \psi_{21}-1
\end{array}\right]\left(\mathrm{Y}_{\mathrm{t}}-\mathrm{Y}_{\mathrm{t}-1}\right)-\left(\mathrm{Y}_{\mathrm{t}}-\mathrm{E}\left[\mathrm{Y}_{\mathrm{t}} \mid \mathrm{I}_{\mathrm{t}-1}\right]\right) } \\
& -\mathrm{C}^{-1}\left(\mathrm{Y}_{\mathrm{t}-1}-\mathrm{E}\left[\mathrm{Y}_{\mathrm{t}-1} \mid \mathrm{I}_{\mathrm{t}-2}\right]\right)=0 .
\end{aligned}
$$




\section{References}

AOKI M. AND M. CANZONERI (1979) : 'Reduced forms of rational expectations models', Quarterly Journal of Economics, 93, 59-71.

BROZE, L., C. GOURIÉROUX and A. SZAFARZ (1988) : 'Computation of multipliers in multivariate rational expectations models', Discussion Paper, ULB.

DAVIDSON, R. (1986) : 'Cointegration in linear dynamic systems', Discussion Paper, London School of Economics.

DAVIDSON, J., D. HENDRY, F. SRBA AND S. YEO (1978) : 'Econometric modelling of the aggregate time series relationship between consumer's expenditure and income in the United Kingdom', Economic Journal, 88, 661-692.

ENGLE, R.and C. GRANGER (1987): 'Cointegration and error correction : representation, estimation and testing', Econometrica, 55, 251-276.

ENGLE, R. AND M. WATSON (1985) : 'The Kalman filter : Applications to forecasting and rational expectations models', in Advances in Econometrics, Fifth World Congress, T. Bewley (ed.), Cambridge University Press.

GRANGER, C. (1981) : 'Some properties of time series data and their use in econometric model specification', Journal of Econometrics, 16, 251-276.

GRANGER, C.(1986) : 'Development in the study of cointegrated economic variables', Oxford Bulletin of Economics and Statistics, 48, 213-228.

HUNTER, J. (1988) : 'Cointegration, rational expectations and error correction', Discussion Paper, University of Surrey.

KOLLINTZAS, T. (1985) : 'The symmetric linear rational expectations model', Econometrica, 53, 963-976.

METRIC (1977) : 'METRIC, modèle économétrique trimestriel de la conjoncture', Annales de l'INSEE, 26-27.

PALM, F. AND G. PFANN (1988) : 'Interrelation, exogenous shocks and cointegration in a multivariate adjustment rational expectations model', Discussion Paper, University of Limburg, Maastricht.

PESARAN, M. (1981) : 'Solution of linear rational expectations models', Journal of Econometrics, 16, 375-398.

PESARAN, M.H. (1987) : The Limits to Rational Expectations, Basil Blackwell, Oxford.

WALLIS, K. (1980) : 'Econometric implications of the rational expectations hypothesis', Econometrica, 48, 49-73. 
WATSON, M. (1986) : 'Recursive solution methods for dynamic linear rational expectations models', Discussion Paper, Northwestern University.

WEGGE, L. (1984) : 'Identifiability of structural models containing Muth-rational current and future expectations', Discussion Paper 233, University of California, Davis.

WEGGE, L. (1984) : 'The canonical form of the dynamic Muth-rational future expectations model', Discussion Paper, University of California, Davis.

Whiteman, C. (1983) : Linear Rational Expectations Models : A User's Guide, Minneapolis, University of Minnesota Press. 


\section{Chapter 6}

\section{A Mean-Variance Model}

In this Chapter, we study the evolution of the equilibrium price of a good (coffee, for instance) that can be traded for speculative purposes and used for consumption. However, the focus is on the effects of speculative trading, hence we specify a very simple excess supply function for the good. The speculative demands are derived from the portofolio choice problem of risk averse traders who can invest in a risky and a riskless asset. We then derive explicit forms of equilibrium paths and discuss the effects of various factors on the amplitude of the risk premium.

The model we consider is related to previous works by Grossman (1976), Danthine (1978), Kawai (1983). The speculators'maximization of constant absolute risk aversion utility function leads to a dynamic stochastic mean-variance model that includes rational expectations.

The introduction of nonlinearities makes the resolution of the model much harder. Therefore, as a first step in our analysis, we extend to mean-variance rational expectations models the solution method developed in the previous chapters for the linear case. From the expressions of equilibrium paths we obtain, it is possible to derive some interesting properties concerning the importance of the risk premium.

\section{The model}

The basic model includes two assets that can be traded at each point in time. The first asset is riskless. It has a price fixed to unity and pays $r$ "dollars" at the end of each period. This constant return $\mathrm{r}(\mathrm{r}>0)$ is assumed to be known by everyone. The second asset, considered as risky, takes the form of a material good storable for speculative purposes, that may be bought at the beginning of period $\mathrm{t}$ at unit price $\mathrm{p}_{\mathrm{t}}$ and sold at the end of the period at a new price $\mathrm{p}_{\mathrm{t}+1}$ (unknown at time $\mathrm{t}$ ).

The complete specification of the model will be given by setting the demand function of the speculators and the excess supply function for the storable good. 


\section{1.a. Demand function of the speculators}

To describe the evolution of the traders'portofolios, we follow the usual approach based on the optimization of an expected utility function conditional on the currently available information. We assume that all the traders have the same endowments, preferences and beliefs. We consider thus the case of a single agent.

At the end of period $t-1$, the agent is endowed with stocks of the two types of assets : $\mathrm{M}_{\mathrm{t}-1}$ for the riskless asset and $\mathrm{X}_{\mathrm{t}-1}$ for the risky one. At the beginning of period $t$, these assets may be sold and a new portofolio is composed. The wealth is given by :

$$
\mathrm{W}_{\mathrm{t}}=\mathrm{p}_{\mathrm{t}} \mathrm{X}_{\mathrm{t}-1}+\mathrm{R} \mathrm{M}_{\mathrm{t}-1}
$$

where $R=1+r$ is the return.

Let $\left(\mathrm{M}_{\mathrm{t}}, \mathrm{X}_{\mathrm{t}}\right)$ denote the new portofolio. The budget constraint is then :

(6.1) $\mathrm{W}_{\mathrm{t}}=\mathrm{p}_{\mathrm{t}} \mathrm{X}_{\mathrm{t}-1}+\mathrm{R} \mathrm{M}_{\mathrm{t}-1}=\mathrm{p}_{\mathrm{t}} \mathrm{X}_{\mathrm{t}}+\mathrm{M}_{\mathrm{t}}$.

To determine the allocation $\left(\mathrm{M}_{\mathrm{t}}, \mathrm{X}_{\mathrm{t}}\right)$ the agent has a myopic optimization behavior : the expected utility is maximized one period ahead with reference to a non-decreasing concave utility function $\mathrm{U}\left(\mathrm{W}_{\mathrm{t}}\right)$ depending only on wealth.

Let $\mathrm{I}_{\mathrm{t}}$ denote the available information. The agent's behavior is summarized by the following program :

$$
\left\{\begin{array}{l}
\operatorname{Max}_{X_{t}, M_{t}} E\left[U\left(W_{t+1}\right) \mid I_{t}\right]=E\left[U\left(p_{t+1} X_{t}+R M_{t}\right) \mid I_{t}\right] \\
\text { s.t. : } p_{t} X_{t}+M_{t}=W_{t}
\end{array}\right.
$$

Generally such a program has no explicit solution. Therefore we specify an exponential form for the utility function :

(6.3) $U\left(W_{\nu}\right)=-\exp \left(-\eta W_{\nu}\right)$,

where $\eta(\eta>0)$, the coefficient of absolute risk aversion, is assumed constant. The expected utility only depends on the conditional distribution of the future price $\mathrm{p}_{\mathrm{t}+1}$ 
given the information set $\mathrm{I}_{\mathrm{t}}$. With a normal conditional distribution, the expected utility only depends on the conditional mean $\mathrm{E}\left[\mathrm{p}_{\mathrm{t}+1} \mid \mathrm{I}_{\mathrm{t}}\right]$ and the conditional variance $\mathrm{V}\left[\mathrm{p}_{\mathrm{t}+1} \mid \mathrm{I}_{\mathrm{U}}\right]$ (equal to the residual variance). More precisely, normality implies :

$$
\begin{aligned}
& E\left[U\left(W_{t+1}\right) \mid I_{t}\right]=-\exp \left(-\eta E\left[W_{t+1} \mid I_{t}\right]+\frac{\eta^{2}}{2} V\left[W_{t+1} \mid I_{t}\right]\right) \\
& =-\exp \left(-\eta\left(E\left[p_{t+1} \mid I_{t}\right] X_{t}+R M_{t}\right)+\frac{\eta^{2}}{2} X_{t}^{2} V\left[p_{t+1} \mid I_{t}\right]\right)
\end{aligned}
$$

Taking into account the budget constraint (6.1), we can substitute for one of the quantities, say $\mathrm{M}_{\mathrm{t}}=\mathrm{W}_{\mathrm{t}}-\mathrm{p}_{\mathrm{t}} \mathrm{X}_{\mathrm{t}}$, and obtain from (6.4):

$$
\begin{aligned}
& E\left[U\left(W_{t+1}\right) \mid I_{t}\right] \\
& \quad=-\exp \left(-\eta\left(X_{t}\left(E\left[p_{t+1} \mid I_{t}\right]-R p_{t}\right)+R W_{t}\right)+\frac{\eta^{2}}{2} X_{t}^{2} V\left[p_{t+1} \mid I_{t}\right]\right)
\end{aligned}
$$

Writing the first-order condition yields a demand function for the risky asset :

$$
X_{t}=\frac{E\left[p_{t+1} \mid I_{t}\right]-R p_{t}}{\eta V\left[p_{t+1} \mid I_{t}\right]}
$$

From now on this particular form of the demand function will be used. It is restrictive for two obvious reasons. Firstly, it only depends on the transition between the past and the future by means of the conditional mean and variance. Secondly, the traders' demand does not depend on the wealth $\mathrm{W}_{\mathrm{t}}$. These restrictions afford decisive advantages in terms of the tractability of the model. Indeed the demand only depends on current expectations $\mathrm{E}\left[\mathrm{p}_{\mathrm{t}+1} \mid \mathrm{I}_{\mathrm{t}}\right], \mathrm{V}\left[\mathrm{p}_{\mathrm{t}+1} \mid \mathrm{I}_{\mathrm{t}}\right]$ instead of both current and lagged expectations $E\left[p_{t+1} \mid I_{t-j}\right], V\left[p_{t+1} \mid I_{t-j}\right], j=0,1,2, \ldots$

However, specification (6.5) of the demand is sufficiently flexible to take into account risk aversion and leads to a model in which the certainty equivalent principle does not apply.

\section{1.b. Excess supply function of storable good}

The net supply of the storable good is the sum of the previous stock $\mathrm{X}_{\mathrm{t}-1}$ and the excess of current production $\mathrm{Q}_{\mathrm{t}}$ over domestic demand $\mathrm{C}_{\mathrm{t}}$. This excess supply can be deduced from producers' and consumers'behaviors. We take here a simple description of this excess supply function assuming linearity, with respect to the current price : 


$$
\mathrm{Q}_{\mathrm{t}}-\mathrm{C}_{\mathrm{t}}=\alpha \mathrm{p}_{\mathrm{t}}+\mathrm{u}_{\mathrm{t}}, \alpha>0
$$

where $\mathrm{u}$ denotes an exogenous stochastic process summarizing all the stochastic factors that affect production and domestic demand at time $\mathrm{t}$.

\section{1.c. Equilibrium condition}

For the risky asset, the equilibrium condition at time $t$ is :

$$
X_{t}=X_{t-1}+Q_{t}-C_{t}
$$

Since the demand function $\mathrm{X}_{\mathrm{t}}$ and the excess supply $\mathrm{Q}_{\mathrm{t}}-\mathrm{C}_{\mathrm{t}}$ are specified respectively by equations ( 6.5$)$ and (6.6), this condition becomes :

$$
\frac{E\left[p_{t+1} \mid I_{t}\right]-R p_{t}}{\eta V\left[p_{t+1} \mid I_{t}\right]}=\frac{E\left[p_{t} \mid I_{t-1}\right]-R p_{t-1}}{\eta V\left[p_{t} \mid I_{t-1}\right]}+\alpha p_{t}+u_{t}
$$

An equilibrium price path is thus defined as a stochastic process $\left.\left(\mathrm{p}_{t}\right)_{\triangleright}\right)_{0}$ satisfying equation (6.7) for any non-negative value of $t$.

\section{Evolution of the equilibrium price}

Equation (6.7) is the starting point of the description of the equilibrium price paths. It is a dynamic rational expectation model including nonlinearities due to the presence of conditional variances.

The following result gives the set of all equilibrium price paths satisfying equation (6.7).

Property (6.8) : Any solution of the system of equilibrium conditions (6.7) satisfies the difference equation :

$$
\frac{p_{t+1}-\varepsilon_{t+1}^{0}-R p_{t}}{\eta E\left[\left(\varepsilon_{t+1}^{0}\right)^{2} \mid I_{t}\right]}=\frac{p_{t}-\varepsilon_{t}^{0}-R p_{t-1}}{\eta E\left[\left(\varepsilon_{t}^{0}\right)^{2} \mid I_{t-1}\right]}+\alpha p_{t}+u_{t},
$$

where $\varepsilon^{0}$ is an arbitrary martingale difference. 
The proof of this property is similar to the one developed in the linear case (see Broze, Gouriéroux and Szafarz (1988)). In particular, $\varepsilon_{\mathrm{t}}^{0}$ can be interpreted as the error made in forecasting the equilibrium price :

$$
\varepsilon_{\mathrm{t}}^{0}=\mathrm{p}_{\mathrm{t}}-\mathrm{E}\left[\mathrm{p}_{\mathrm{t}} \mid \mathrm{I}_{\mathrm{t}-1}\right]
$$

It is interesting to note that Property (6.8) is valid without any assumption on the stochastic structure of the exogenous process $\mathrm{u}$ and without any restriction concerning the solutions. Mean-variance rational expectations models are often solved under the assumption that the conditional variance of the price $\mathrm{V}\left[\mathrm{p}_{\mathrm{t}+1} \mid \mathrm{I}_{\mathrm{t}}\right]$ is time-independent (see for instance Kawai (1983)). Under this additional condition the study of a meanvariance model is similar to the analysis of a linear rational expectations model and the risk aversion feature disappears. To illustrate the consequences of this stationarity restriction on the second order moment, consider the simple case where the exogenous process $\mathrm{u}$ is a sequence of independent and identically distributed variables, with mean $\mathrm{m}$ and variance $\sigma^{2}$.

A subset of all possible prediction errors is given by :

$$
\varepsilon_{t}^{0}=f(t)\left(u_{t}-m\right)
$$

where $\mathrm{f}$ is any deterministic function. The process $\varepsilon^{0}$ is a martingale difference since :

$$
\begin{aligned}
E\left[\varepsilon_{t+1}^{0} \mid I_{t}\right] & =E\left[f(t+1)\left(u_{t+1}-m\right) \mid I_{t}\right] \\
& =f(t+1) E\left[\left(u_{t+1}-m\right) \mid I_{t}\right] \\
& =0 .
\end{aligned}
$$

Since $\mathrm{f}$ is an arbitrary function, the mean-variance model is compatible with any kind of time heteroscedasticity of the price. Furthermore, even if the solutions considered are restricted to those having a constant conditional variance, the value of this constant $\mathrm{V}\left[\mathrm{p}_{\mathrm{t}+1} \mid \mathrm{I}_{\mathrm{t}}\right]$ is fixed by the model (since $\mathrm{p}_{\mathrm{t}}$ is endogenous) and therefore it cannot be taken as an additional structural parameter. 


\section{Risk premia}

\section{3.a. Asymptotic behavior of the solutions}

Consider a totally risk averse agent in the sense that the parameter $\eta=\infty$. Consequently, the portofolio only contains the safe asset. One unit of this asset hold at time 0 gives a return $\mathrm{R}^{\mathrm{t}}$ at time $\mathrm{t}$.

Symmetrically a (money) unit of the risky asset hold at time 0 gives a stochastic return of $\mathrm{p} / \mathrm{p}_{0}$. Since it is natural for agents holding the risky asset to benefit from a risk premium, one may intuitively expect that the ratio $\mathrm{p} / \mathrm{p}_{0}$ will (on average) be larger than $\mathrm{R}^{\mathrm{t}}$. Moreover, since agents'expectations have a direct effect on the price level, one may also hypothesize that the more risk averse is the trader, the higher is the discrepancy between the ratio $\mathrm{p} / \mathrm{p}_{0}$ and the certain return $\mathrm{R}^{\mathrm{t}}$.

We now proceed to a formal analysis of these ideas. To simplify the presentation, we assume that the exogenous process $u$ has an asymptotically stationary moving average representation :

$$
\text { (6.11) } \mathrm{u}_{\mathrm{t}}=\mathrm{m}+\mathrm{h}(\mathrm{L}) \tilde{\varepsilon}_{\mathrm{t}} \text {, }
$$

where $\mathrm{m}$ is the mean of $\mathrm{u}_{\mathrm{t}}(\forall \mathrm{t} \geq 0)$ and $\tilde{\varepsilon}$ is an independent white noise with variance $\sigma^{2}$. The values of $\tilde{\varepsilon}_{\mathrm{t}}$ associated with negative indices are fixed to zero.

We also restrict the analysis to solutions having the following form :

$$
\text { (6.12) } \mathrm{p}_{\mathrm{t}}=\mu_{\mathrm{t}}+\mathrm{C}(\mathrm{L}) \tilde{\varepsilon}_{\mathrm{t}}=\mu_{\mathrm{t}}+\sum_{\mathrm{j}=0}^{\mathrm{t}} \mathrm{C}_{\mathrm{j}} \tilde{\varepsilon}_{\mathrm{t}-\mathrm{j}} \text {, }
$$

where $\mu_{t}$ is the time-dependent mean of the price.

This class of processes is rather large. It may contain stationary as well as nonstationary solutions. Non-stationarity may appear not only through the mean, but also through the moving average coefficients since the sequence $\left(\mathrm{C}_{\mathrm{j}}\right)$ is not necessarily summable. The previous restrictions have the advantage of providing a large parametric class of solutions, which is described in Broze, Gouriéroux and Szafarz (1988). 
Property (6.13) : The equilibrium price paths having the following representation :

$$
\mathrm{p}_{\mathrm{t}}=\mu_{\mathrm{t}}+\mathrm{C}(\mathrm{L}) \tilde{\varepsilon}_{\mathrm{t}},
$$

are such that $\mathrm{C}(\mathrm{L})$ verifies :

$$
C(L)=\frac{C_{0}-C_{0} L+L h(L) \eta C_{0}^{2} \sigma^{2}}{1-\left[1+R+\alpha \eta C_{0}^{2} \sigma^{2}\right] L+R L^{2}}
$$

and the sequence $\left(\mu_{t}\right)$ verifies :

$$
\mu_{\mathrm{t}+1}-\left(\mathrm{R}+1+\alpha \eta \mathrm{C}_{0}^{2} \sigma^{2}\right) \mu_{\mathrm{t}}+\mathrm{R} \mu_{\mathrm{t}-1}=\eta \mathrm{C}_{0}^{2} \sigma^{2} \mathrm{~m}, \mathrm{t} \geq 0
$$

where the value of $\mathrm{C}_{0}$ may be chosen arbitrarily.

A price increase greater than $\mathrm{R}^{\mathrm{t}}$ may be described in two different ways, through the mean and/or through the stochastic part $C(L) \tilde{\varepsilon}_{t}$. In fact, if $h(L)$ has the form of a rational operator, the same is true for $\mathrm{C}(\mathrm{L})$ :

$$
C(L)=\frac{\Theta(L)}{\Phi(L)} .
$$

Although the mean of the stochastic part is always zero, unstable roots of $\Phi(\mathrm{L})$ might have great effects on the variability of prices. More precisely, to study the price increase through the stochastic part, one has to check whether $\Phi(\mathrm{L})$ has roots lying in the unit circle that are smaller than $1 / \mathrm{R}$.

We have to study the behavior of the trend $\mu_{t}$ and of the stochastic part $C(L) \tilde{\varepsilon}_{t}$. However, both may be analyzed together because the difference equation satisfied by the mean price is :

$$
\Phi *(L) \mu_{\mathrm{t}+1}=\left(1-\left(\mathrm{R}+1+\alpha \eta \mathrm{C}_{0}^{2} \sigma^{2}\right) \mathrm{L}+\mathrm{R} \mathrm{L}^{2}\right) \mu_{\mathrm{t}+1}=\eta \mathrm{C}_{0}^{2} \sigma^{2} \mathrm{~m}
$$


and $\Phi^{*}(\mathrm{~L})$ and $\Phi(\mathrm{L})$ have the same roots outside the unit circle. Thus divergent trend and variance occur simultaneously according to the values taken by the roots of the following equation :

$$
\Phi^{*}(\mathrm{x})=\mathrm{R} \mathrm{x}^{2}-\left(\mathrm{R}+1+\alpha \eta \mathrm{C}_{0}^{2} \sigma^{2}\right) \mathrm{x}+1=0 .
$$

This equation is equivalent to :

$$
\alpha \eta C_{0}^{2} \sigma^{2} x=(1-x)(1-R x)
$$

Since $\eta>0, R \geq 1$ and $\alpha>0$, the curves given by $y=\alpha \eta C_{0}^{2} \sigma^{2} x$ and $y=(1-x)(1-R x)$ have the following graphs :

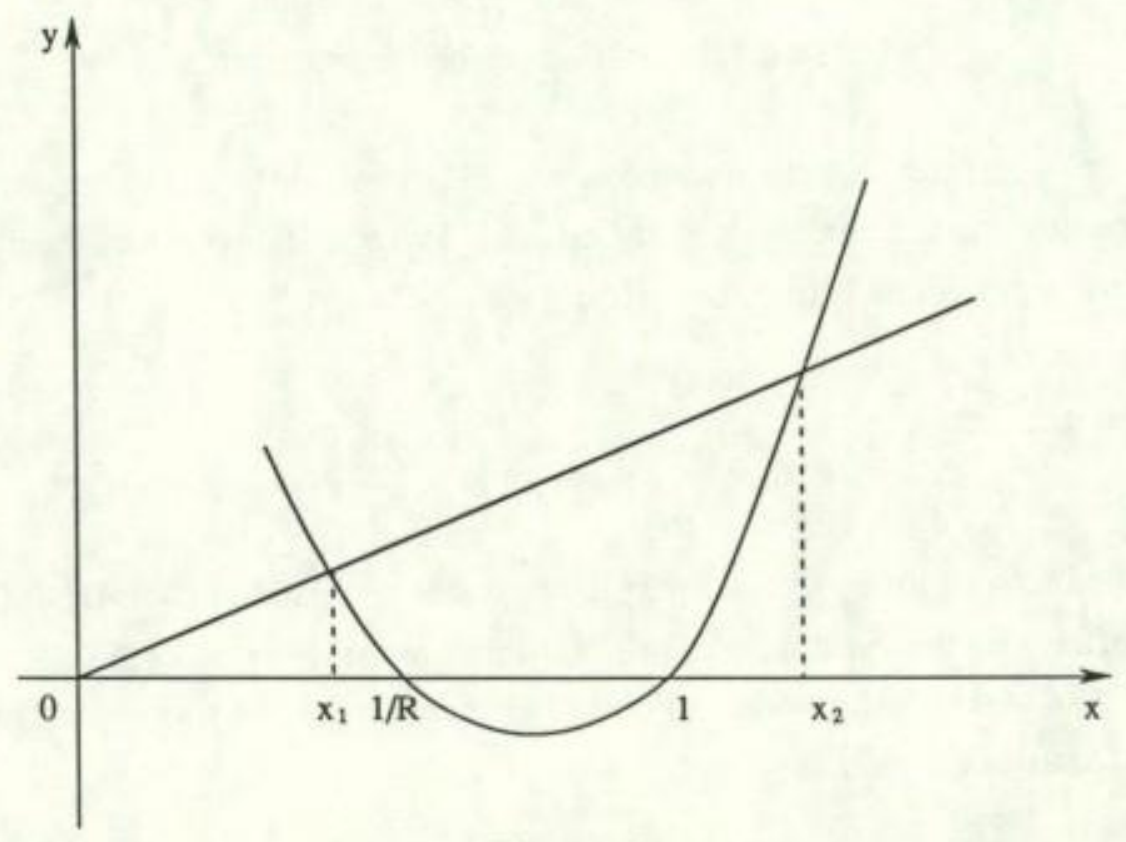

Figure 9

Consequently, the roots $\mathrm{x}_{1}$ and $\mathrm{x}_{2}$ of the equation are real and such that :

$$
0 \leq \mathrm{x}_{1} \leq \frac{1}{\mathrm{R}} \leq 1 \leq \mathrm{x}_{2}
$$




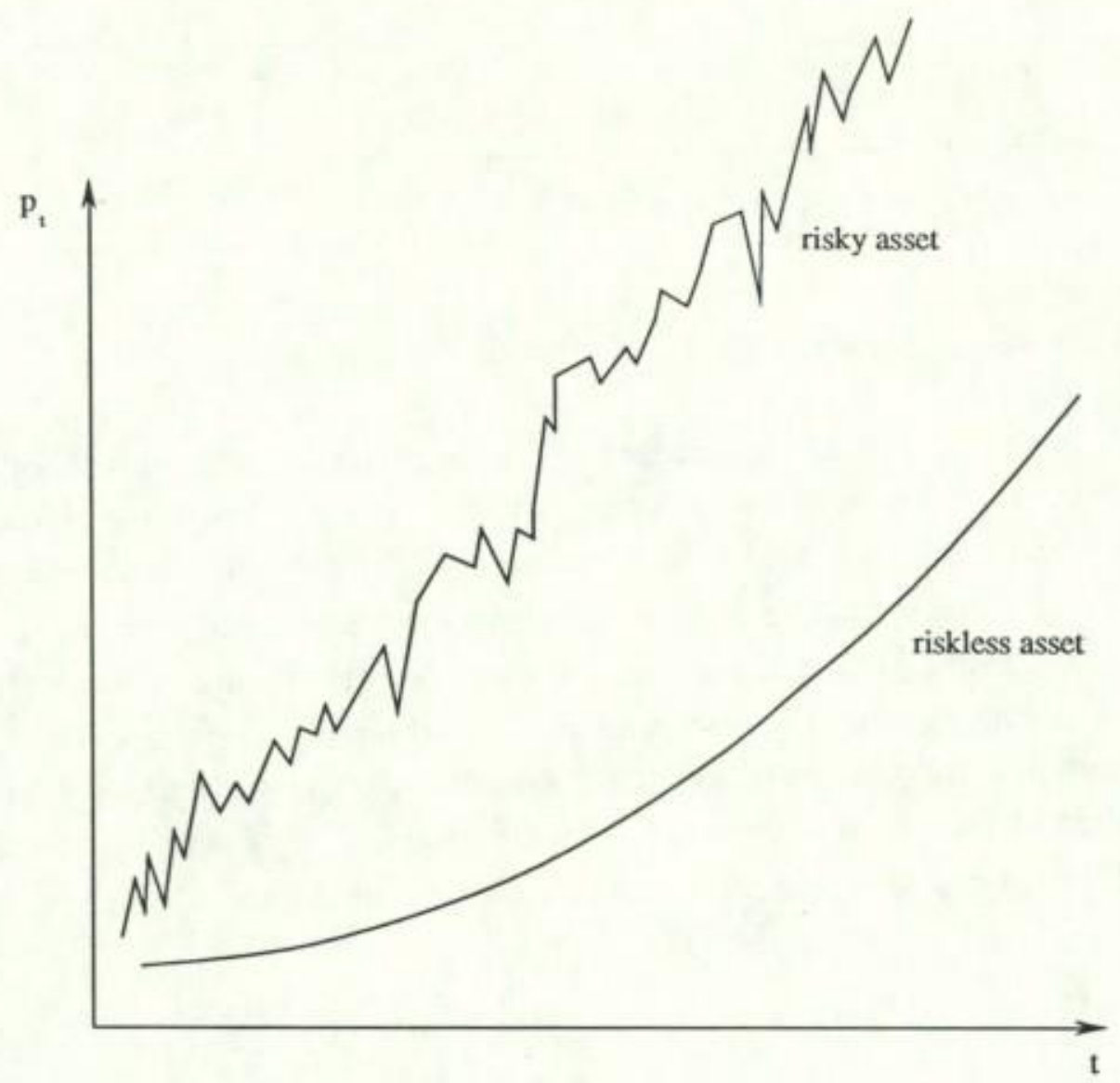

Figure 10

Thus, except in the case where suitable initial conditions give a constant sequence $\mu=\mu_{\mathrm{t}} \forall \mathrm{t}$, and where $\mathrm{C}_{0}$ is chosen so that the explosive root of $\phi^{*}(\mathrm{~L})$ cancels with a corresponding root of $\Theta(L)$, any solution : $p_{t}=\mu_{t}+C(L) \tilde{\varepsilon}_{t}$, asymptotically increases with rate $\left(1 / x_{1}\right)^{t}$, i.e. faster than the return on the riskless asset (see Figure 10).

\section{3.b. Comparative statics}

The ratio $\frac{1 / R}{x_{1}}$ may be viewed as a natural index of the asymptotic importance of the risk premium. This ratio is :

$$
\mathrm{C}\left(\alpha, \eta, \mathrm{C}_{0}^{2}, \sigma^{2}, \mathrm{R}\right)=\frac{2}{1+\mathrm{R}+\alpha \eta \mathrm{C}_{0}^{2} \sigma^{2}-\sqrt{\left(1+\mathrm{R}+\alpha \eta \mathrm{C}_{0}^{2} \sigma^{2}\right)^{2}-4 \mathrm{R}}} .
$$

This index takes values from 1 to $+\infty$. It increases with $\alpha, \eta, C_{0}^{2}$ and $\sigma^{2}$, and depends negatively on R. It takes the value : 
$\frac{2}{2+\alpha \eta C_{0}^{2} \sigma^{2}-\sqrt{\left(2+\alpha \eta C_{0}^{2} \sigma^{2}\right)^{2}-4}}$

when $R=1$ and the value 0 when $R$ tends to infinity.

The structural parameters that have positive effects on the magnitude of the risk premium are $\alpha$, which relates excess supply to the current price, $\eta$, the risk aversion parameter and $\sigma^{2}$, the variability of excess supply. The additional parameter $C_{0}$ may take any real value, each value corresponding to a specific solution of the model. Thus, for given structural parameters, the various possible paths do not give the same risk premium to the agents. This premium may considerably vary depending on the equilibrium path followed by the economic system, i.e. on the value of $\mathrm{C}_{0}$. An intuitive explanation of this result is the following : the parameter $\mathrm{C}_{0}$ has an interpretation in terms of the mean square prediction error on the future price. This is so since :

$$
V\left(p_{t+1}-E\left[p_{t+1} \mid I_{t}\right]\right)=V\left(C_{0} \tilde{\varepsilon}_{t+1}\right)=C_{0}^{2} \sigma^{2}
$$

where $\sigma^{2}$ is the variance of the innovation of the exogenous process. Hence, $I \mathrm{C}_{0} \mid$ may be seen as a measure of the level of confidence the agent has in his own expectations. For instance, if the agent has no precise prediction of the price (even if these predictions are optimal ex post), the consequence is the faster increase in the price to balance a risk viewed as important. Note that $\mathrm{C}_{0}$ is related to the degree of confidence in his prediction and not to the structural variability of the exogenous environment. The latter is captured by the value of $\sigma^{2}$. 


\section{References}

BLANCHARD, O. AND M. WATSON (1982) : "Bubbles, rational expectations and financial markets", in Crises in the Economic and Financial Structure, P. Wachtel (ed.), Lexington Book.

BROZE, L., C. GoURIEROUX AND A. SZAFARZ (1988) : "Speculative bubbles and exchange of information on the market of a storable good", in Economic Complexity : Chaos, Sunspots, Bubbles and Nonlinearity, W. Barnett, J. Geweke and K. Shell (eds), Cambridge University Press.

DANTHINE, J.P. (1978) : "Information, future prices and stabilizing speculation", Journal of Economic Theory, 17, 79-98.

FAIR, R. AND J. TAYLOR (1983) : "Solution and maximum likelihood estimation of dynamic non-linear rational expectations models", Econometrica, 51, 11691184 .

GROSSMAN, S.J. (1976) : "On the efficiency of comparative stock markets where traders have diverse information", Journal of Finance, 31, 573-585.

GROSSMAN, S.J. (1981) : "An introduction to the theory of rational expectations under asymmetric information", Review of Economic Studies, 48, 541-559.

GROSSMAN, S.J. AND J.E. STIGLITZ (1980) : "On the impossibility of informationally efficient markets", American Economic Review, 70, 393-408.

HANSEN, L.P. AND K.J. SINGLETON (1982) : "Generalized instrumental variables estimation of non-linear rational expectations models", Econometrica, 50, 12691286.

HELLWIG, M.F. (1982) : "Rational expectations equilibrium with conditioning on past prices : A mean-variance example", Journal of Economic Theory, 26, 435-459.

KAWAI, M. (1983) : "Price volatility of storable commodities under rational expectations in spot and future markets", International Economic Review, 24, 435-459. 


\section{INDEX}

adjoint operator method 108

ARIMA solutions 120

backward solution 55

canonical forms 104

certainty equivalent principle 131

cointegrated 118

cointegration 117

cointegration vector 118

conditional variance 131

degree of multiplicity 113

direct effect $37 ; 82$

equilibrium error term 119

error correction 10

error correction form 118

error correction representation 119

expectation 7

expectation problem 7

expectation scheme 7

explosive part 117

exponential smoothing 13

extrapolative form 12

forward approach 52

forward solution 53

general model 104

general univariate model 87

homogeneous equation 62

horizon 8

hyperinflation models 45

indirect effect 37

information set 7 initial condition 66

law of iterated predictions 16

learning processes 40; 73

linear solutions $56 ; 92$

linear stationary solutions 60

long-term equilibrium relation 119

martingale 18

martingale difference 18

mean-variance model 129

naive 10

non-stationary solutions 115

nonlinearities 132

optimal prediction 13

perfect foresight 10

prediction error 7

predictions 7

processes 8

rational expectation 13

rational scheme 13

risk premium $129 ; 134$

smoothing 10

stationary part 117

stationary solutions 69

sunspots 68

Taylor model 46

terminal condition 66

undetermined coefficients procedure 59

updating 9

variance analysis equation 16 
